\title{
Diffusion of Sulfur in Gallium Phosphide
}

and Gallium Arsenide

$$
\begin{aligned}
& \text { N69-28128 } \\
& \text { NASA } C R-101429
\end{aligned}
$$

by

Alvin Bau Yuen Young

March 1969
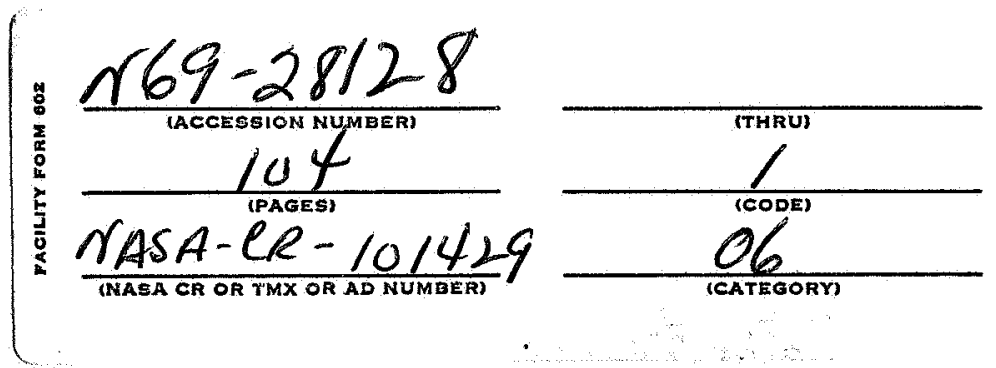

Technical Report No. 5116-1

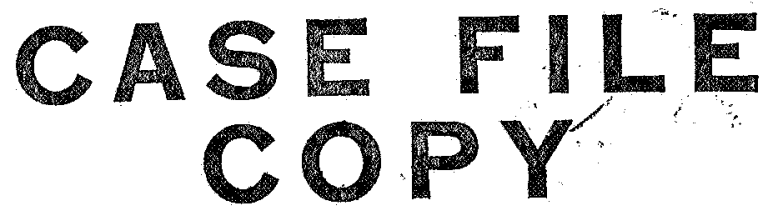

Prepared under

National Aeronautics and Space Administration

Research Grant No. NsG-05-020-043

\section{SOLD-STATE ELECTROnICS IABORATORY} STAMFORD ELECTROMItS LABORATORIES 


\title{
DIFFUSION OF SULEUR IN GALLIUM PHOSPHIDE AND GALLIUM ARSENIDE
}

by

Alvin Bau Yuen Young

March 1969

Technical Report No. 5116-1

Prepared under

National Aeronautics and Space Administration

Research Grant No. NsG-05-020-043

\author{
Solid State Laboratory \\ Stanford Electronics Laboratories \\ Stanford University Stanford, California
}




\section{PRECEDING PAGE BLANK NOT FILMED.}

\section{ABSTRACT}

The diffusion of substitutional impurities in III-V compounds has usually been explained in the literature by a model of vacancy diffusion within a single sublattice. Experimental evidence for this model, however, has been obtained solely from measurements of the temperature variation of the diffusion coefficient.

In the work reported here, a radiotracer technique was used to study the diffusion of sulfur, a substitutional donor impurity, in GaP and GaAs as a function of temperature, sulfur pressure, component pressure, and background doping of the host crystal. The importance of uniquely defining the experimental conditions has been stressed, and the necessity of elucidating diffusion mechanisms in compound semiconductors by determining the quantitative dependence of diffusion coefficient on component pressure has been emphasized. Previous reports in the literature concerning sulfur diffusion in GaAs have been inadequate in both of these respects. The diffusion of sulfur in GaP has not been reported previously.

The results reported here indicate that the variation of the diffusion coefficient with component pressure for sulfur in both GaP and GaAs is not in agreement with the model of vacancy diffusion within a single sublattice. The diffusion coefficient of sulfur in GaP was found to be independent of phosphorus pressure, whereas the diffusion coefficient of sulfur in GaAs varied as $\left(\mathrm{P}_{\mathrm{As}_{4}}\right)^{1 / 2}$ at low arsenic pressures, and appeared to saturate at arsenic pressures greater than 0.5-1 atmospheres. The results for sulfur in GaP are consistent with diffusion via the divacancy $\mathrm{V}_{\mathrm{Ga}}-\mathrm{V}_{\mathrm{P}}$, while the diffusion of sulfur in GaAs can be explained by movement via the gallium divacancy $\mathrm{V}_{\mathrm{Ga}}-\mathrm{V}_{\mathrm{Ga}}$. A review of the literature indicates that the fallure of the sublattice model to explain the dependence of impurity diffusion on component pressure may be a general phenomenon in III-V compounds.

The variation of solubility in III-V compounds with impurity vapor pressure has, with few exceptions, been ignored in the literature. The 
results reported here indicate that the dependence of surface concentration on sulfur vapor density for both GaP and GaAs is not in agreement with the usual model of incorporation of sulfur atoms on isolated anion sites. Possible reasons for this discrepancy are discussed.

Incremental Hall and plasma reflection methods were used to study the electrically active part of the impurity distribution in the diffused layers. At high concentrations, a large concentration of the sulfur was found to be electrically inactive at room temperature. This observation is of practical importance since previous reports in the literature concerning sulfur diffusion in GaAs have often assumed complete ionization of the impurities in the diffused layer. Diffusion coefficients calculated using this assumption may be in error. 
CONTENTS

Page

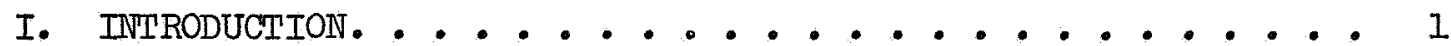

II. TERNARY PHASE DIAGRAMS AND APPLICATIONS TO DIFFUSIONS . • • 3

A. The Ga-P-S System .............. . 3

1. The GaP Liquidus ............. . . 3

2. Vapor Pressures Along the GaP Liquidus. . . . . . 5

3. The GaP Solidus Region. . . . . . . . . . 6

B. The Ga-As-S System. . . . . . . . . . 8

1. The GaAs Liquidus . . . . . . . . . . . 8

2. Vapor Pressures Along the GaAs Liquidus . . . . . 8

3. The GaAs Solidus Region ............. 9

C. Application to This Study ........... 10

III. DIFFUSION OF SULFUR IN GaP AND GaAs . . . . . . . . . . 13

A. Experimental Procedures . . . . . . . . . . 14

1. Properties of Starting Materials and Sample

Preparation ............ 14

2. Encapsulation and Annealing . . . . . . . . 15

3. Construction of Diffusion Profiles. . . . . . . 16

4. Vapor Pressures During Diffusion. . . . . . . . 18

5. Determination of Diffusion Coefficient. . . . . 20

B. Experimental Results in GaP . . . . . . . . . 22

1. Variation with Sulfur Pressure. ........ 22

2. Variation with Phosphorus Pressure. . . . . . . 23

3. Variation with Temperature. ........ 25

C. Experimental Results in GaAs. . . . . . . . 28

1. Variation with Sulfur Pressure. . . . . . . . 29

2. Variation with Arsenic Pressure . . . . . . 30

3. Variation with Temperature. . . . . . . . 35

4. Variation with Background Doping. . . . . . . 37

IV. ELECTRICAL PROPERTIES OF SULFUR IN GaP AND GaAs . . . . . . 4 I

A. Sulfur Diffused Layers in GaP . . . . . . . . . 42

1. Incremental Hall Measurements ......... 42

2. Experimental Results. .......... . 43

B. Sulfur Diffused Layers in GaAs. . . . . . . . . . 44

1. Plasma Reflection Measurements. . . . . . . 44

2. Experimental Results. . . . . . . . . 45

C. Homogeneous Sulfur-Doped GaP and GaAs Crystals. . . . 48 
CONTENTS (Cont)

Page

D. Discussion. . . . . . . . . . 51

1. Homogeneous Crystals of GaAs and GaP. . . . . . . 51

2. Sulfur Diffused Layers in GaAs and GaP. . . . . . 54

E. Some Consequences of the High Concentration Electrical

Behavior of Group VI Donors in GaP and GaAs . . . . . 55

V. DIFFUSION MODELS FOR SULFUR IN GaP and GaAs . . . . . . 59

A. Sublattice Model. . . . . . . . . . . 59

B. Interstitial-Substitutional Model . . . . . . . 63

C. Proposed Models of Diffusion. . . . . . . . . 67

1. Sulfur in GaP ............. 68

2. Sulfur in GaAs. . . . . . . . . . . . 73

D. Solid Solubility Versus Vapor Pressure of Gaseous

Impurities. . . . . . . . . . . 78

VI. CONCLUSION. . . . . . . . . . . . 83

A. Summary of Experimental Results .......... 83

B. Suggestions for Future Research . . . . . . . . 85 


\section{ILLUSTRATIONS}

1. Assumed ternary condensed phase diagram for the Ga-P-S system. .................. 4

2. Variation of vapor pressures at $1200^{\circ} \mathrm{C}$ along the Iiquidus in the Ga-P-S system as calculated by the regular solution method. ............. 6

3. Mapping of the GaP solidus boundary at $1200^{\circ} \mathrm{C}$ from the ternary condensed phase diagram of the Ga-P-S system . . . . . . . . . . . . . . . . . 7

4. Assumed ternary condensed phase diagram for the Ga-As-S system . . . . . . . . . . . . 9

5. Variation of vapor pressures at $1100^{\circ} \mathrm{C}$ along the liquidus in the Ga-As-S system as calculated by the regular solution method. ..............

6. Mapping of the GaAs solidus boundary at $1100^{\circ} \mathrm{C}$ from the ternary condensed phase diagram of the Ga-As-S system ........................

7. Schematic drawing of a diffusion ampoule and its

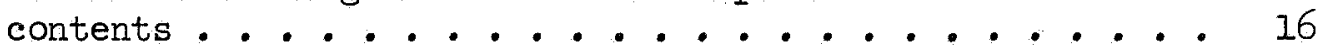

8. Measured absorption curves of $0.167 \mathrm{MeV}$ beta particles in various materials . . . . . . . . . . 17

9. Partial pressures of $P_{2}$ and $P_{4}$ versus the vapor density of phosphorus in the ampoule . . . . . . .

10. Partial pressures of $\mathrm{As}_{2}$ and As4 versus the vapor density of arsenic in the ampoule. ........ 20

11. Pressure of $S_{2}$ versus the vapor density of sulfur in the ampoule......................

12. Diffusion profiles of sulfur in GaP at various sulfur pressures. . . . . . . . . . . . . . . . .

13. Dependence of the surface concentration of diffusion profiles in GaP on the sulfur vapor density. . . . . . 24

14. Diffusion profiles of sulfur in GaP at various phosphorus pressures ... . . . . . 25

15. Dependence of the diffusion coefficient of sulfur in GaP on the phosphorus pressure ........ 26

16. Diffusion profiles of sulfur in GaP at various temperatures .............. . . 27

17. Dependence of the diffusion coefficient of sulfur in GaP on temperature ............. 28

18. Diffusion profiles of sulfur in GaAs at various sulfur pressures. . . . . . . . . . . . 30 


\section{IILUSTRATIONS (Cont)}

19. Dependence of the surface concentration of diffusion profiles in GaAs on the sulfur vapor density. . . . . . . 31

20. Diffusion profiles of sulfur in GaAs at various arsenic pressures . . . . . . . . . . . . 32

21. Dependence of the diffusion coefficient of sulfur in GaAs on the arsenic pressure. . . . . . . . . 33

22. Diffusion profiles of sulfur in GaAs at various temperatures.............. 35

23. Dependence of the diffusion coefficient of sulfur in GaAs on temperature. . . . . . . . . . . 36

24. Diffusion profiles of sulfur in undoped and heavilydoped n-type GaAs ........... 38

25. Outdiffusion profiles of tellurium from heavily-doped GaAs under high and low arsenic pressures . . . . . . 39

26. Comparison of the electron (determined by incremental Hall measurements) and total sulfur concentration (determined by radiotracer techniques) profiles in diffused layers in GaP at high and low phosphorus pressures . . . . . . . . . . . . . 44

27. Comparison of the electron (determined by plasma reflection techniques) and total sulfur concentration (determined by radiotracer techniques) profiles in a diffused layer in GaAs. . . . . . . . . . . 46

28. Dependence of the electron concentration on the total sulfur concentration in diffused layers in GaAs at various temperatures. . . . . . . . . . . 47

29. Maximum electron concentration versus reciprocal temperature for GaAs doped with sulfur from the melt and by diffusion. . . . . . . . . . . . 50

30. Comparison of the temperature dependence of the diffusion coefficient of sulfur in GaAs as reported by different workers. . . . . . . . . . 56

31. Concentration dependence of the diffusion coefficient of sulfur in GaP at $1215^{\circ} \mathrm{C}$ as determined from a Boltzmann-Matano analysis . . . . . . . . 71

32. Diffusion profiles of sulfur in GaAs at various arsenic pressures . . . . . . . . . . . 77 


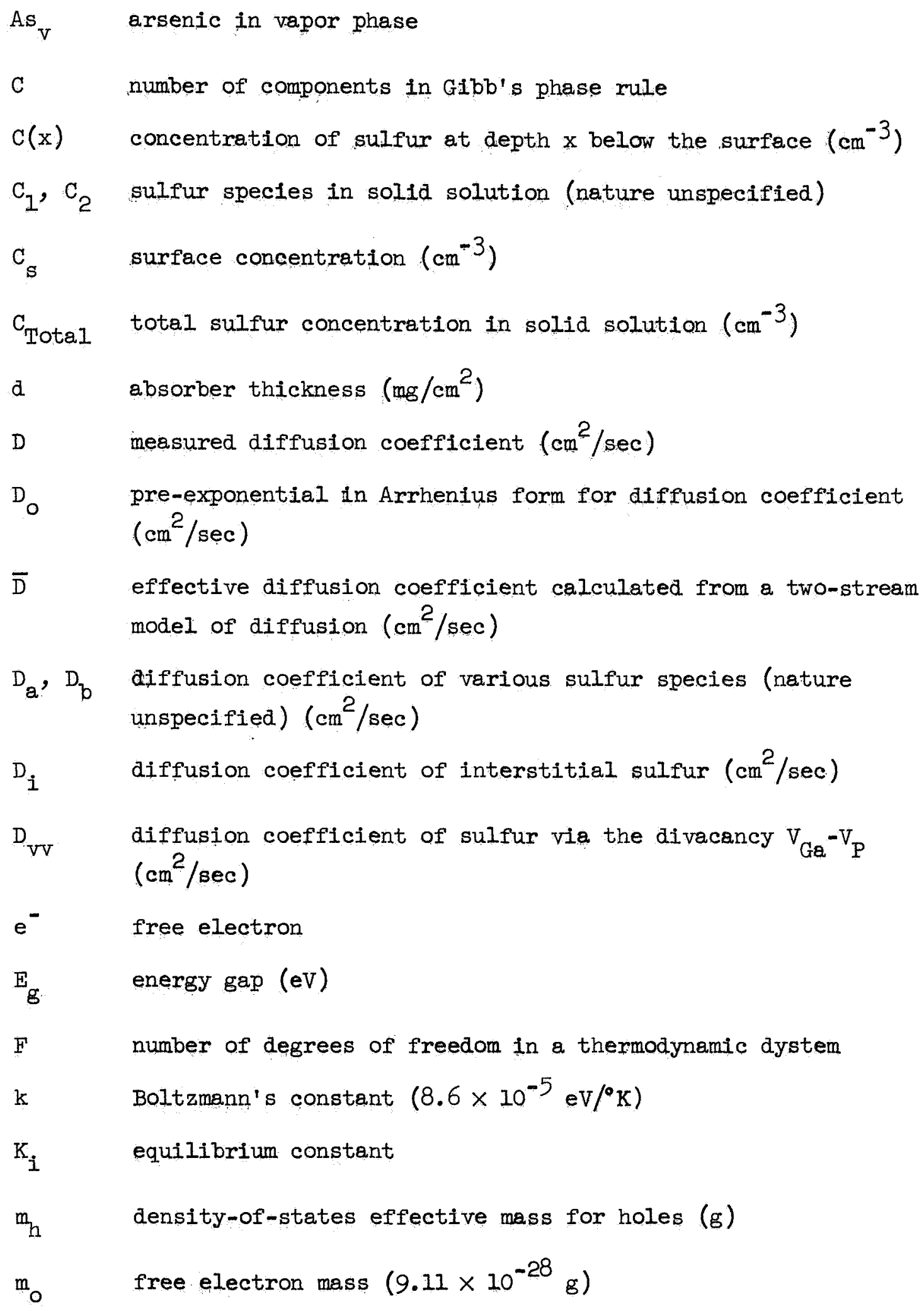




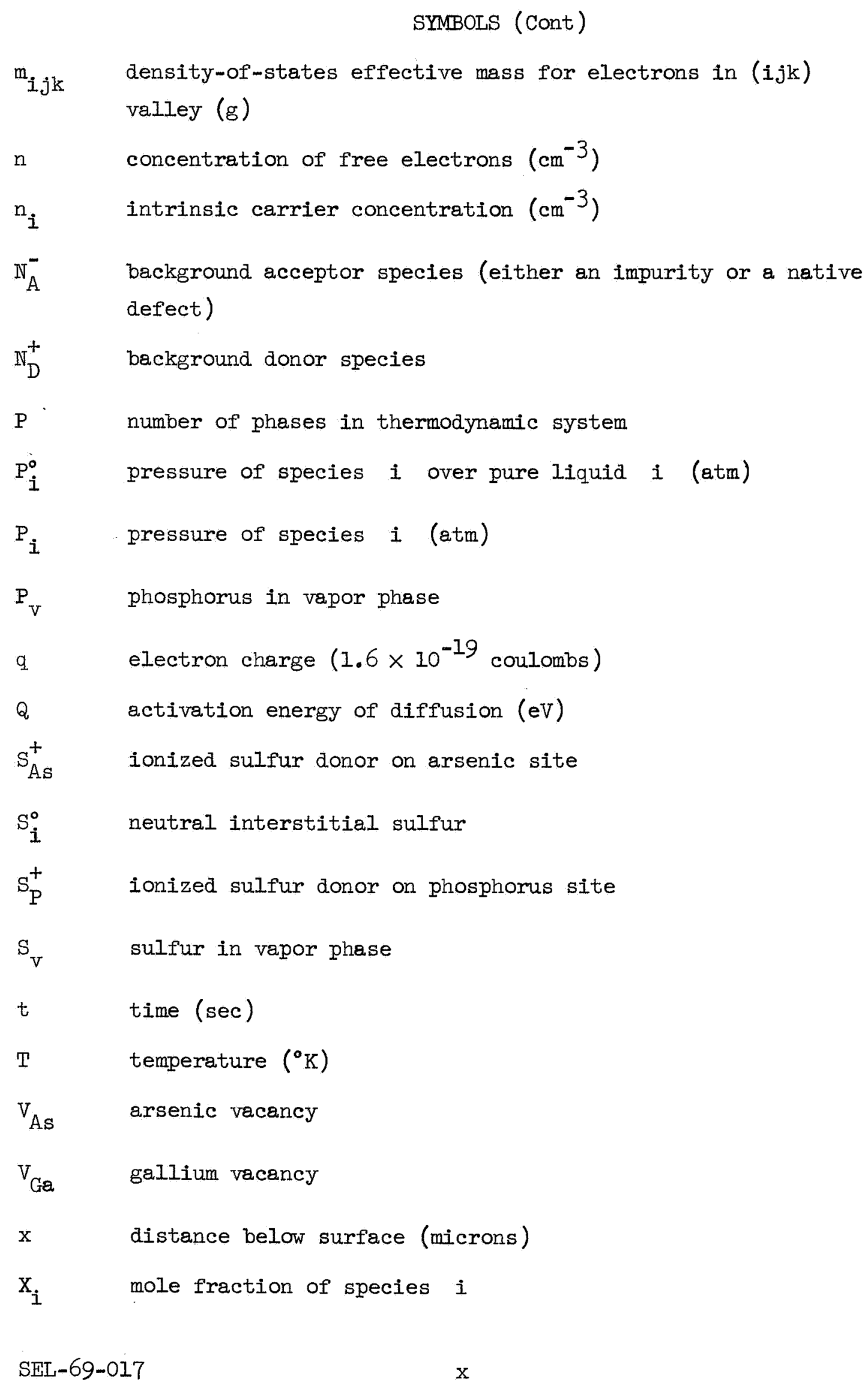




\section{SYMBOLS (Cont)}

$\Delta \quad$ energy gap between (000) and (100) valleys in GaAs (eV)

$\gamma_{i} \quad$ activity coefficient of species $i$

$\mu_{m} \quad$ mass absorption coefficient of radiation in a material $\left(\mathrm{cm}^{2} / \mathrm{mg}\right)$

$\bar{\mu}_{\mathrm{n}} \quad$ average electron mobility in diffused layer $\left(\mathrm{cm}^{2} / \mathrm{v}-\mathrm{sec}\right)$

$\sigma \quad$ conductivity $\left(\mathrm{ohm}^{-1} \mathrm{~cm}^{-1}\right)$

$\sigma_{\mathrm{s}} \quad$ sheet conductivity $\left(\mathrm{ohm}^{-1}\right)$ 



\section{PRECEDING PAGE BLANK NOT FILMED.}

\section{ACKNOWLEDGMENT}

The author wishes to express his appreciation to his advisor, Professor G. L. Pearson, for his patient guidance and encouragement during the course of this study. Valuable discussions with Professors $\mathrm{J}$. W. Allen and J. L. Moll of Stanford University and Dr. D. L. Kendall of Texas Instruments are gratefully acknowledged. Special thanks are due Mr. U. J. Sorenson for his patient and invaluable assistance with much of the experimental apparatus.

Financial support was provided by the National Aeronautics and Space Administration and the National Science Foundation. Use was made of the facilities provided by the Advanced Research Projects Agency through the Center for Materials Research at Stanford University. 
Chapter I

INTRODUCTION

The diffusion of sulfur in GaAs has been investigated by a number of workers [1-5]. Goldstein measured the temperature dependence of the diffusion coefficients of a number of substitutional impurities in GaAs and concluded that sulfur diffused by means of vacancies within the arsenic sublattice [6]. The activation energy for sulfur in GaAs found by Goldstein, however, is considerably larger than that found by other experimenters [2]. Vieland carried out a qualitative study of the effect of arsenic pressure on sulfur diffusion in GaAs and concluded that the results were in conflict with the sublattice model proposed by Goldstein [4]. The possibility of the participation of nearest-neighbor gallium vacancles in the diffusion process was suggested by Vieland, but no definite model was proposed.

In the work reported here, the diffusion of sulfur in GaP and GaAs was studied to determine the relevant diffusion mechanisms. The importance of uniquely defining the experimental conditions has been stressed, and the necessity of elucidating diffusion mechanisms in compound semiconductors by determining the quantitative dependence of the diffusion coefficient on component pressure has been emphasized. Previous reports in the literature concerning sulfur diffusion in GaAs have been inadequate in both of these respects. The diffusion of sulfur in GaP has not been reported previously.

In Chapter II, some relevant aspects of the termary phase diagrams of the Ga-P-S and Ga-As-S systems are discussed. It is shown that diffusion probably takes place within the GaP or GaAs solidus regions. In this investigation, diffusion was studied as a function of the temperature, the sulfur pressure, and the arsenic or phosphorus pressure.

In Chapter III, the experimental procedures are described, and the diffusion results are presented. The dependence of the diffusion coefficient on component pressure for sulfur in both GaP or GaAs was found to be in conflict with the predictions of the sublattice model previously 
proposed in the literature. Some anomalous results of solubility measurements are also presented in this chapter.

In Chapter IV, the electrical behovior of sulfur-diffused layers in GaP and GaAs is discussed. A large concentration of the sulfur was found to be electrically inactive. A comparison with the electrical properties of a homogeneous sulfur-doped melt-grown GaAs crystal is given.

Chapter $V$ discusses, in some detail, the sublattice model and the interstitial-substitutional model, both of which have been suggested in the literature to explain sulfur diffusion in GaAs. The inadequacies of these models are pointed out, and other models are proposed to explain the experimental results reported here for sulfur diffusion in GaP and Ga.As.

Finally, in Chapter VI, a summary of the experimental results and conclusions is presented, along with some suggestions for future research. 
Chapter II

THE TERNARY PHASE DIAGRAM AND

APPLICATIONS TO DIFFUSION

Impurity diffusion in compound semiconductors such as GaAs and GaP displays more complex behavior than the analogous problem involving elemental semiconductors. Fortunately, experiments which take advantage of the additional degree of freedom inherent in a ternary system can give additional insight into the mechanism of diffusion in compound semiconductors.

An understanding of the ternary phase diagram is essential in studies of this type. In particular, it is necessary that one knows the region in which experiments are being performed and that a sufficient number of thermodynamic variables be specified to uniquely determine the experimental conditions.

In this chapter, estimates of the ternary phase diagrams of the Ge-P-S and Ge-As-S systems are presented and their application to the problem of sulfur diffusion in GaP and GaAs is discussed. It is shown that under most experimental conditions, diffusions are performed within the solidus boundary and that three independent variables must be given for a unique specification of the state of the system. Previous reports in the literature concerning sulfur diffusion in GeAs have frequently neglected to specify the experimental conditions uniquely, and interpretation of such results is difficult.

\section{A. The Ga-P-S System}

1. The GaP Liquidus

Although the ternary condensed phase diagrams have been studied for the Ga-As-Te [7] and Ga-P-Te [8] systems, there has been no work reported on the corresponding systems involving sulfur in place of tellurium. A useful first approximation to the Ga-P-S ternary system may be obtained by the method discussed by Allen and Pearson [9]. This technique estimates the liquidus lines for the GaP phase field in the ternary system from thermodynamic data on the binary GaP system alone [10]. In 
this study it will be assumed that sulfur and tellurium atoms have similar behavior in the liquid at the temperatures of interest. Thus the experimental liquidus curves measured for the Ga-P-Te system are taken to be valid for the corresponding system where sulfur is substituted for tellurium. The validity of this assumption is difficult to justify. However it is felt that, in the absence of experimental data on the Ga-P-S system, the assumption is a reasonable one since the qualitative conclusions to be made are not critically dependent on the exact position of the liquidus curves.

The assumed Ga-P-S ternary phase diagram is shown in Fig. 1. Because of experimental limitations, the liquidus curves in the Ga-P-Te system were determined only on the gallium-rich side of the phase diagram. Smooth extrapolations of these curves to the Ga-P binary line are shown by the dashed curves. Also shown in the figure are the solid

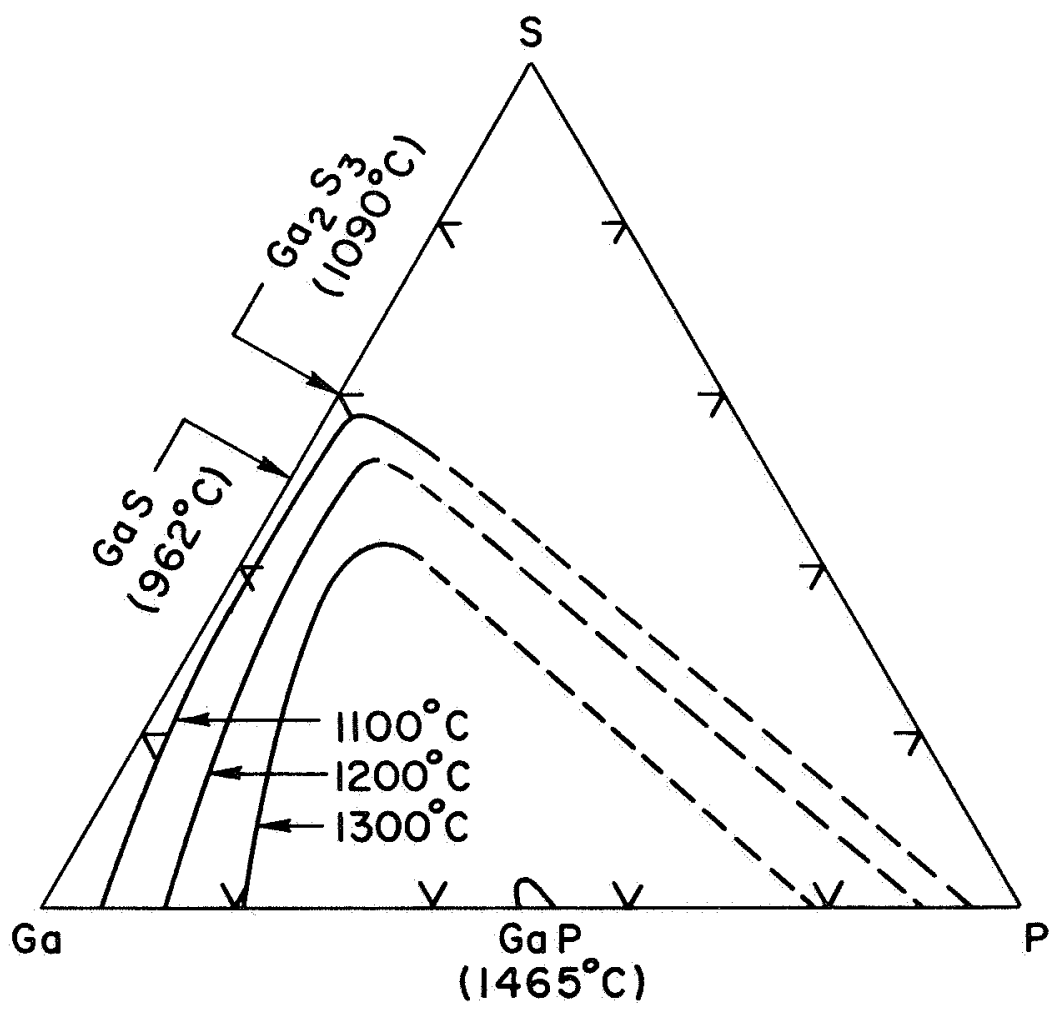

Fig. 1. ASSUMED TERNARY CONDENSED PHASE DIAGRAM FOR THE Ga-P-S SYSTEM . (Liquidus isotherms were taken from the Ga-P-Te system as determined by Panish [8].) 
phases that exist at the temperatures of interest, and their melting points-GaP $\left(1465^{\circ} \mathrm{C}\right), \mathrm{Ga}_{2} \mathrm{~S} 3\left(1090^{\circ} \mathrm{C}\right)$, and $\mathrm{GaS}\left(962^{\circ} \mathrm{C}\right)$ [11]. Since all diffusions in the GaP system were performed above $1100^{\circ} \mathrm{C}$, sulfur-doped GaP is the only solid phase that should be present under equilibrium conditions. The GaP solid phase region is shown exaggerated in size for clarity in Fig. 1 .

Several compounds containing phosphorus and sulfur also exist but the melting temperatures of these compounds are below $400^{\circ} \mathrm{C}$ and these species are not of interest in the present work [12].

2. Vapor Pressures Along the GaP Liquidus

Before one can determine the region in which diffusions are performed, it is necessary to know the vapor pressures that exist along the GaP liquidus. These pressures are not available in the literature, but they may be estimated by using the following set of equations,

$$
\begin{aligned}
\mathrm{P}_{\mathrm{P}_{2}} & =\left(\gamma_{\mathrm{P}_{\mathrm{P}}}\right)^{2} \mathrm{P}_{\mathrm{P}_{2}}^{0}, \\
\mathrm{P}_{\mathrm{P}_{4}} & =\left(\gamma_{\mathrm{P}_{\mathrm{P}}}\right)^{4} \mathrm{P}_{\mathrm{P}_{4}}^{\circ}, \\
\text { and } \quad \mathrm{P}_{\mathrm{S}_{2}} & =\left(\gamma_{\mathrm{S}} \mathrm{X}_{\mathrm{S}}\right)^{2} \mathrm{P}_{\mathrm{S}_{2}}^{\circ},
\end{aligned}
$$

where $P_{i}, \gamma_{i}$, and $X_{i}$ are the vapor pressure, activity coefficient, and mole fraction in the liquid of species $i$, and $P_{i}^{\circ}$ is the vapor pressure over pure liquid i. These equations are derived from the definition of activity coefficient [13]. The vapor pressures of gallium and of other vapor species are low and are ignored here.

The pressures of phosphorus and sulfur over the pure liquids were obtained from the JANAF tables [14]. The activity coefficients were calculated by using the regular solution method of Furukawa and Thurmond [15] to fit the assumed liquidus curves in Fig. I. 
The calculated pressures of the important vapor species over the $1200^{\circ} \mathrm{C}$ Iiquidus are shown in Fig. 2. It is understood that the calculated pressures are subject to large errors because an approximate theory was used to obtain $\gamma$ and $x$, both of which are raised to the second or fourth power. However, an order-of-magnitude estimate is still useful in predicting experimental operating conditions.

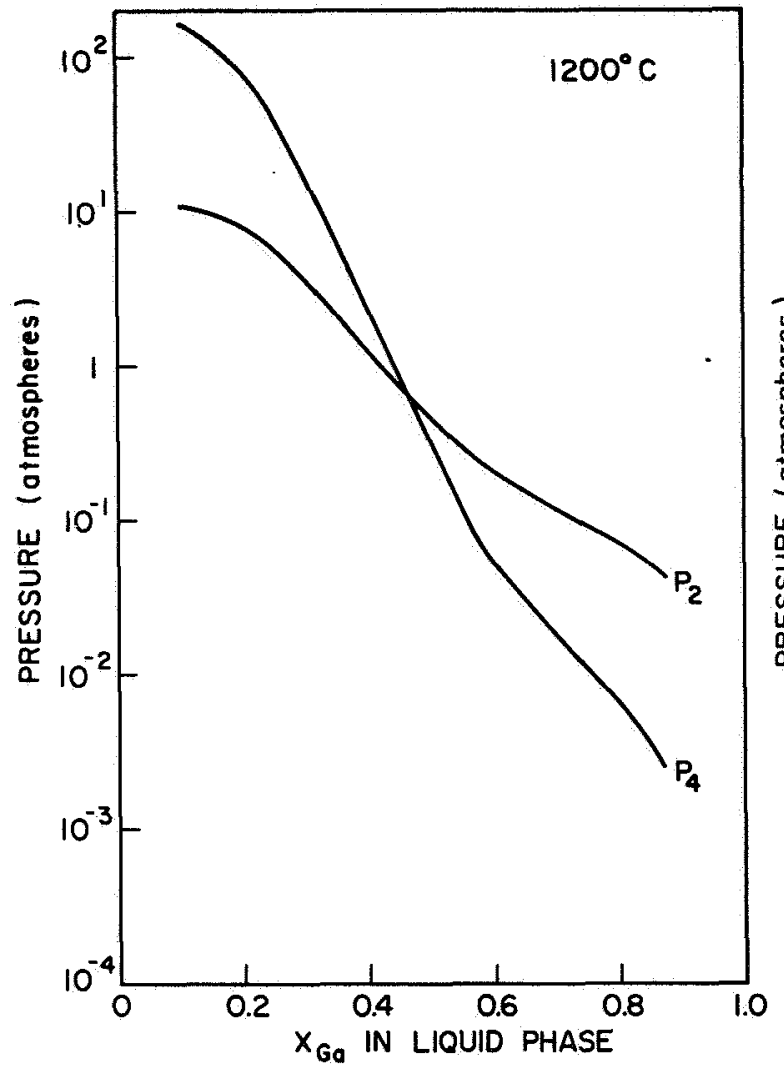

a. Pressures of $P_{2}$ and $P_{4}$

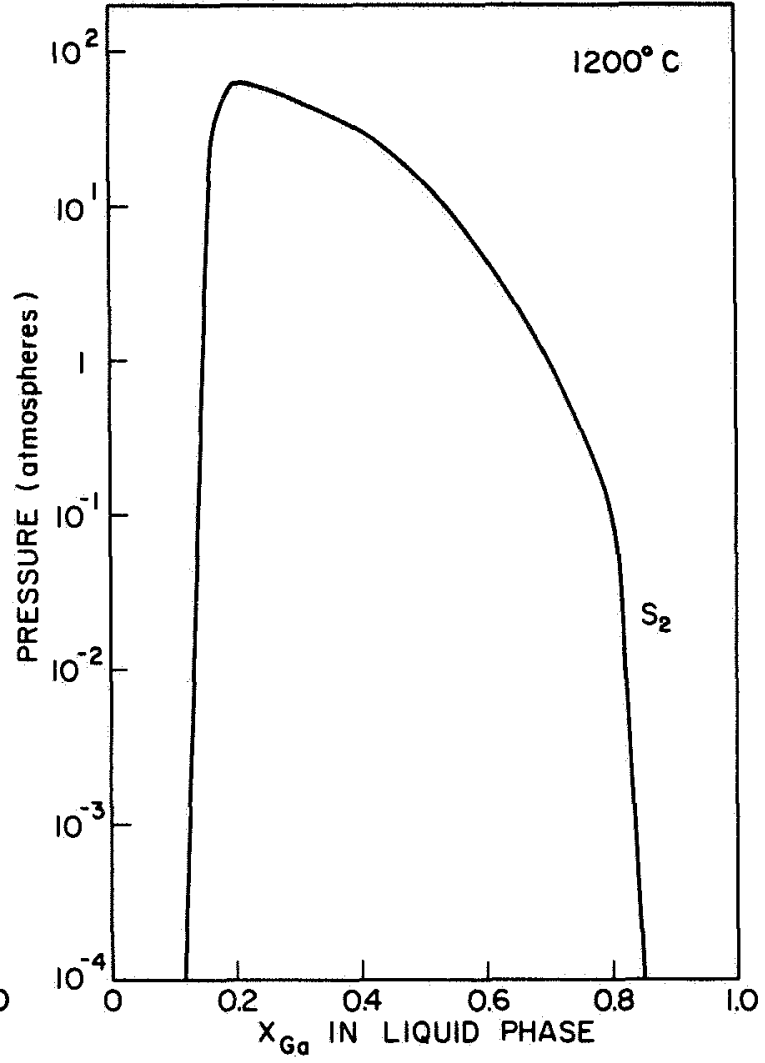

b. Pressure of $s_{2}$

Fig. 2. VARIATION OF VAPOR PRESSURES AT $1200^{\circ} \mathrm{C}$ ALONG THE LIQUIDUS IN THE Ga-P-S SYSTEM AS CALCULATED BY THE REGULAR SOLUTION METHOD.

\section{The GaP Solidus Region}

At a given temperature, the region of stability of sulfurdoped GaP can be specified by giving a description of the solidus boundary in terms of the mole fractions of the individual components in the 
solid phase as shown in Fig. 1. However, when deviations from stoichiometry are small and solid solubilities are limited, this description is limited value.

A more meaningful picture of the solidus region may be given in terms of the phosphorus $\left(\mathrm{P}_{\mathrm{P}_{2}}\right)$ and sulfur $\left(\mathrm{P}_{\mathrm{S}_{2}}\right)$ pressures. An illustration for the $\mathrm{GaP}$ solidus region at $1200^{\circ} \mathrm{C}$ is shown in Fig. 3 .

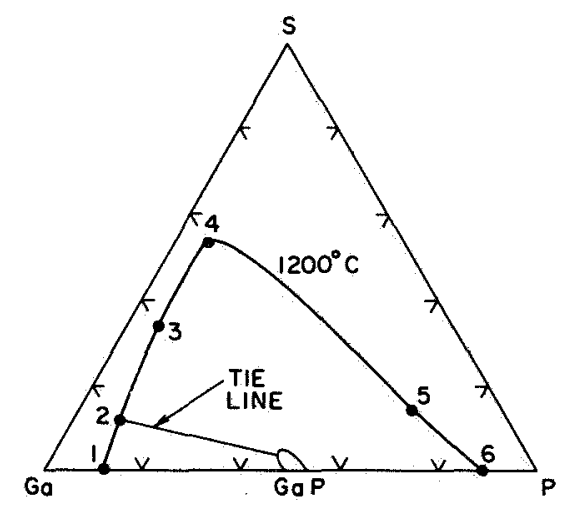

a. Ternary condensed phase diagram with a tie line relating a point on the solidus boundary and its equilibrium liquid

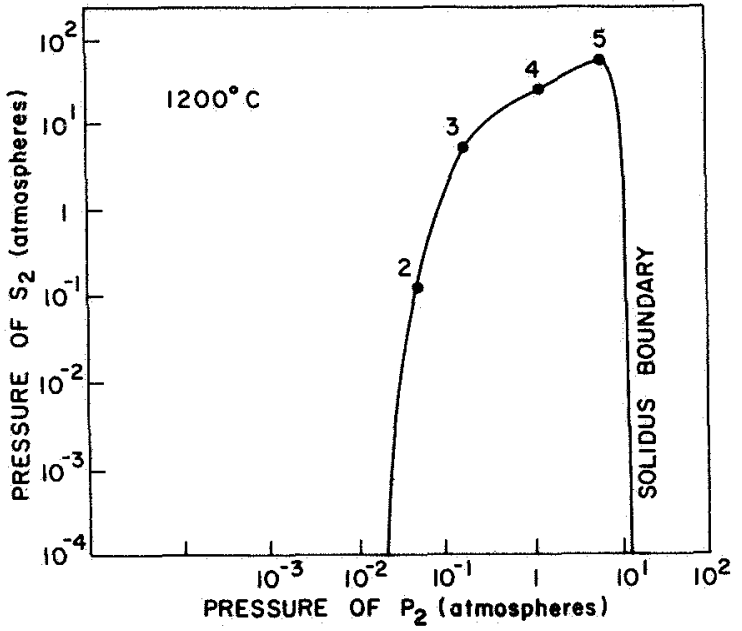

b. Schematic diagram of the region of existence of solid. GaP in terms of the vapor pressures $\mathrm{P}_{\mathrm{S}_{2}}$ and $\mathrm{P}_{\mathrm{P}_{2}}$. Points $I$ and 6 are not shown because they represent points on the Ga-P binary line for which $\mathrm{P}_{\mathrm{S}_{2}}$ is zero

Fig. 3. MAPPING OF THE GaP SOLIDUS BOUNDARY AT $1200^{\circ} \mathrm{C}$ FROM THE TERNARY CONDENSSED PHASE DIAGRAM OF THE Ga-P-S SYSTEM.

Each point on the solidus boundary in the ternary condensed phase diagram shown in Fig. 3a can be related to a point on the liquidus curve by a tie line. Each point on the boundary then corresponds to a specific set of sulfur and phosphorus pressures. Thus point 2 in Fig. $3 a$ corresponds to point 2 in Fig. 3b. Using the vapor pressures that were calculated in the previous section, the solidus boundary for the GaP 
phase at $1200^{\circ} \mathrm{C}$ is mapped out as shown in Fig. 3b. Points within the boundary represent values of phosphorus and sulfur pressures for which the GaP phase is stable, i.e., a vapor phase and a sulfur-doped GaP solid phase exist, but no liquid phase is present.

The upper and lower bounds on phosphorus pressure correspond to the limits of stability of the solid phase in the binary Ga-P system. The high upper limit on sulfur pressure is a consequence of the very high vapor pressure of sulfur over pure liquid sulfur at this temperature.

\section{B. The Ga-As-S System}

\section{The GaAs Liquidus}

The phase diagram for the Ga-As-S system has not been determined, so techniques similar to those discussed above for the Ga-P-S system were used to estimate the liquidus curves, vapor pressures, and the solidus boundary of the GaAs phase. Figure 4 shows the assumed ternary condensed phase diagram for the Ga-As-S system. Liquidus lines for the GaAs solid phase for several temperatures were taken from the Ga-AsTe system as determined by Panish [8]. The solid phases that exist at the temperatures of interest are also shown on this diagram. In this study, several diffusions were done at temperatures lower than $1090^{\circ} \mathrm{C}$, the melting point of the $\mathrm{Ga}_{2} \mathrm{~S}_{3}$ phase, so the existence of this and other compounds is possible under equilibrium conditions.

Several compounds containing arsenic and sulfur also exist [12]. However, they all have melting points below $400^{\circ} \mathrm{C}$ and are not of interest in this study.

\section{Vapor Pressures Along the GaAs Liquids}

The vapor pressures along the liquidus of the GaAs phase region are estimated using the following set of equations:

$$
\begin{aligned}
& \mathrm{P}_{\mathrm{As}_{2}}=\left(\gamma_{\mathrm{As}} \mathrm{X}_{\mathrm{As}}\right)^{2} \mathrm{P}_{\mathrm{As}}^{\circ}, \\
& \mathrm{P}_{\mathrm{As}_{4}}=\left(\gamma_{\mathrm{As}} \mathrm{X}_{\mathrm{As}}\right)^{4} \mathrm{P}_{\mathrm{As}_{4}}^{\circ},
\end{aligned}
$$




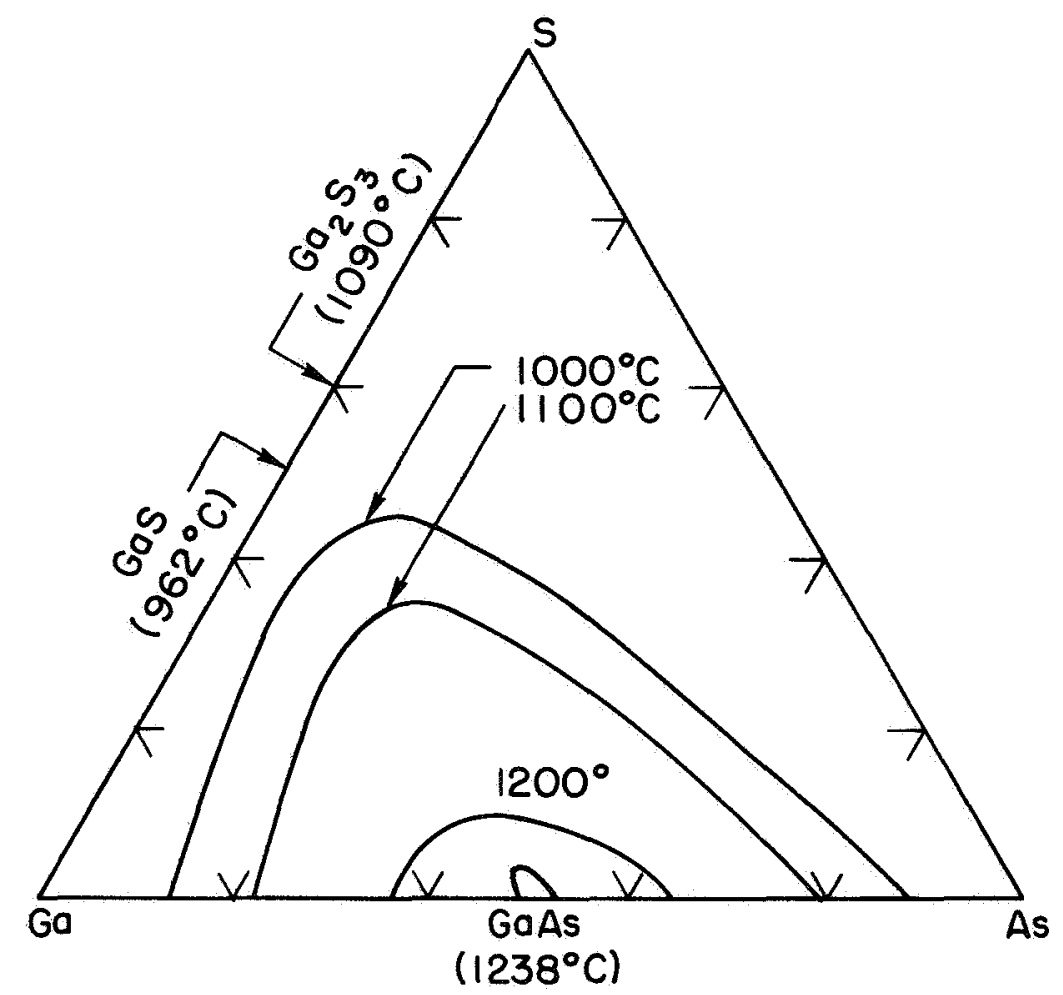

Fig. 4. ASSUMED TERIVARY CONDENSED PHASE DIAGRAM FOR THE Ga-As-S SYSTEM. (Liquidus isotherms were taken from the Ga-As-Te system as determined by Panish [7].)

$$
\text { and } \quad \mathrm{P}_{\mathrm{S}_{2}}=\left(\gamma_{\mathrm{S}_{\mathrm{S}}} \mathrm{X}^{2} \mathrm{P}_{\mathrm{S}_{2}}^{\circ}\right.
$$

The vapor pressures of gallium and other vapor species are low and neglected here. The pressures of arsenic over pure liquid arsenic were taken from Thurmond's paper [10], and the activity coefficients were obtained by fitting the liquidus curves of Fig. 4 with the regular solution method of Furukawa and Thurmond [15]. The calculated pressures of the important vapor species along the $1100^{\circ} \mathrm{C}$ isotherm are shown in Fig. 5.

\section{The GaAs Solidus Region}

The vapor pressures calculated in the previous section can be used to map the boundary of the GaAs solidus region at $1100^{\circ} \mathrm{C}$ as discussed 

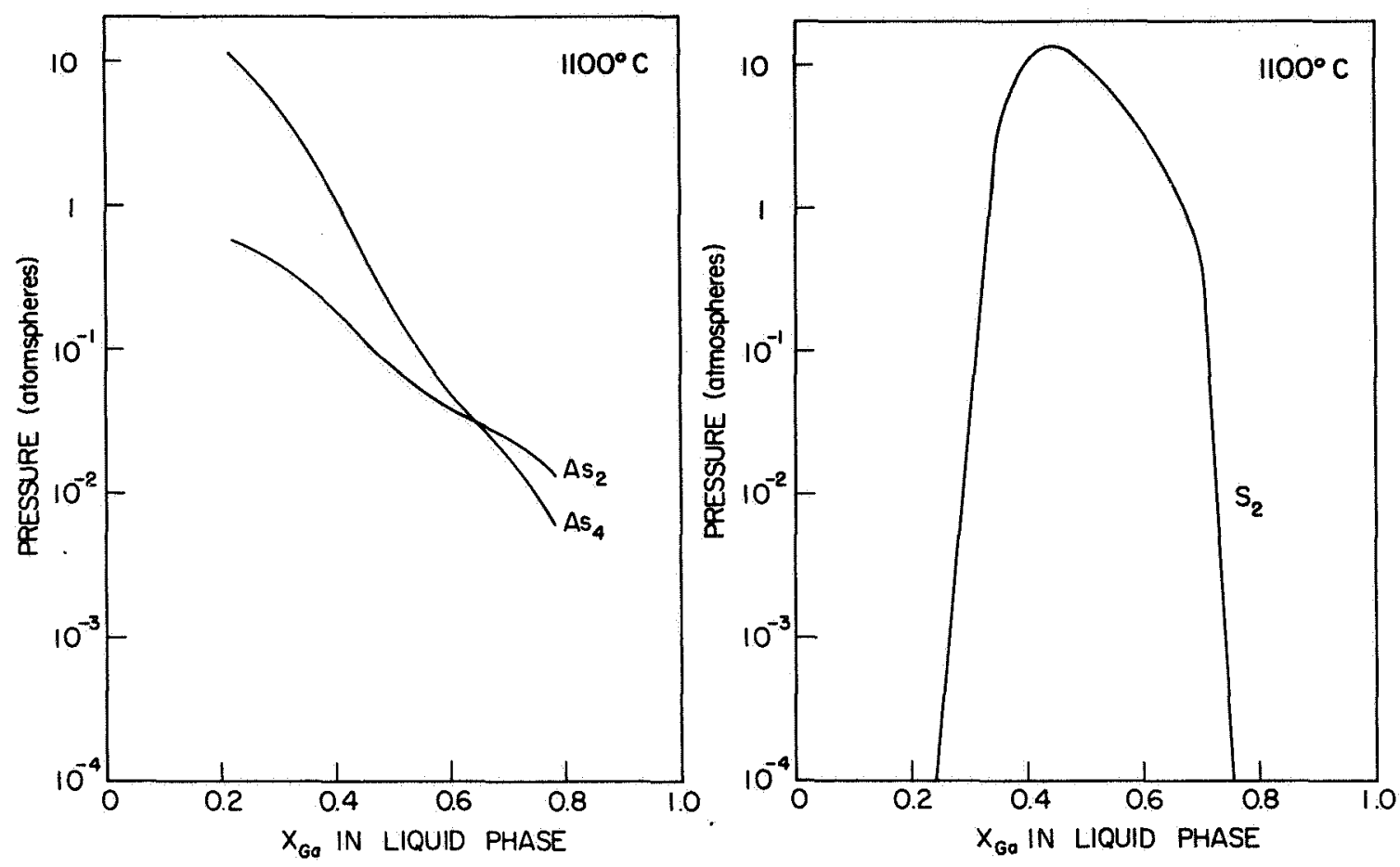

a. Pressures of $\mathrm{As}_{2}$ and $\mathrm{As}_{4}$. b. Pressure of $\mathrm{S}_{2}$

Fig. 5. VARIATION OF VAPOR PRESSURES AT $1100^{\circ} \mathrm{C}$ ALONG THE IIQUIDUS IN THE Ga-As-S SYSTEM AS CALCULATED BY THE REGULAR SOLUTION METHOD.

previously for the GaP system. Again the one-to-one correspondence between points on the liquidus in Fig. 6 a and points on the solidus boundary in Fig. $6 \mathrm{~b}$ is shown.

\section{Application to This Study}

In Chapter III, the experimental procedures and results are discussed. The phosphorus (or arsenic) and sulfur pressures present during diffusion can be determined from the amounts of phosphorus (or arsenic) and sulfur added to the ampoule together with the relations shown in Fig. 9 (or 10) and 11 respectively. If the experimental conditions of phosphorus (or arsenic) and sulfur pressures are plotted on Fig. 3b (or Fig. 6b), it can be seen that diffusions usually take place within the GaP (or GaAs) solidus boundary. When no excess phosphorus (or arsenic) 


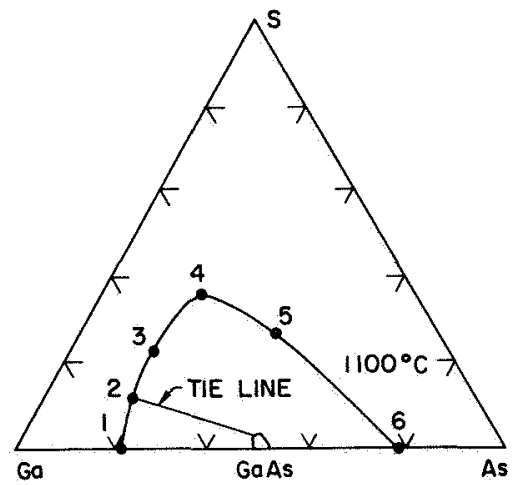

a. Ternary condensed phase diagram with a tie line relating a point on the solidus boundary and its equilibrium liquid

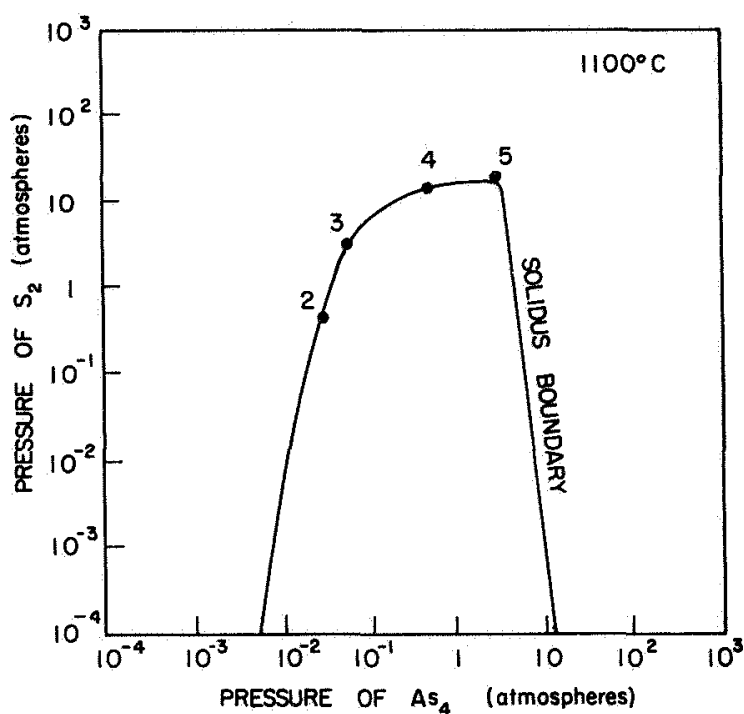

b. Schematic diagram of the region of existence of solid GaAs in terms of the vapor pressures $\mathrm{P}_{\mathrm{S}_{2}}$ and $\mathrm{P}_{\mathrm{As}_{4}}$.. Points 1 and 6 are not shown because they represent points on the Ga-P binary line for which $\mathrm{P}_{2}$ is zero

Fig. 6. MAPPING OF THE GaAs SOLIDUS BOUNDARY AT $1100^{\circ} \mathrm{C}$ FROM THE TERNARY CONDENSED PHASE DIAGRAM OF THE Ga-As-S SYSTEM.

is added, the diffusion probably occurs at a point on the solidus boundary with the solid phase in equilibrium with a small amount of galliumrich liquid [9]. The portion of the GaP solidus region that can be explored, however, is quite limited since either the phosphorus or sulfur pressure is excessive, except for a small region of the gallium-rich portion of the solidus. In this respect, the diffusion of sulfur in GaP differs from that of $\mathrm{Zn}$ in GaAs. In the latter system, the lower pressures of $\mathrm{Zn}$ and As over the pure liquids permit diffusion studies over a more extensive range of the solidus region.

Within the solidus region, only two phases are present--a sulfurdoped GaP (or GaAs) solid phase, and a vapor phase composed of various species of Ga, P (or As), and $\mathrm{S}$. The phase rule [16] gives the number 
of independent parameters required to specify the state of a system unambiguously as

$$
F=C+2-P
$$

Here $F$ is the number of degrees of freedom, $C$ is the number of components, and $P$ is the number of phases. In a ternary system there are three degrees of freedom within the solidus region. It is not meaningful to ask, for example, for the solubility of sulfur in GaP at, say, $1200^{\circ} \mathrm{C}$. Since the solubility depends not only on the temperature, but on two other independent variables as well, all three parameters must be specified before a unique answer to the question can be given.

In this study, the three independent variables were taken to be the temperature, the sulfur pressure, and the phosphorus or arsenic pressure. By studying the diffusion and solubility of sulfur in GaP and GaAs when these parameters were varied, it was hoped that insight into the mechanisms of diffusion and defect structure of the crystal could be obtained. 
Chapter III

DIFFUSION OF SULFUR IN GaP AND GaAs

Diffusion and solubility studies of impurities in semiconductors can give valuable information about the mechanisms of impurity movement and incorporation. In this study, a radiotracer technique was used to obtain diffusion profiles of sulfur in GaP and GaAs. This technique was used because it gives information about the total impurity concentration in the diffused layers and is not influenced by incomplete ionization or by compensation by other impurities. In addition, radiotracer profiles give a direct measure of the surface concentration under experimental conditions and make any concentration dependence of the diffusion coefficient easy to detect. The radioisotope used was sulfur-35* (specific activity $\approx 0.4 \mathrm{mc} / \mathrm{mg}$ ) which is a weak beta emitter $(0.167 \mathrm{MeV})$ and has a half-Iife of 87 days [12].

In this chapter, the experimental procedures are described, and the experimental results are presented. Within the solidus region of the ternary systems of interest, the three variables needed to specify uniquely the state of the system are taken to be the temperature, the phosphorus $\left(\mathrm{P}_{\mathrm{P}_{2}}\right)$ or arsenic $\left(\mathrm{P}_{\mathrm{As}_{4}}\right)$ pressure, and the sulfur pressure $\left(\mathrm{P}_{\mathrm{S}_{2}}\right)$. The results of experiments in which each of the three parameters is varied independently are discussed. It is shown that the behavior of sulfur diffusion in GaP and GaAs when the component pressure is varied is not in agreement with a model of vacancy diffusion on the anion sublattice which has been proposed in the literature [1]. The dependence of surface concentration on sulfur pressure is also anomalous.

Additional information about the diffusion mechanism can be obtained by varying the Fermi level by means of a change in the background doping. The results of diffusing sulfur in heavily-doped n-type GaAs are presented and compared to diffusion in the undoped crystals.

\footnotetext{
* Volk Radiochemical Company, Burbank, California.
} 
1. Properties of Starting Materials and Sample Preparation

GaP single crystals were grown by an open tube vapor epitaxial process using $\mathrm{PCl}_{3}$ as the transport agent [17]. The GaP crystals were grown on \{1II\} Ga faces of GaAs seed crystals. Typical parameters of these undoped crystals were: electron concentration, $10^{15}-10^{16} \mathrm{~cm}^{-3}$; mobility, 80 to $100 \mathrm{~cm}^{2} / \mathrm{v}$-sec; and dislocation density, $10^{6} \mathrm{~cm}^{-2}$. These crystals have a high density of planar lattice defects (these are beIieved to be stacking faults or microtwins [18]) and contain up to 6 percent of arsenic on the anion site from contamination from the GaAs seed [19]. The effect of this arsenic content was minimized by using the same crystal when a direct comparison among several diffusions was necessary.

GaAs single crystals were obtained from the Monsanto Company. ${ }^{*}$ Undoped crystals were used in most of the work. The undoped samples were boat-grown and oriented in the 〈III〉 direction. Typical parameters of these crystals were: electron concentration, $10^{15}-10^{16} \mathrm{~cm}^{-3}$; mobility, $4000 \mathrm{~cm}^{2} / \mathrm{v}-\mathrm{sec}$; dislocation density, $1-2 \times 10^{3} \mathrm{~cm}^{-2}$. Heavily-doped GaAs was also used for the experiments described in section $\mathrm{C} .4$ of this chapter. The n-type samples were Czochralski-grown and doped with tellurium. The carrier concentration was $5 \times 10^{18} \mathrm{~cm}^{-3}$, mobility was $1910 \mathrm{~cm}^{2} /$ $\mathrm{v}-\mathrm{sec}$ and the dislocation density was $6.5 \times 10^{3} \mathrm{~cm}^{-2}$.

The crystals were lapped with 3200 grit abrasive, mechanically polished in Linde A 0.3 micron alumina powder, and cleaned in an ultrasonic vibrator. After the usual degreasing procedure (trichloroethylene, acetone, methanol), the samples were etched for 10 minutes to remove damage due to the polishing procedure. The etchant for the GaP was $8 \mathrm{~g} \cdot \mathrm{K}_{3} \mathrm{Fe}(\mathrm{CN})_{6}: 12 \mathrm{~g} \cdot \mathrm{KOH}: 100 \mathrm{~g} \cdot \mathrm{H}_{2} \mathrm{O}$ [20], and for the GaAs, an 0.15 percent Br-methanol solution. After etching, the \{111\} $P$ and [111\} As faces were smooth and shiny, while the \{1II\} Ge face was dull and pitted.

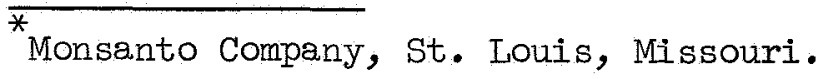




\section{Encapsulation and Annealing}

Standard solutions of the impurity diffusant were prepared by dissolving known amounts of the radioactive sulfur- $35^{*}$ in Spectroquality benzene. Controlled amounts of sulfur were then introduced into cleaned quartz ampoules by pipetting appropriate volumes of liquid. The benzene was evaporated by passing a stream of dry nitrogen (high purity) over the liquid while the benzene vapor was heated with an infrared lamp.

Appropriate quantities of phosphorust or arsenic ${ }^{\ddagger}$ were placed in the ampoule along with the sample to be diffused. One of the difficulties of high temperature diffusions in GaAs and GaP with sulfur as the diffusant has been the presence of a vapor transport mechanism which can result in severe surface deterioration, large weight losses, and consequently, unreliable data [21]. The use of a quartz place "sandwich," with the sample contained between two quartz plates, has been suggested as a technique for reducing the surface deterioration [22-24]. Using this technique, good surfaces were obtained in our experiments. A typical weight loss in the GaP diffusions corresponded to a loss of one micron from each face. In the GaAs diffusions, the corresponding loss was only 0.25 microns from each face.

The ampoule was evacuated to $1-5 \times 10^{-5}$ torr and then sealed. off. Wet asbestos tape was wrapped around the end of the ampoule to prevent vaporizing of the sulfur and phosphorus or arsenic during sealing. A sketch of the diffusion ampoule appears in Fig. 7. An inner plug was used to reduce the volume of the ampoule to $1.0 \mathrm{ml}$ ( \pm 10 percent).

The ampoule was placed in a furnace for annealing at elevated temperatures. The diffusion temperature range was from 1100 to $1300^{\circ} \mathrm{C}$ for the GaP diffusions, and from 900 to $1200^{\circ} \mathrm{C}$ for the corresponding GaAs work. The diffusion time varied from 20 minutes to 5 days depending on the temperature and the purpose of the particular experiment. The

\footnotetext{
* Radiopurity 99 percent.

†High purity, American Agricultural Chemical Company, Division of Continental Oil Company.

¥6 9's purity, United Mineral and Chemical Corp., New York.
} 


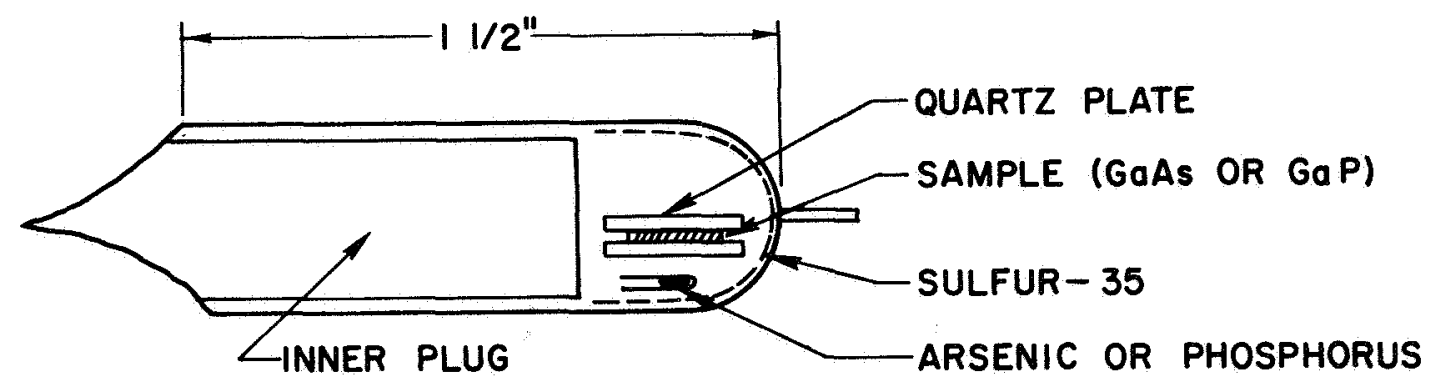

Fig. 7. SCHEMATIC DRAWING OF A DIFFUSION AMPOULE AND ITS CONTENTS.

temperature was controlled to $\pm 2^{\circ} \mathrm{C}$ during the diffusion. After diffusion, the ampoule was water quenched and the samples were removed.

\section{Construction of Diffusion Profiles}

The samples were soaked for 30 minutes in a warm benzene solution to remove any sulfur that might have condensed on the surface. They were then checked for weight loss. This was negligible in most cases. Circular discs 0.150 in. in diameter were cut out with an ultrasonic tool to eliminate edge diffusion effects and to give a standard geometrical shape.

Because the diffused layers were generally less than 10 microns deep, reproducible profiles could not be obtained using a precision lapping machine. Instead, an etching technique was used to remove thin layers parallel to the surface. The sample was mounted with Apiezon $W$ wax onto a microscope slide. It was then immersed into a beaker of the appropriate etchant (given in section A.I of this chapter) and stirred vigorously for the desired time [25]. Typically layers 0.5 to $1.0 \mathrm{mi-}$ crons thick were removed in 1-2 minutes. The samples were rinsed and degreased after each etch. The etchants were changed periodically to prevent contamination of subsequent layers.

The thickness of each removed layer was calculated by weighing the sample with a Mettler Micro Gram-atic balance before and after each etching. Counting was done with a Baird Atomic proportional counter and scaler timer. The activity of each removed layer could not be counted directly because the $0.167 \mathrm{MeV}$ beta emission was strongly absorbed by 
the etching solutions. However, the activity of sulfur in each layer. could be determined by counting the sample before and after each etch. The results were corrected for self-absorption since attenuation of the beta emission in the GaP or GaAs crystals was significant.

The correction was made by assuming that the absorption of the beta emission in the crystals could be characterized by an exponential curve of the form,

$$
\text { Relative intensity } \propto \exp \left(-\mu_{\mathrm{m}} \mathrm{d}\right)
$$

where $\mu_{m}$ is the mass absorption coefficient in $\mathrm{cm}^{2} / \mathrm{mg}$, and $d$ is the absorber thickness in $\mathrm{mg} / \mathrm{cm}^{2}[26,27]$. The measured absorption curves of the $0.167 \mathrm{MeV}$ beta particles for several materials are shown in Fig. 8 .

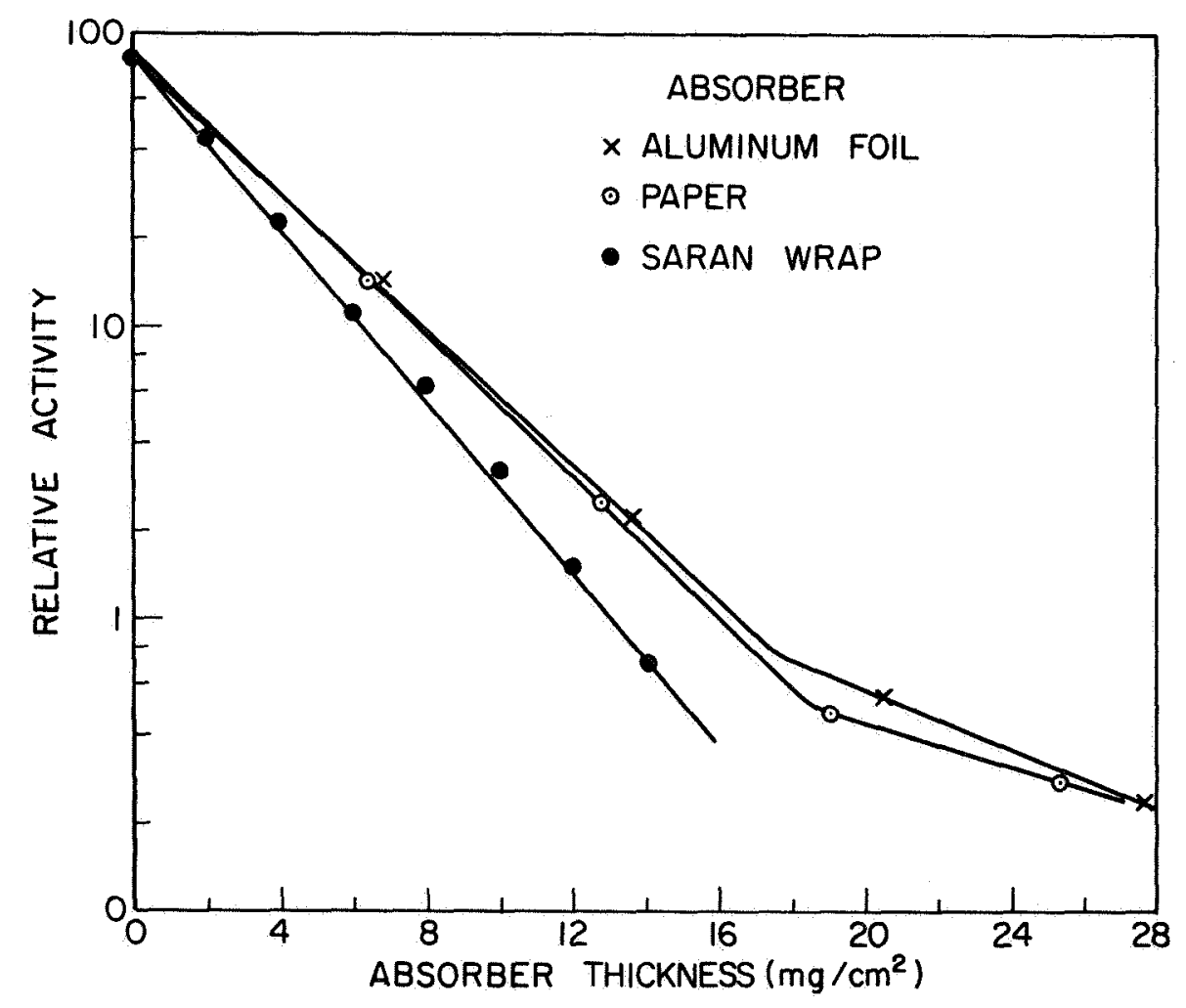

Fig. 8. MFASURED ABSORPTION CURVES OF $0.167 \mathrm{MeV}$ BETA PARTICLFS IN VARIOUS MATERIALS. 
In this study, it was assumed that absorption in GaAs and GaP was similar to that in aluminum where $\mu_{m}$ is $0.27 \mathrm{~cm}^{2} / \mathrm{mg}$. The beta intensity is reduced to $1 / \mathrm{e}$ of its initial value in 9 microns of GaP and 7 microns of GaAs. The correction term becomes increasingly important as the depth of the profile increases.

Sulfur concentrations in the diffused layers were determined by comparing the activities of the removed layers with that of a calibrated sulfur-35 standard made from the standard solutions discussed previously.

Diffusion profiles were usually determined only on the $\{111\}$ $P$ or $\{111\}$ As faces because the etchants used produced polished surfaces only on these faces. In most cases, however, when good surfaces were retained, surface counts of the \{111\} A and \{111\} B faces were within 25 percent of each other, indicating that the diffusion was probably the same on both faces. Diffusions at $1020^{\circ} \mathrm{C}$ in GaP in the presence of excess phosphorus ( $2 \mathrm{mg} / \mathrm{ml}$ ), however, showed a marked difference between the two faces. The \{11l\} $P$ face remained smooth and shiny, while the $\{111\} \mathrm{Ga}$ face apparently was chemically attacked and had a much higher surface concentration and penetration than the other face. It is interesting to note that the diffusion temperature in this case was lower than the melting temperature of the $\mathrm{Ga}_{2} \mathrm{~S}_{3}$ phase $\left(1090^{\circ} \mathrm{C}\right)$. In the GaAs system, no such effect was noted for temperatures as low as $900^{\circ} \mathrm{C}$. A significant difference, however, may have been the lower sulfur vapor density for the GaAs case $(0.2 \mu \mathrm{g} / \mathrm{ml}$ versus $20 \mu \mathrm{g}$ for the GaP diffusion). Goldstein reported that compound formation was a more serious problem at high sulfur concentrations in the GaAs-S system [I].

\section{Vapor Pressures During the Diffusion}

In the interpretation of the experimental results, it is necessary to know the pressures of the various species in the vapor phase. The relationship between pressure and vapor density is shown in Figs. 9, 10, and 11 for $P, A s$, and $S$ respectively. The calculations were done using equilibrium constants from the literature [14,28] and a "conservation-of-moles" equation for each component. The sulfur dimer $\left(\mathrm{S}_{2}\right)$ dominates under all experimental conditions. For arsenic, the tetramer 


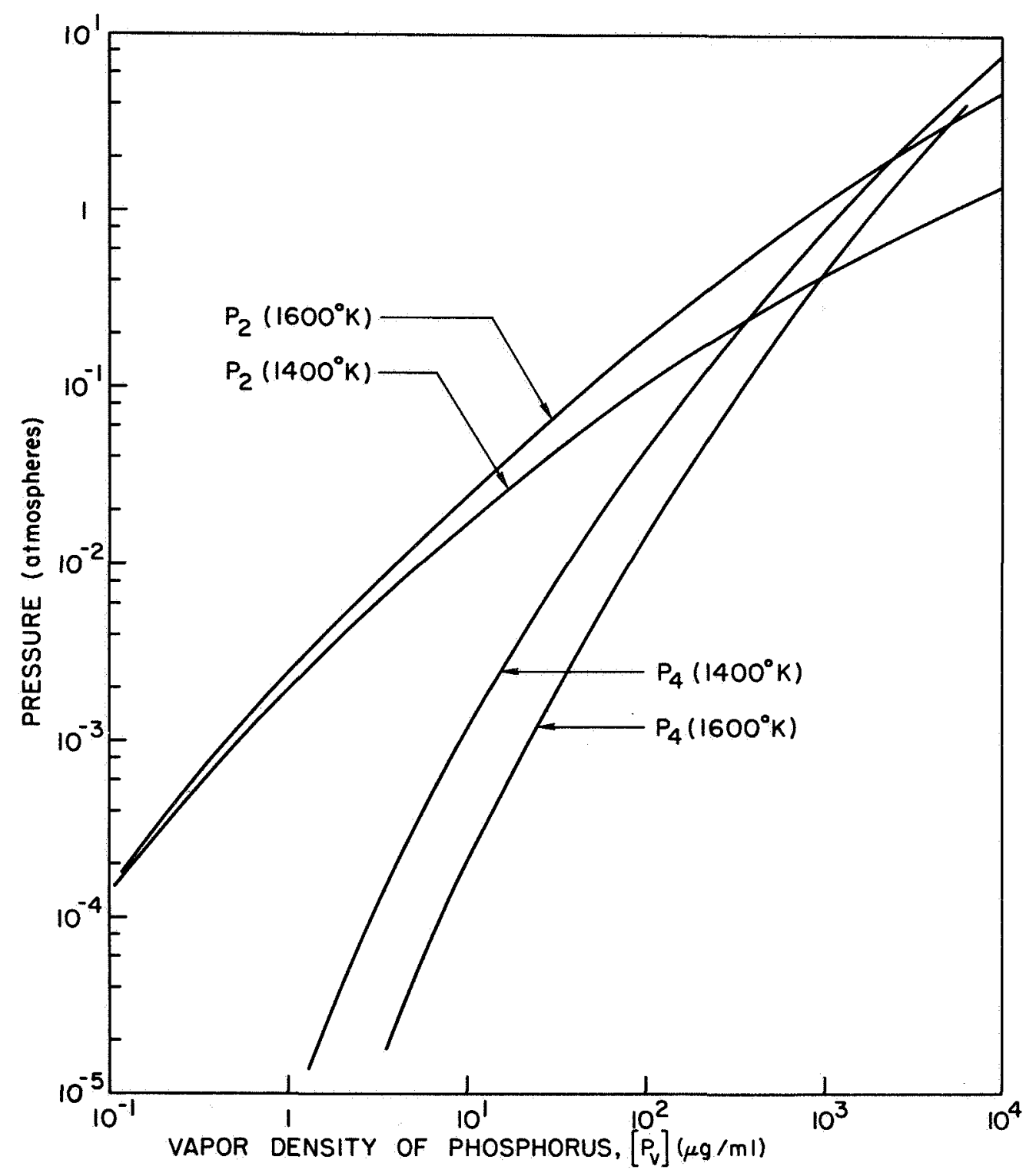

Fig. 9. PARTIAL PRESSURES OF $\mathrm{P}_{2}$ AND $\mathrm{P}_{4}$ VERSUS THE VAPOR DENSITY OF PHOSPHORUS IN THE AMPOULE.

$\left(\mathrm{As}_{4}\right)$ dominates except at the lowest pressures, while for phosphorus, the dimer $\left(\mathrm{P}_{2}\right)$ dominates except at the higher pressures. The pressures of $S_{8}$ and the monomers of all species can be shown to be negligible under the experimental conditions in this study. These calculations should be valid when the pressures are less than the pressures over the pure liquids and, for $P$ and $A s$, when they are greater than the pressures at the Ga-rich part of the GaP or GaAs solidus boundary 


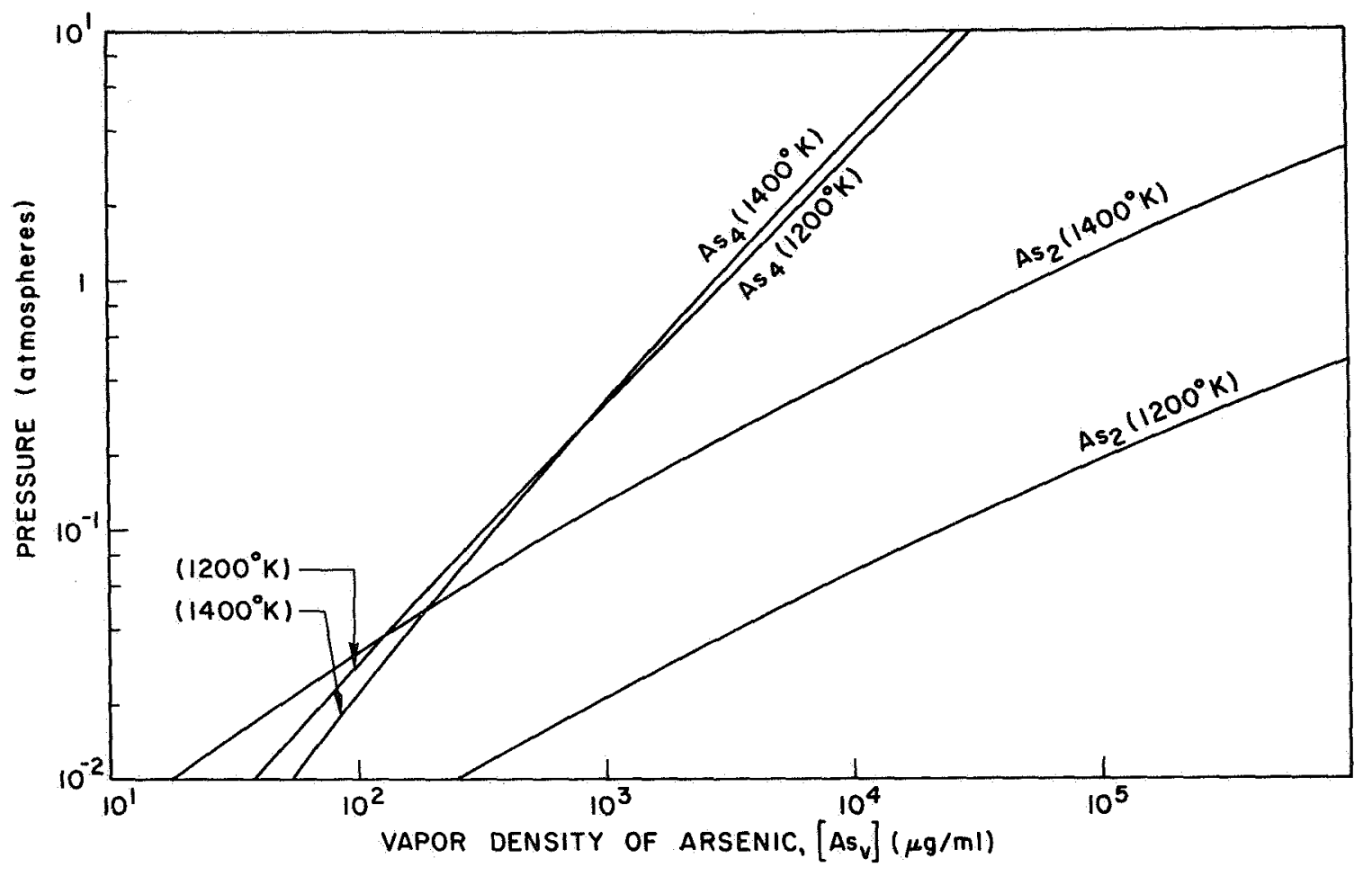

Fig. 10. PARTIAI PRESSURES OF As2 AND As4 VERSUS THE VAPOR DENSITY OF ARSENIC IN THE AMPOULE

[10]. It is also stressed that the calculations assume no interactions between the species in the vapor phase.

The arsenic (or phosphorus) pressure when no excess arsenic (or phosphorus) was added was assumed to be the decomposition pressure for the GaAs (or GaP) solid phase in the binary Ga-As (or Ga-P) system $[10,33]$.

\section{Determination of Diffusion Coefficient}

In the experiments described in the next section, sulfur was diffused into the samples from a vapor source. For nearly all of the diffusions, the amount of sulfur that diffused into the sample was small in relation to the amount of sulfur initially in the ampoule. Thus the assumption of an infinite source was valid. When the diffusion coefficient, $D$, is a constant, and there are no rate limitations at the 


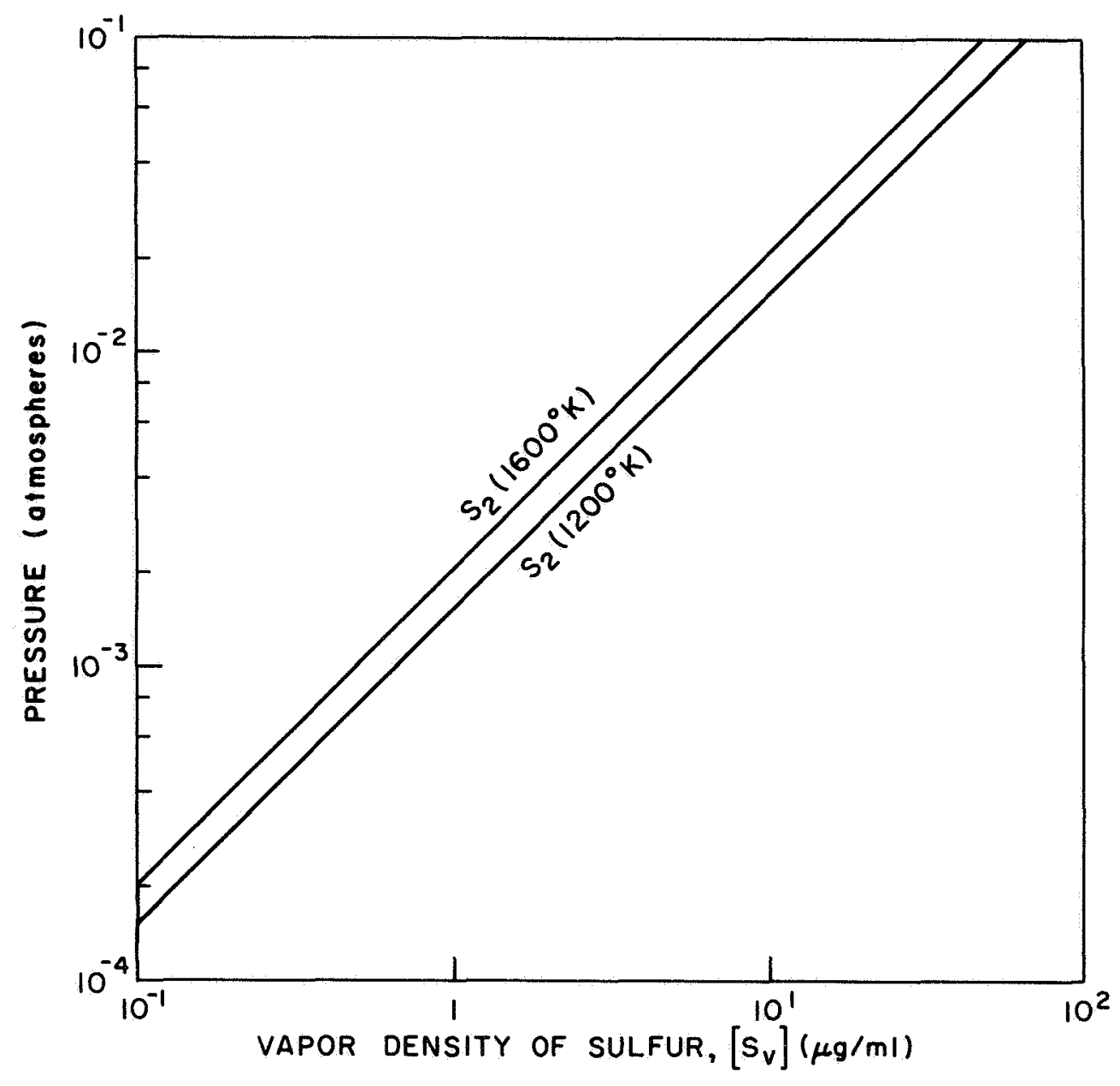

Fig. 11. PRESSURE OF S2 VERSUS THE VAPOR DENSITY OF SULFUR IN THE AMPOULE.

vapor-solid interface, the diffusion profiles are complementary error functions [29] which satisfy the relation:

$$
C(x)=C_{s} \operatorname{erfc}\left(\frac{x}{2 \sqrt{D t}}\right)=C_{s}\left[1-\int_{0}^{x / 2 \sqrt{D t}} e^{-z^{2}} d z\right],
$$

where $C(x)$ is the impurity concentration at a given distance, $x$, below the surface, $C_{s}$ is the surface concentration, and $t$ is the diffusion time. As will be shown, the diffusion profiles at low sulfur 
concentration appear to obey Eq. (3.2). The diffusion coefficient was obtained by Hall's method [30] in which normalized profiles, ( $\left.\mathrm{c} / 2 \mathrm{C}{ }_{\mathrm{s}}\right)$ versus $(x / \sqrt{t})$, plotted on probability paper yield straight lines whose slopes are related to the diffusion coefficient.

\section{B. Experimental Results in GaP}

In this section the experimental results for the diffusion of sulfur in GaP are presented. As discussed previously, diffusion within the GaP solidus region can be assumed to depend on three variables--the sulfur pressure, the phosphorus pressure, and the temperature. The results obtained by varying each of these parameters, while the other two are kept constant, are discussed in the following section. Models that explain the observed results are discussed in Chapter $V$.

\section{Variation with Sulfur Pressure}

Figure 12 illustrates the effect of varying the sulfur vapor density in the ampoule, $\left[\mathrm{S}_{\mathrm{V}}\right]$, from 0.2 to $20 \mu \mathrm{g} / \mathrm{ml}$, while keeping the temperature fixed at $1215^{\circ} \mathrm{C}$, and the phosphorus vapor density, $\left[\mathrm{P}_{\mathrm{v}}\right]$, at $2-3 \mathrm{mg} / \mathrm{ml} \quad\left(\mathrm{P}_{\mathrm{P}_{2}} \approx I \mathrm{~atm}\right)$. At the lower surface concentrations the profiles are smooth curves which obey the complementary error function solutions of the diffusion equation reasonably well. Therefore these profiles do not indicate any marked dependence of the diffusion coefficient on sulfur concentration. This result is in contrast to the strong concentration dependence reported for Zn in GaP [21]. However, when the

surface concentration exceeds $10^{20} \mathrm{~cm}^{-3}$, the shape of the profile changes. This indicates a change in the diffusion behavior at high concentrations. Similar profiles have been reported for selenium diffusion in GaAs when the surface concentration exceeded $10^{21} \mathrm{~cm}^{-3}$ [22].

As the sulfur vapor density increases, the surface conentration increases as shown in Fig. 13. The relation appears to be

$$
\text { surface concentration } \propto\left[\mathrm{S}_{\mathrm{V}}\right]^{1.3},
$$




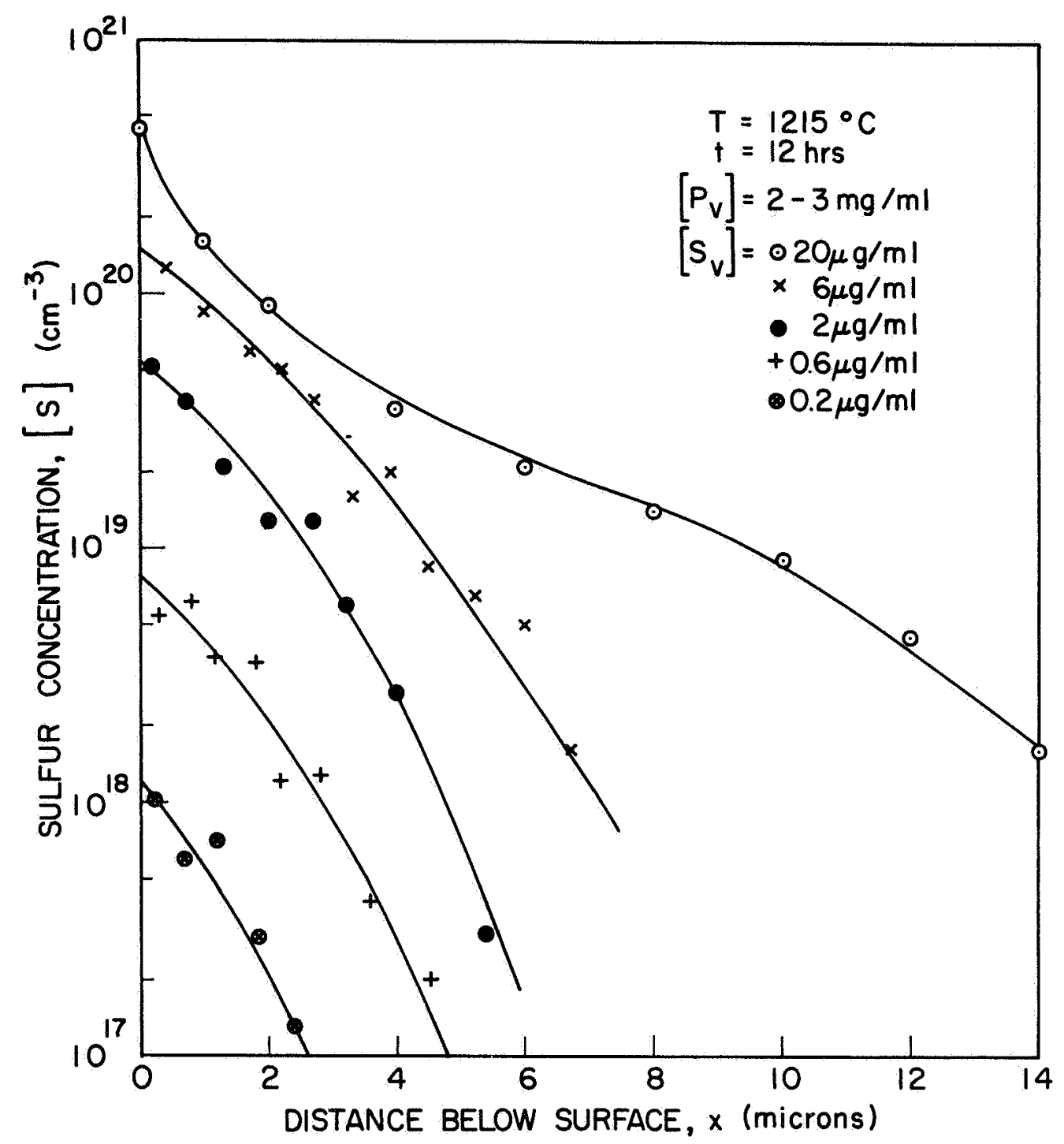

Fig. 12. DIFFUSION PROFILES OF SULFUR IN GaP AT VARIOUS SULFUR PRESSURES。

where $\left[\mathrm{S}_{\mathrm{V}}\right]$ is the sulfur vapor density. This relation is not in agreement with the usual model of incorporation of sulfur atoms on isolated phosphorus sites. This point is discussed more fully in Chapter V.

\section{Variation with Phosphorus Pressure}

Since the concentration of phosphorus and gallium vacancies depends on the phosphorus pressure in equilibrium with the GaP crystal, 


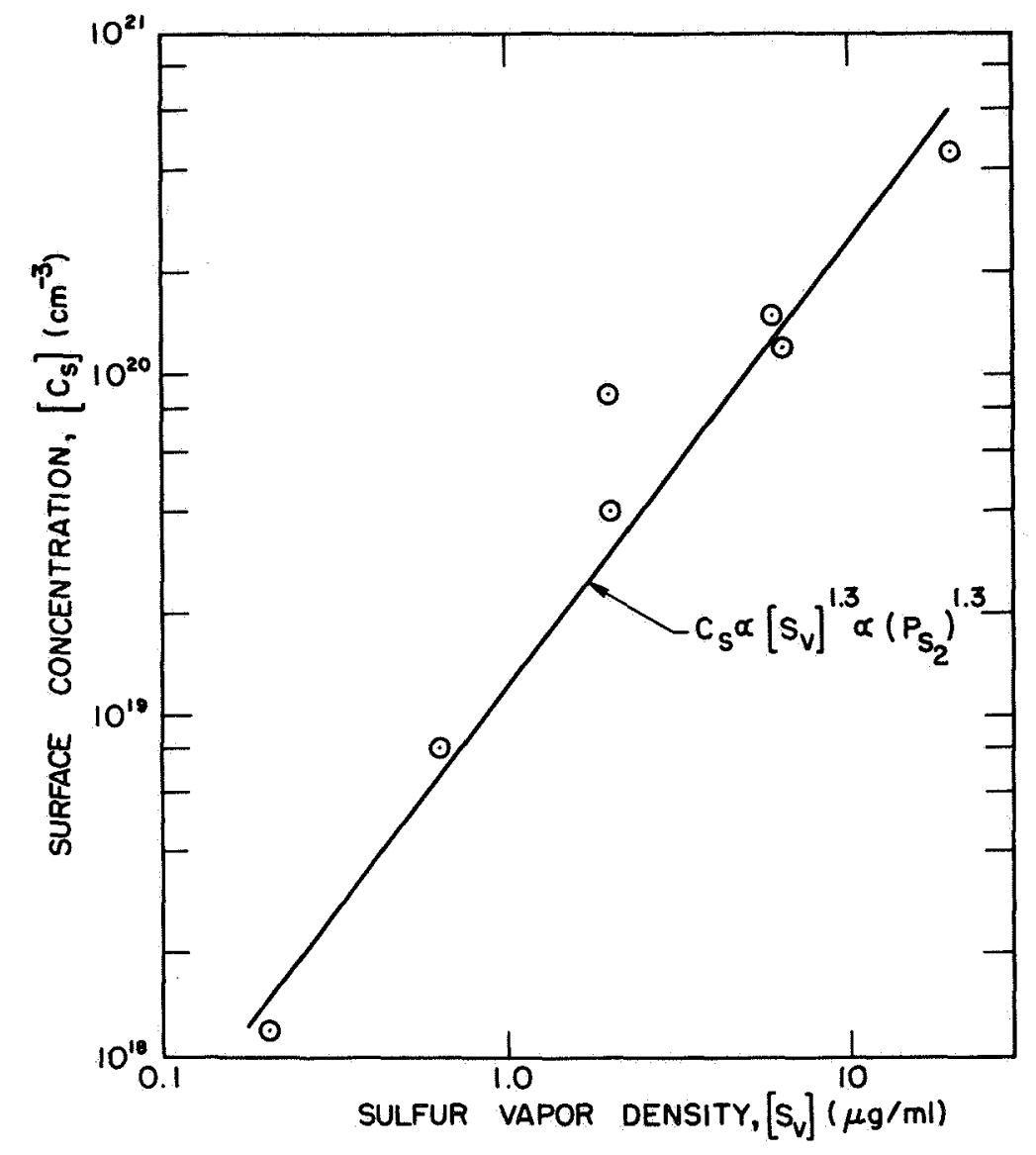

Fig. 13. DEPENDENCE OF THE SURFACE CONCENTRATION OF DIFFUSION PROFILES IN GaP ON THE SULFUR VAPOR DENSTIY. $\mathrm{T}=1215^{\circ} \mathrm{C} ; \quad\left[\mathrm{P}_{\mathrm{V}}\right]=2-3 \mathrm{mg} / \mathrm{mI}$.

valuable information about the diffusion process may be obtained by studying the dependence of diffusion on phosphorus pressure. Figure 14 shows the results of such an experiment where the excess phosphorus added to the ampoule was varied from 0 to $3.2 \mathrm{mg} / \mathrm{ml}$. The sulfur vapor density for all three profiles was $6 \mu \mathrm{g} / \mathrm{ml}$, and the temperature was $1217^{\circ} \mathrm{C}$. Both the diffusion coefficient and the surface concentration appear to be relatively independent of the phosphorus pressure.

Figure 15 demonstrates explicitly the dependence of diffusion coefficient on phosphorus pressure for the profiles shown in Fig. 14, as well as additional data for a temperature of $1112^{\circ} \mathrm{C}$ and a sulfur vapor density of $2 \mu \mathrm{g} / \mathrm{ml}$. The phosphorus pressure when no excess phosphorus was added was taken to be the pressure at the gallium-rich solidus 


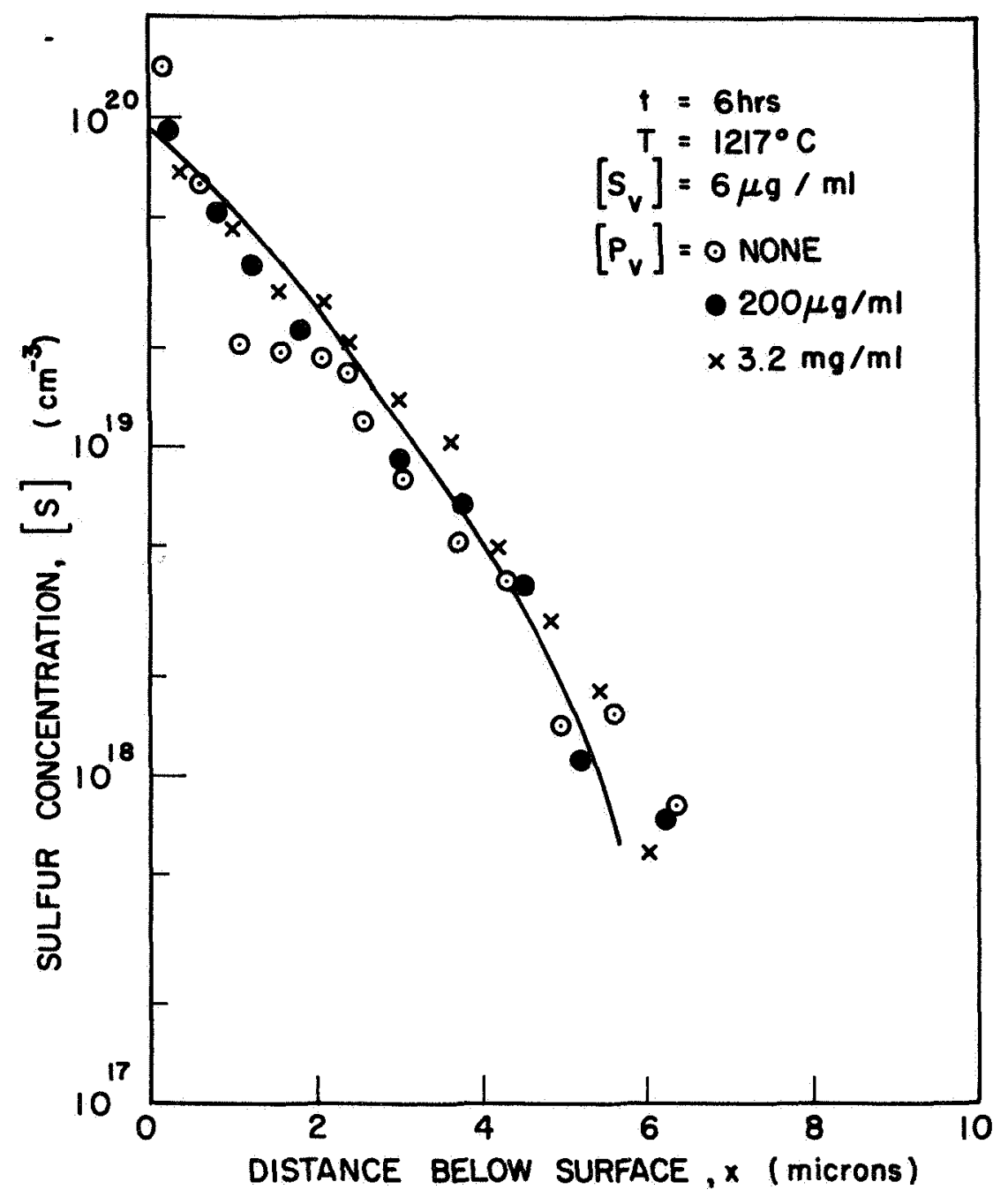

Fig. 14. DIFFUSTON PROFILES OF SULFUR IN GaP AT VARIOUS PHOSPHORUS PRESSURES.

boundary as determined by Thurmond [10]. The phosphorus pressure when excess phosphorus was added was determined from Fig. 9. The observed dependence of diffusion coefficient on phosphorus pressure is not in agreement with a model of vacancy diffusion within the phosphorus sublattice. This is discussed more fully in Chapter V.

3. Variation with Temperature

Figure 16 illustrates the effect of varying the temperature from $1112^{\circ} \mathrm{C}$ to $1311^{\circ} \mathrm{C}$ while keeping the sulfur and phosphorus pressures 


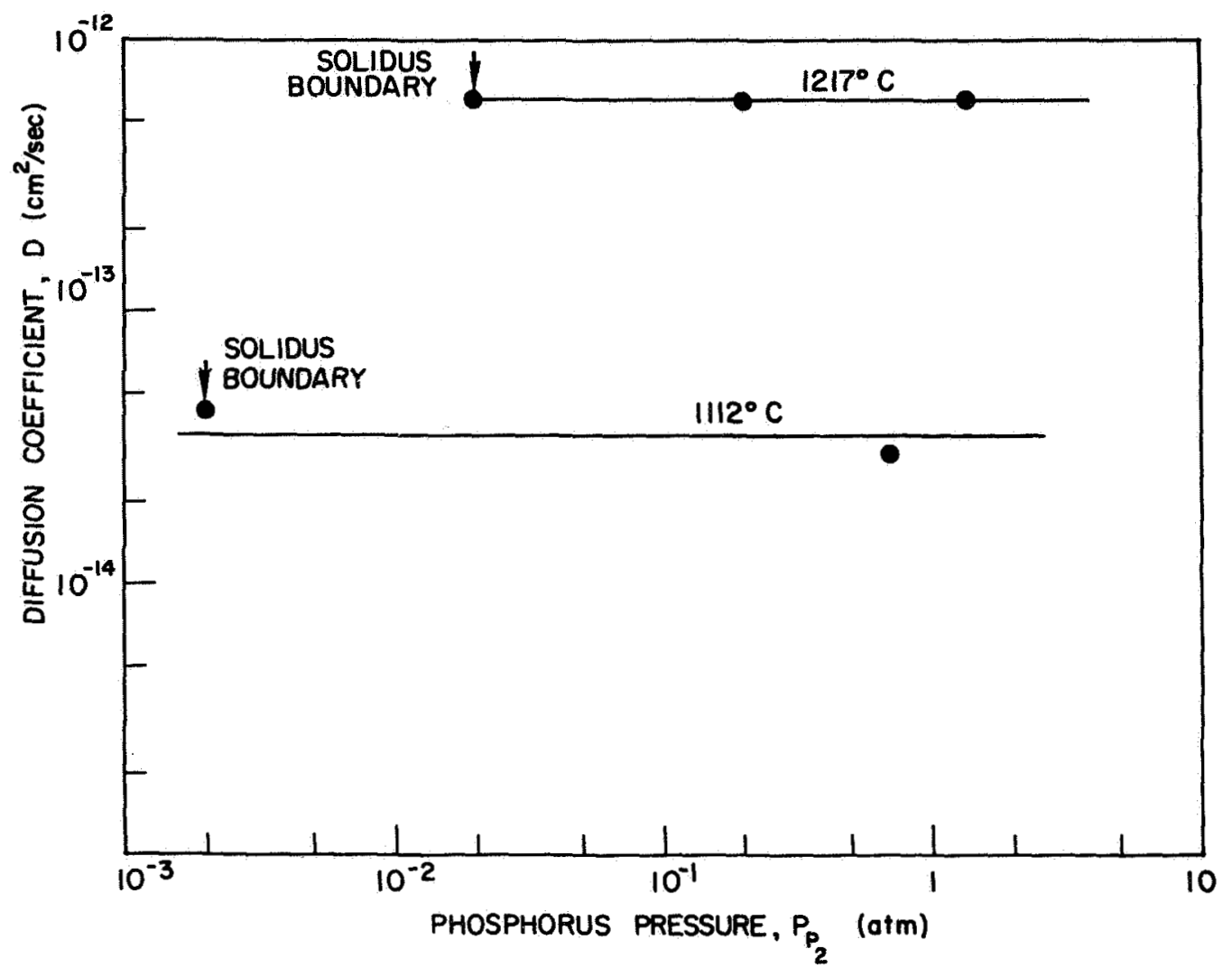

Fig. 15. DEPENDENCE OF THE DIFFUSION COEFFICIENT OF SULFUR IN GaP ON THE PHOSPHORUS PRESSURE. $\left[\mathrm{S}_{\mathrm{V}}\right]=6 \mu \mathrm{g} / \mathrm{ml}$ at $1217^{\circ} \mathrm{C}$; $\left[\mathrm{S}_{\mathrm{V}}\right]=2 \mu \mathrm{g} / \mathrm{ml}$ at $1112^{\circ} \mathrm{C}$.

approximately constant. Actually the vapor densities were not the same in all diffusions. However, the preceding sections have demonstrated that the diffusion coefficient is not strongly dependent on either the phosphorus pressure or the sulfur concentration (at least at concentrations below $10^{20} \mathrm{~cm}^{-3}$ ). The sulfur vapor density was $6 \mu \mathrm{g} / \mathrm{ml}$ at the two higher temperatures, and $2 \mu \mathrm{g} / \mathrm{ml}$ at $1112^{\circ} \mathrm{C}$. In order to plot the profiles on the same graph, they have been scaled to a normalized time of 12 hours by assuming that they scale as the square root of time. Measurements at $1217^{\circ} \mathrm{C}$ indicate that this is a reasonable assumption. These results are shown in Chapter $V$. The actual diffusion times were 3 hours at $1311^{\circ} \mathrm{C}, 12$ hours at $1215^{\circ} \mathrm{C}$, and 48 hours at $1112^{\circ} \mathrm{C}$. 


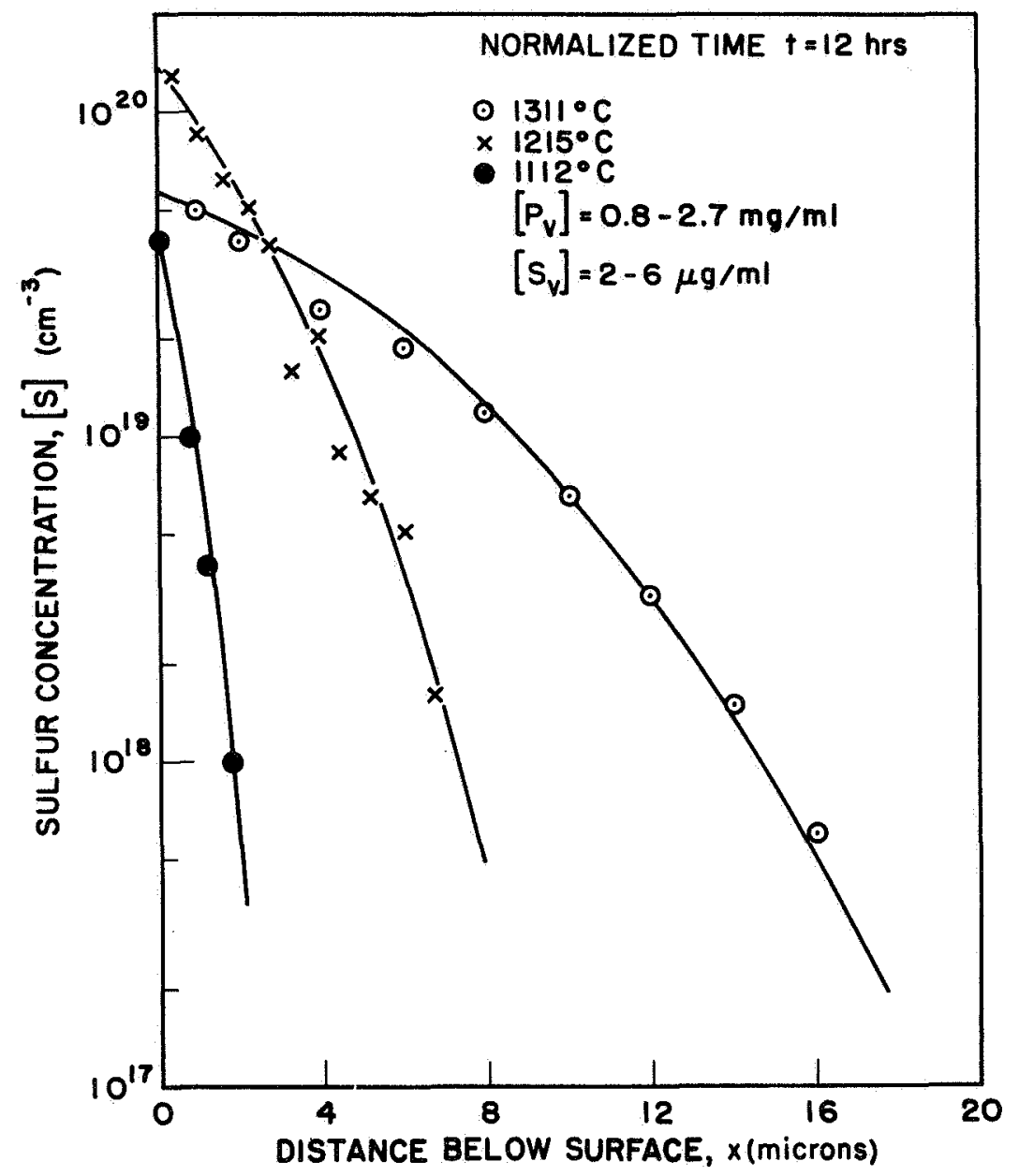

Fig. 16. DIFFUSION PROFILES OF SULFUR IN GaP AT VARIOUS TEMPERATURES. Actual diffusion times are $3 \mathrm{hr}$ at $1311^{\circ} \mathrm{C}$, $12 \mathrm{hr}$ at $1215^{\circ} \mathrm{C}$, and $48 \mathrm{hr}$ at $1112^{\circ} \mathrm{C}$.

The diffusion coefficients determined from these profiles are plotted in Fig. 17 as a function of reciprocal temperature. A straight line through the points yields

$$
D=D_{0} \exp (-Q / k T)
$$

where the pre-exponential $D_{0}$ was $3.2 \times 10^{3} \mathrm{~cm}^{2} / \mathrm{sec}$, and the activation energy $Q$ was $4.7 \mathrm{eV}$. Because extensive measurements have been made 


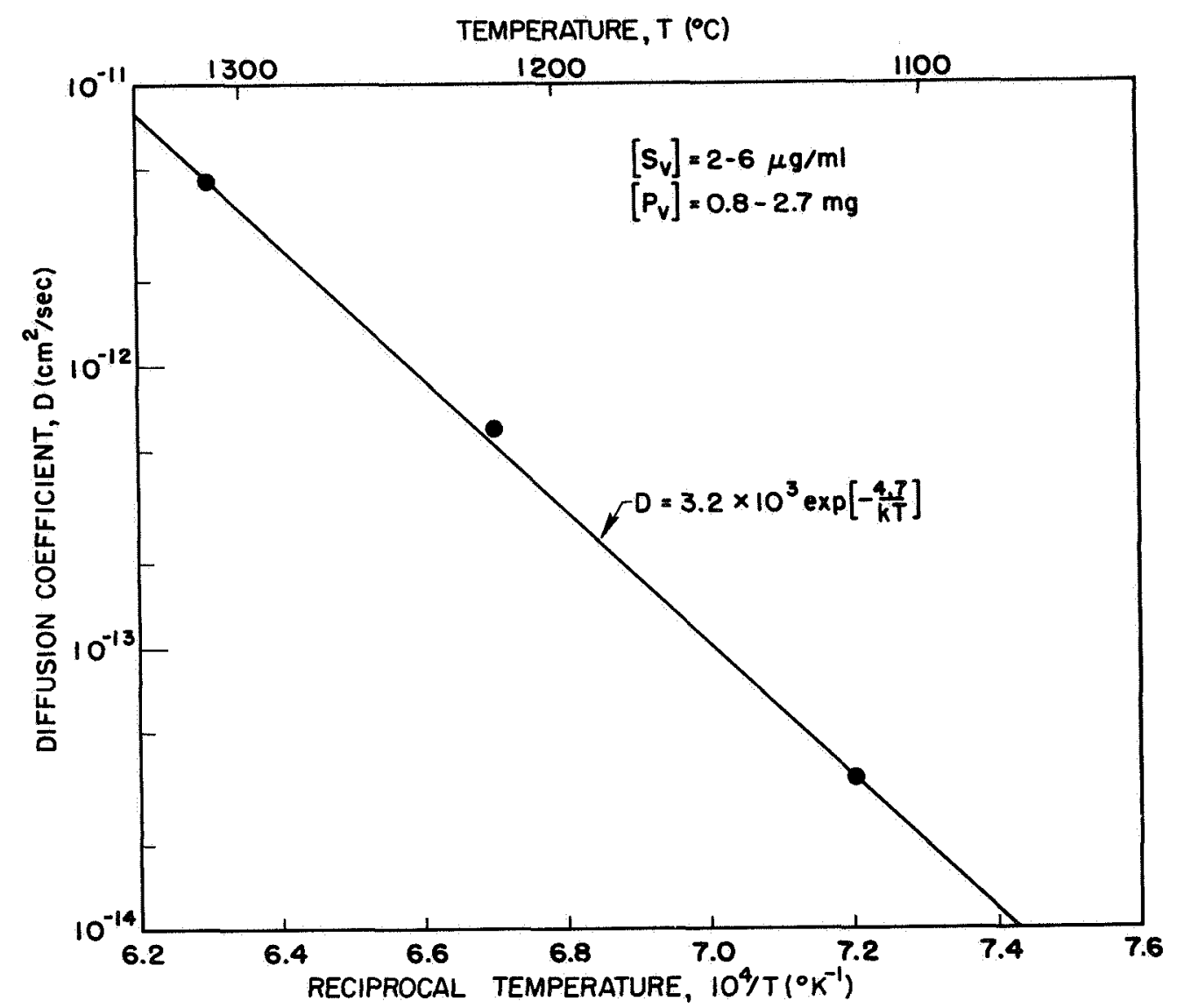

Fig. 17. DEPENDENCE OF THE DIFFUSION COEFFICIENT OF SULFUR IN GaP ON TEMPERATURE.

only at $1215^{\circ} \mathrm{C}$, the values for $\mathrm{D}_{\mathrm{o}}$ and $\mathrm{Q}$ quoted above may be somewhat in error. However, in the discussion of the diffusion mechanism in Chapter $V$, emphasis is placed on the results of experiments in which the phosphorus or sulfur pressures have been varied. The temperature variation is significant only in indicating whether or not an interstitiallycontrolled diffusion process is feasible, and even fairly large $( \pm 1.0 \mathrm{eV})$ errors in $Q$ will not change the conclusions that are made.

\section{Experimental Results in GaAs}

The diffusion of sulfur in GaAs has been studied by a number of experimenters [2]. However, previous reports in the literature, in analogy with work in $\mathrm{Ge}$ and $\mathrm{Si}$, were usually simply measurements of the 
diffusion coefficient as a function of temperature. There appears to be no work reported on the variation of diffusion and solubility parameters as a function of the sulfur vapor density during diffusion, and the role of the arsenic pressure has, with few exceptions [3,4], been ignored.

In this section, a systematic study of the effects of varying independently the sulfur pressure, the arsenic pressure, and the temperature are reported. The measurements reported here have extended Vieland's work on the effect of arsenic pressure on diffusion [4] to cover a much wider range of arsenic pressures, and differs quantitatively, although not qualitatively, from his results. This section also includes the results of diffusing sulfur into very heavily-doped n-type GaAs. Models to explain the observed results are discussed in Chapter V.

1. Variation with Sulfur Pressure

Figure 18 shows a number of profiles for which the sulfur vapor density was varied from 0.2 to $6.0 \mu \mathrm{g} / \mathrm{ml}$, while the temperature and arsenic vapor density were kept constant at $1130^{\circ} \mathrm{C}$ and $4-6 \mathrm{mg} / \mathrm{ml} \quad\left(\mathrm{P}_{\mathrm{As}_{4}} \approx\right.$ 2 atm) respectively. The nature of the profiles is similar to that reported above for sulfur in GaP. The initial point in several of the profiles seems to indicate a sulfur-rich layer at the surface which was not seen in the GaP results at a higher temperature. This may be due simply to surface contamination that was not removed during the benzene rinse, but more fundamental phenomena might be responsible. Similar observations of impurity-rich surface layers were made when $\mathrm{Sb}$ was diffused into $\mathrm{Ge}$. This effect was attributed to the binding of $\mathrm{Sb}$ at unsaturated bonds of surface Ge atoms [32]. Whether a similar mechanism is operative in the GaAs-S system could only be determined by more extensive work.

The variation of surface concentration with sulfur vapor density is shown in Fig. 19. The surface concentration for the profiles in Fig. 18 appears to be proportional to the sulfur vapor density at low surface concentrations, and increases more rapidly above $10^{20} \mathrm{~cm}^{-3}$. These results are not in agreement with the usual model of sulfur incorporation on isolated arsenic sites. A discussion of this and the related GaP results is presented in Chapter $V$. 


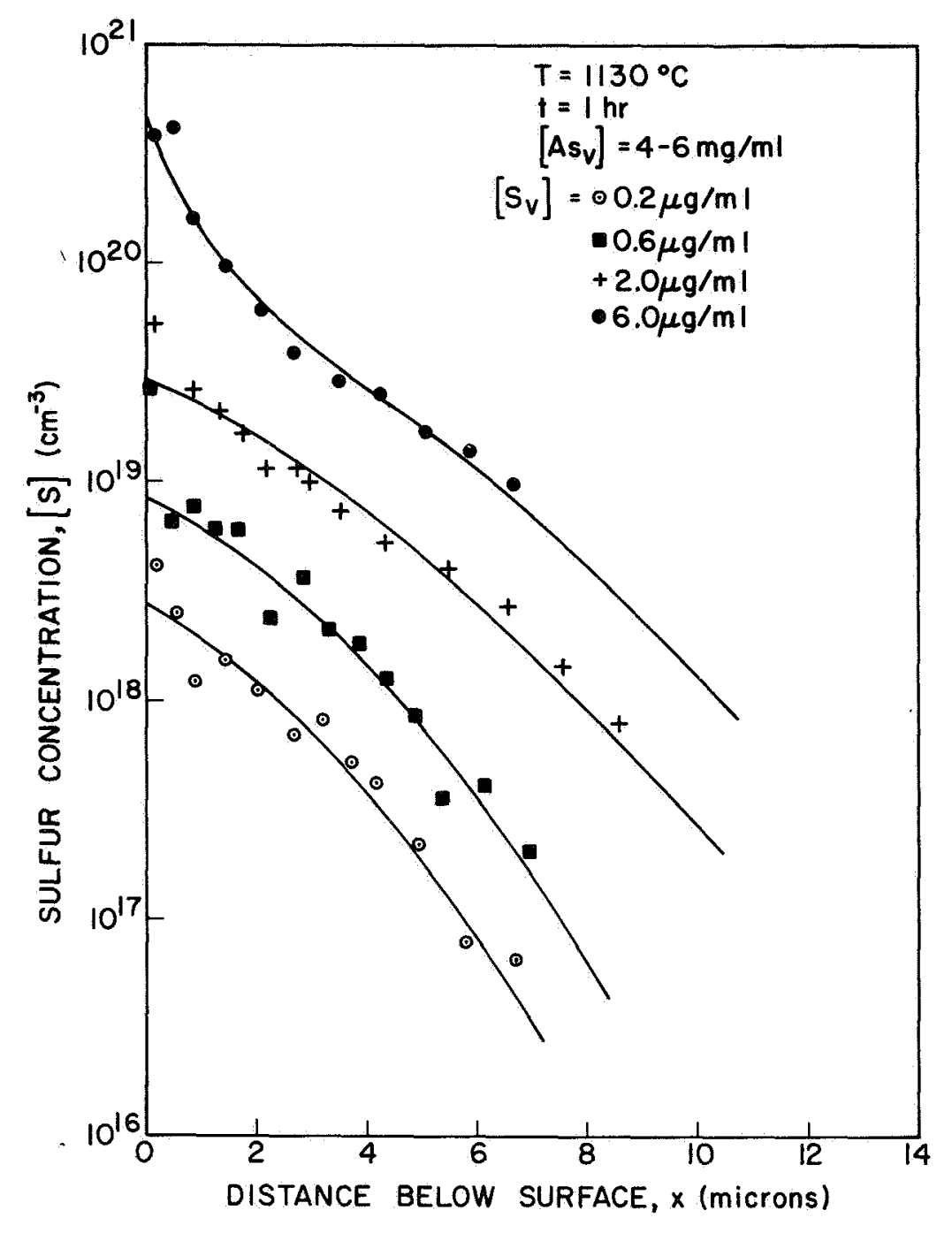

Fig. 18. DIFHUSION PROFILES OF SULFUR IIV GaAs AT VARIOUS SULFUR PRESSURES.

\section{Variation with Arsenic Pressure}

Figure 20 shows the effect of varying the arsenic pressure while keeping the temperature and sulfur vapor density constant at $1130^{\circ} \mathrm{C}$ and $0.2 \mu \mathrm{g} / \mathrm{ml}$ respectively. The excess arsenic added to the ampoule varied from 0 to $4.4 \mathrm{mg} / \mathrm{ml}$ for the profiles in this figure. Several profiles have been omitted for clarity. The results demonstrate quite clearly that the penetration depth increases as the arsenic pressure increases. 


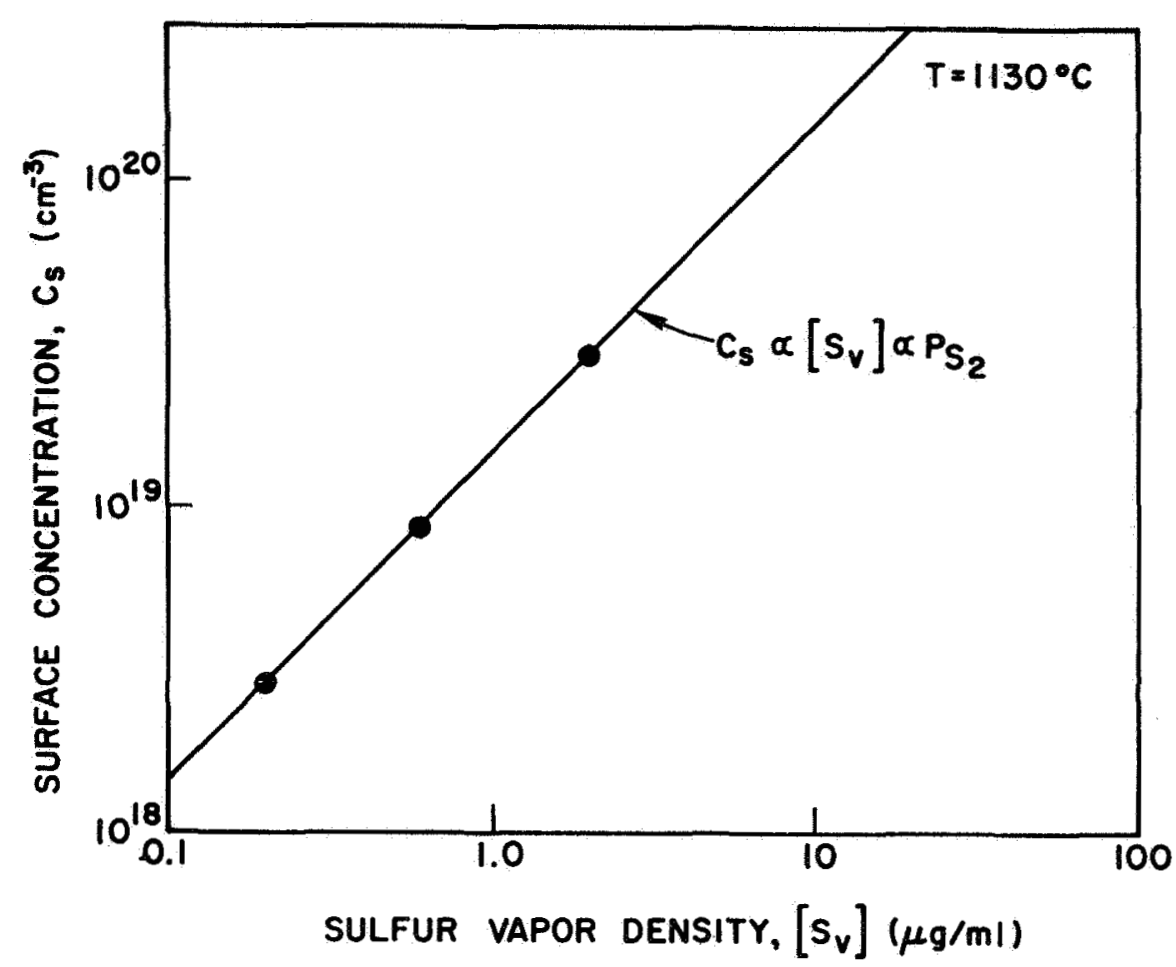

Fig. 19. DEPENDENCE OF THE SURFACE CONCENTRATION OF DIFFUSION PROFILES IN GaAs ON THE SULFUR VAPOR DENSTTY. $\left[\mathrm{As}_{\mathrm{V}}\right]=4-6 \mathrm{mg} / \mathrm{ml}$.

Figure 21 shows more explicitly the dependence of the diffusion coefficient on arsenic pressure for the profiles in Fig. 20, as well as additional data for a temperature of $1003^{\circ} \mathrm{C}$. The sulfur vapor density in both cases was $0.2 \mu \mathrm{g} / \mathrm{ml}$. The arsenic pressure when no arsenic was added. was assumed to be the same as that over the gallium-rich liquid in the Ga-As binary system [33], while the arsenic pressure when excess arsenic was added was obtained from Fig. 10.

The results for both temperatures are quite similar. At low pressures, the diffusion coefficient increases with increasing pressure as $\left(\mathrm{P}_{\mathrm{As}_{4}}\right)^{1 / 2}$. Above 0.5-1 atmospheres, however, the diffusion coefficient appears to be relatively independent of the arsenic pressure.

There have been two other reports in the literature concerning the variation of sulfur diffusion in GaAs with arsenic pressure. Frieser reported that the junction depth obtained when an $\mathrm{Al}_{2} \mathrm{~S}_{3}$ source was used 


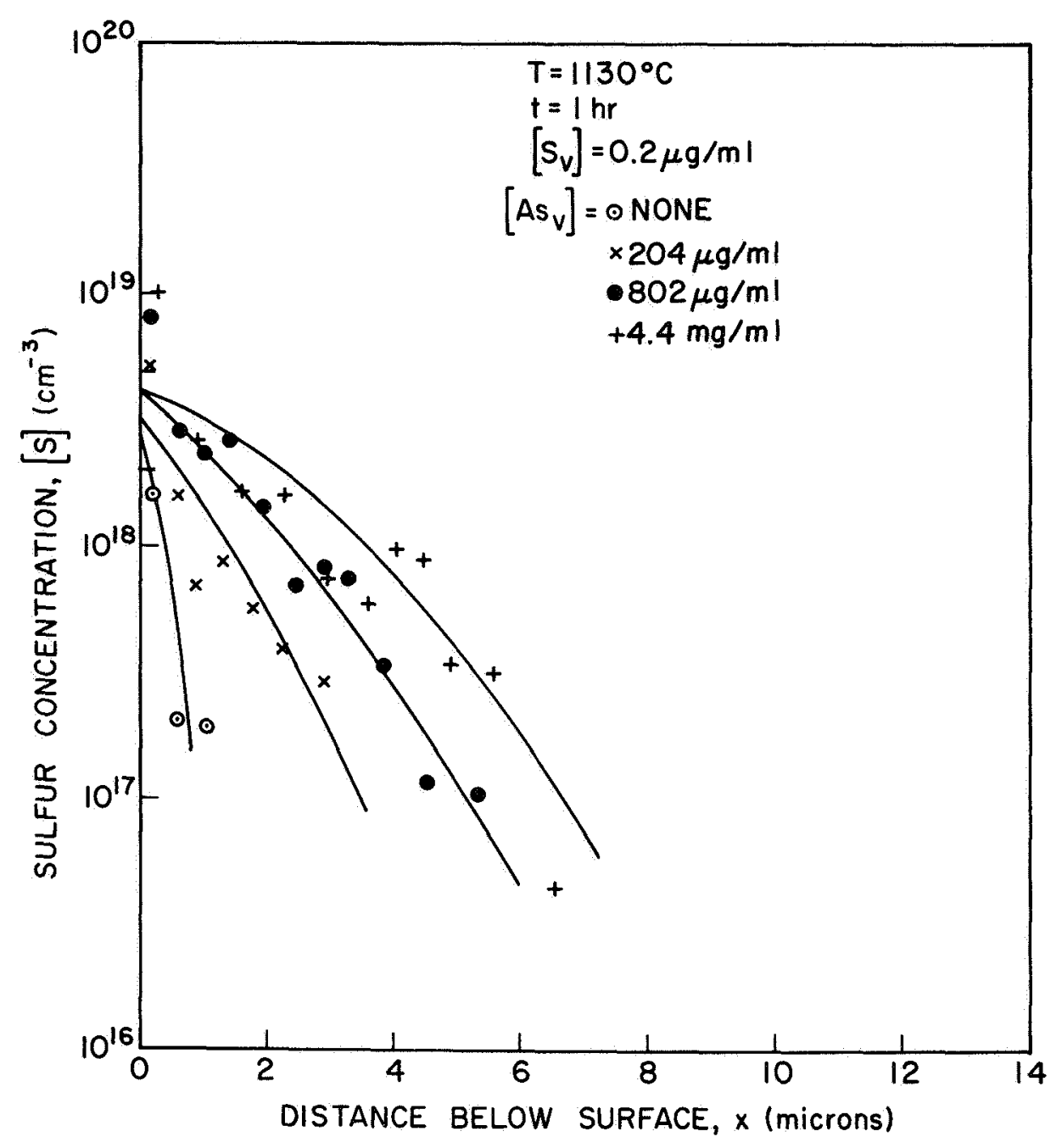

Fig. 20. DIFFUSION PROFILES OF SULFUR IN GaAs AT VARIOUS ARSENIC PRESSURES.

was the same when either crushed GaAs or elemental arsenic (amount unspecified) was used in the ampoule [3]. Vieland reported that the diffusion of sulfur at $1000^{\circ} \mathrm{C}$ was independent of arsenic pressure above 1 atmosphere, but noted a very sharp decrease in juction depth in one run at lower arsenic pressure $\left(\mathrm{P}_{\mathrm{As}_{4}}=0.5 \mathrm{~atm}\right)$ [4]. Kendall commented that this was likely an anomalous result due to a vapor etching process [2]. Since Vieland's work was done using the p-n juction method, it is also possible that the anomalous results were due to contamination by other electrically active impurities [2]. 


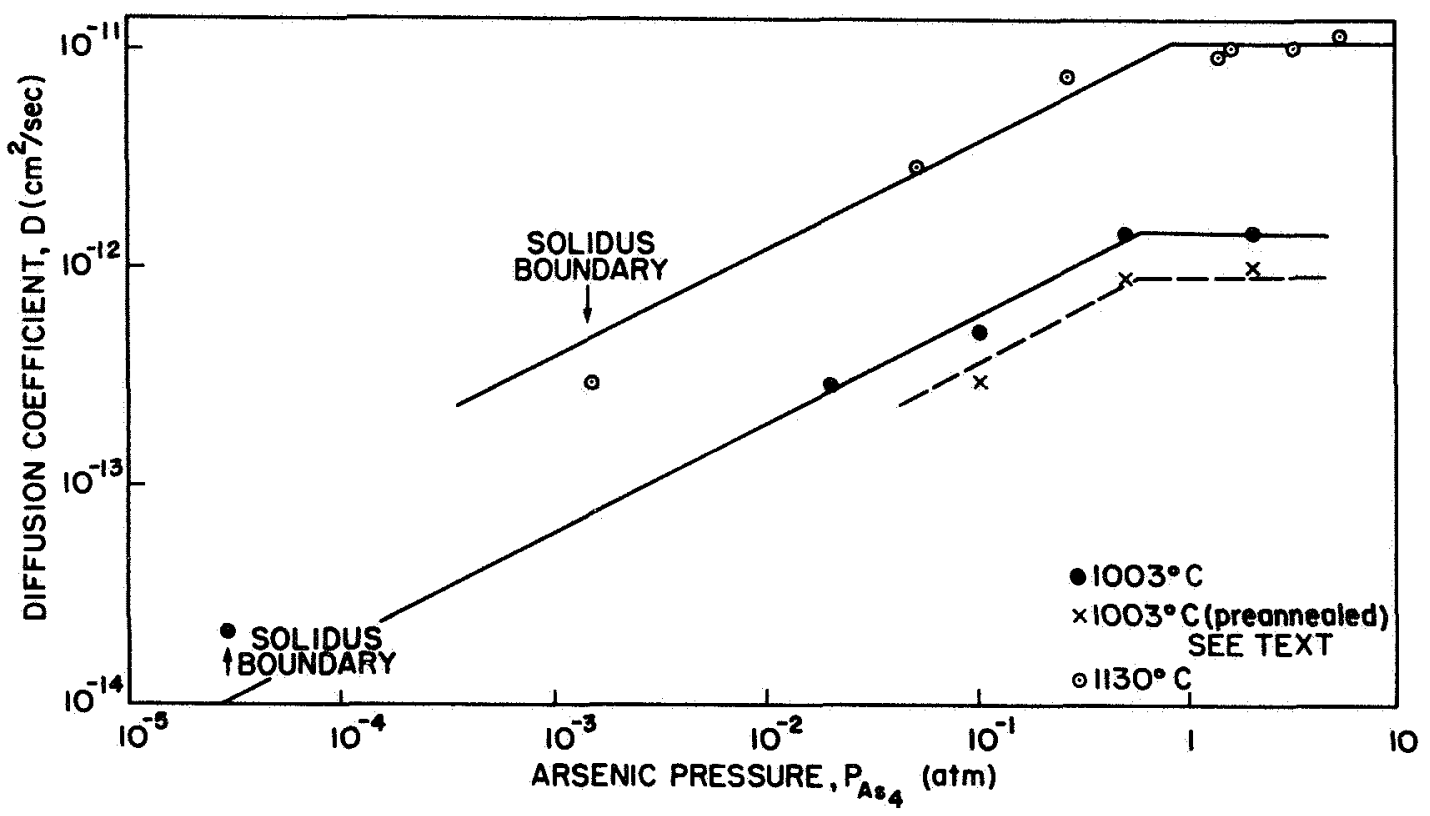

Fig. 21. DEPENDENCE OF THE DIFFUSION COEFFICIENT OF SULFUR IN GaAs ON THE ARSENIC PRESSURE. $\left[\mathrm{S}_{\mathrm{V}}\right]=0.2 \mu \mathrm{g} / \mathrm{ml}$.

As previously stated, the radiotracer techniques was used in the experiments reported here. In addition, the typical loss due to vapor etching was only 0.25 micron on each face. In contrast to Vieland's results, no sharp decrease in diffusion coefficient was observed below the knee, although a smooth and continuous decrease in penetration was found as the arsenic pressure decreased from 1 atmosphere to the pressure over the gallium-rich liquid. This variation occurred over more than two. orders of magnitude in arsenic pressure, and is not in agreement with a vacancy model of diffusion within the arsenic sublattice. This point is discussed in Chapter $V$.

The reason for the knee in the $D$ versus $P_{A_{4}}$ curve is of some interest. It is possible that the knee occurs because of some nonequilibrium effect, e.g., between the external arsenic vapor and the vacancy concentration in the crystal. In order to determine whether such an effect was important, a number of samples were preannealed for 5 days at $1003^{\circ} \mathrm{C}$ under the same arsenic pressures that would be used during the diffusion anneal. The ampoules were quenched to room temperature, and 
the samples were removed. The samples were then encapsulated with radioactive sulfur-35 and the appropriate amounts of arsenic. They were then diffused for 12 hours at $1003^{\circ} \mathrm{C}$. The results are shown by the dashed curve in Fig. 2l. Although the results indicate a slight decrease in diffusion coefficient, the shape of the curve remains the same. Thus it is unlikely that non-equilibrium effects between the vapor and the solid are responsible for the knee. There is other evidence in the literature that suggests that the vacancy concentration in compound semiconductors comes into equilibrium with the external vapor in times short compared with the diffusion time of slowly-diffusing impurities [34,35].

The knee could be caused by a saturation effect, e.g., in the concentration of the native defect responsible for the diffusion. Curves qualitatively similar to the results presented here with knees at about $I$ atmosphere have been reported for the diffusion of silicon [36] and tin [22] in GaAs. However, the experimental data was obtained from $p-n$ junction work, and interpretation of the results may be complicated due to the amphoteric nature of these impurities. Seltzer found no saturation effect for the diffusion of $\mathrm{Mn}$ in GaAs at $900^{\circ} \mathrm{C}$ for arsenic pressures as high as 5 atmospheres [34]. This appears to indicate that the concentration of gallium and arsenic vacancies does not saturate at these pressures. In addition, the arsenic pressure in the binary Ga-As system at the arsenic-rich side of the GaAs solidus region appears to be an order of magnitude higher than the pressures at the knee [33]. Thus it appears unlikely that a saturation in the concentration of native defects is responsible for the knee.

It should be noted that a simple superposition of two competing diffusion modes cannot explain the observed shape of the $D$ versus $\mathrm{P}_{A s_{4}}$ curve. For this case

$$
\mathrm{D}=\mathrm{D}_{\mathrm{a}}+\mathrm{D}_{\mathrm{b}}\left(\mathrm{P}_{\mathrm{As}_{4}}\right)^{1 / 2}
$$

where $D_{a}$ and $D_{b}$ are constants. It is clear that such a model cannot explain the experimental results since it predicts a constant diffusion 
coefficient at low arsenic pressures. This prediction is not in agreement with the experimental results which show a saturation of $D$ at high arsenic pressures.

In Chapter V, a model is proposed to explain both the square root dependence at low arsenic pressures, and the saturation behavior at high pressures.

\section{Variation with Temperature}

Figure 22 shows profiles for which the temperature was varied from 900 to $1200^{\circ} \mathrm{C}$. The diffusion time was normalized to 12 hours. The actual diffusion times were 20 minutes at $1203^{\circ} \mathrm{C}, 1$ hour at $1130^{\circ} \mathrm{C}, 12$ hours at $1003^{\circ} \mathrm{C}$, and 5 days at $900^{\circ} \mathrm{C}$. The sulfur vapor density was $0.2 \mu \mathrm{g} / \mathrm{ml}$ for all profiles, and the arsenic vapor density was $3-5 \mathrm{mg} / \mathrm{ml}$. These experimental parameters should provide well-defined values of activation energy since, from the previous section, the operating point should be in the saturation region of the $D$ versus $P_{A_{4}}$ curve.

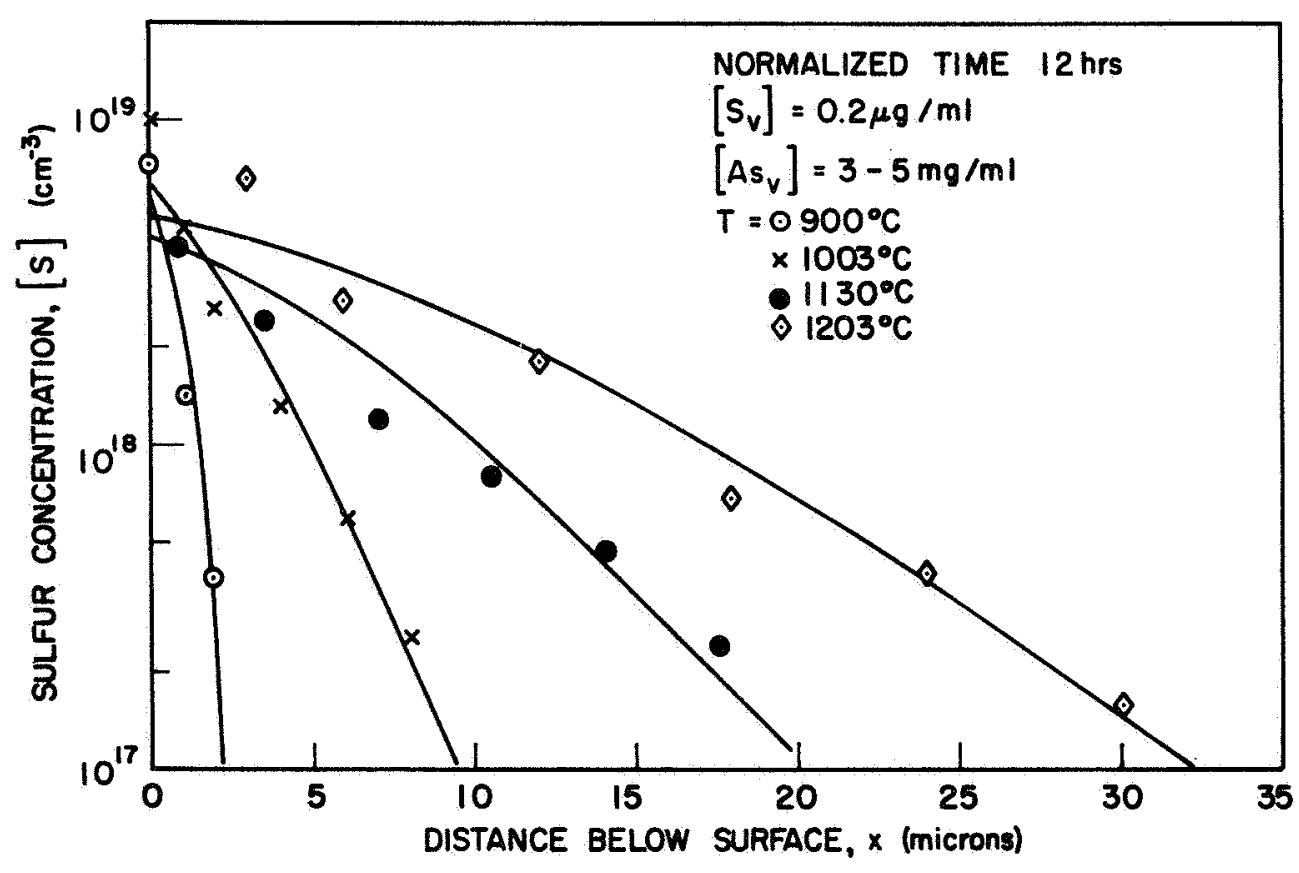

Fig. 22. DIFFUSION PROFILES OF SULFUR IN GaAs AT VARIOUS TEMPERATURES. Actual diffusion times are $20 \mathrm{~min}$ at $1203^{\circ} \mathrm{C}, 1 \mathrm{hr}$ at $1130^{\circ} \mathrm{C}, 12 \mathrm{hr}$ at $1003^{\circ} \mathrm{C}$, and 5 days at $900^{\circ} \mathrm{C}$. 
The diffusion coefficients determined from the profiles are plotted in Fig. 23 as a function of reciprocal temperature. A straight line through the experimental points yields

$$
D=1.85 \times 10^{-2} \exp (-2.6 / \mathrm{kT}) \mathrm{cm}^{2} / \mathrm{sec}
$$

A comparison with the results of other workers is given in Chapter IV.

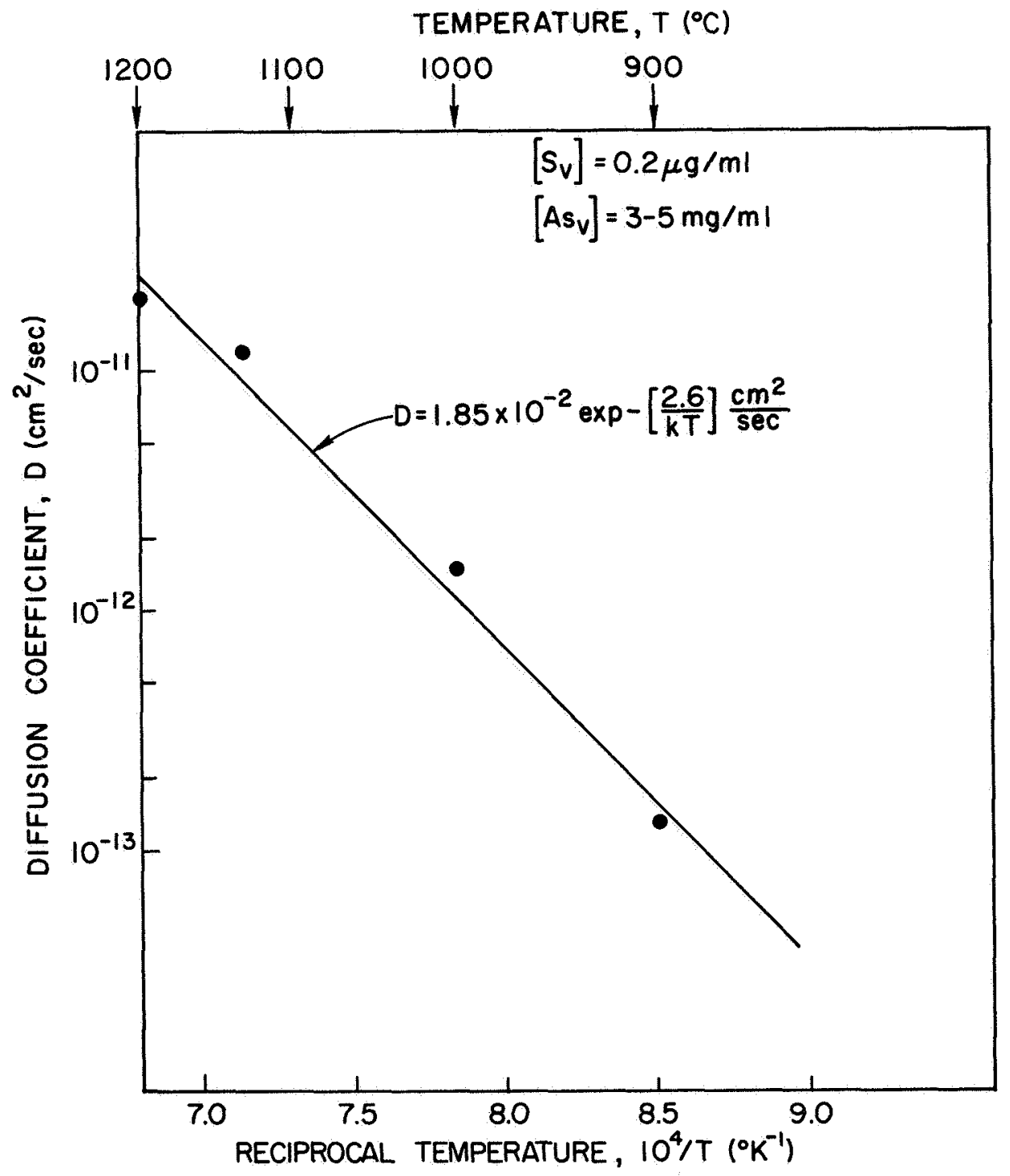

Fig. 23. DEPENDENCE OF THE DIFFUSION COEFFICIENT OF SULFUR IN GaAs ON TEMPERATURE. 


\section{Variation with Background Doping}

In a ternary system involving pure GaAs and a single diffusing impurity, the phase rule indicates that there are three degrees of freedom within the solidus region. An additional degree of freedom is possible in impure GaAs. The Fermi level is determined by the charge neutrality balance between charged native defects, background impurities, and the diffusing impurity. By changing the Fermi level, the concentrations of the various charged species may be varied, thus affecting the diffusion. By studying the diffusion of impurities in impure semiconductors, doped to a level above the intrinsic carrier concentration at the diffusion temperature, important information can be obtained about the mechanism of diffusion. This technique has been used to study impurity diffusion in Ge [37], Si [38], and GaAs [31].

Figure 24 compares the result of diffusing sulfur into both undoped and heavily-doped n-type GaAs under an arsenic pressure of about 1 atmosphere. The impure sample was doped with tellurium and had a carrier concentration of $5-6 \times 10^{18} \mathrm{~cm}^{-3}$. The undoped crystal had an electron concentration of $10^{15}-10^{16} \mathrm{~cm}^{-3}$. The profiles for the two samples are practically identical. Similar results were obtained for a 5-day diffusion at $900^{\circ} \mathrm{C}$ under essentially the same conditions of sulfur and arsenic pressure.

It is possible that the results of diffusing into undoped and heavily-doped material were identical because of outdiffusion of tellurium near the surface of the heavily-doped sample. To check this possibility homogenous crystals of GaAs (Te, $\mathrm{n}=5-6 \times 10^{18} \mathrm{~cm}^{-3}$ ) were annealed, both with no excess arsenic, and with an arsenic pressure of several atmospheres, at $1000^{\circ} \mathrm{C}$ for 11.25 hours. The electron concentrations after the anneal as determined by a plasma reflection technique (described in Chapter IV) are shown in Fig. 25.

The results indicate that, although there is significant outdiffusion, the electron concentration is still greater than $2.5 \times 10^{18}$ $\mathrm{cm}^{-3}$ at the surface. Outdiffusion (and presumably indiffusion) of $\mathrm{Te}$ is seen to be more rapid at the higher arsenic pressure. This result 


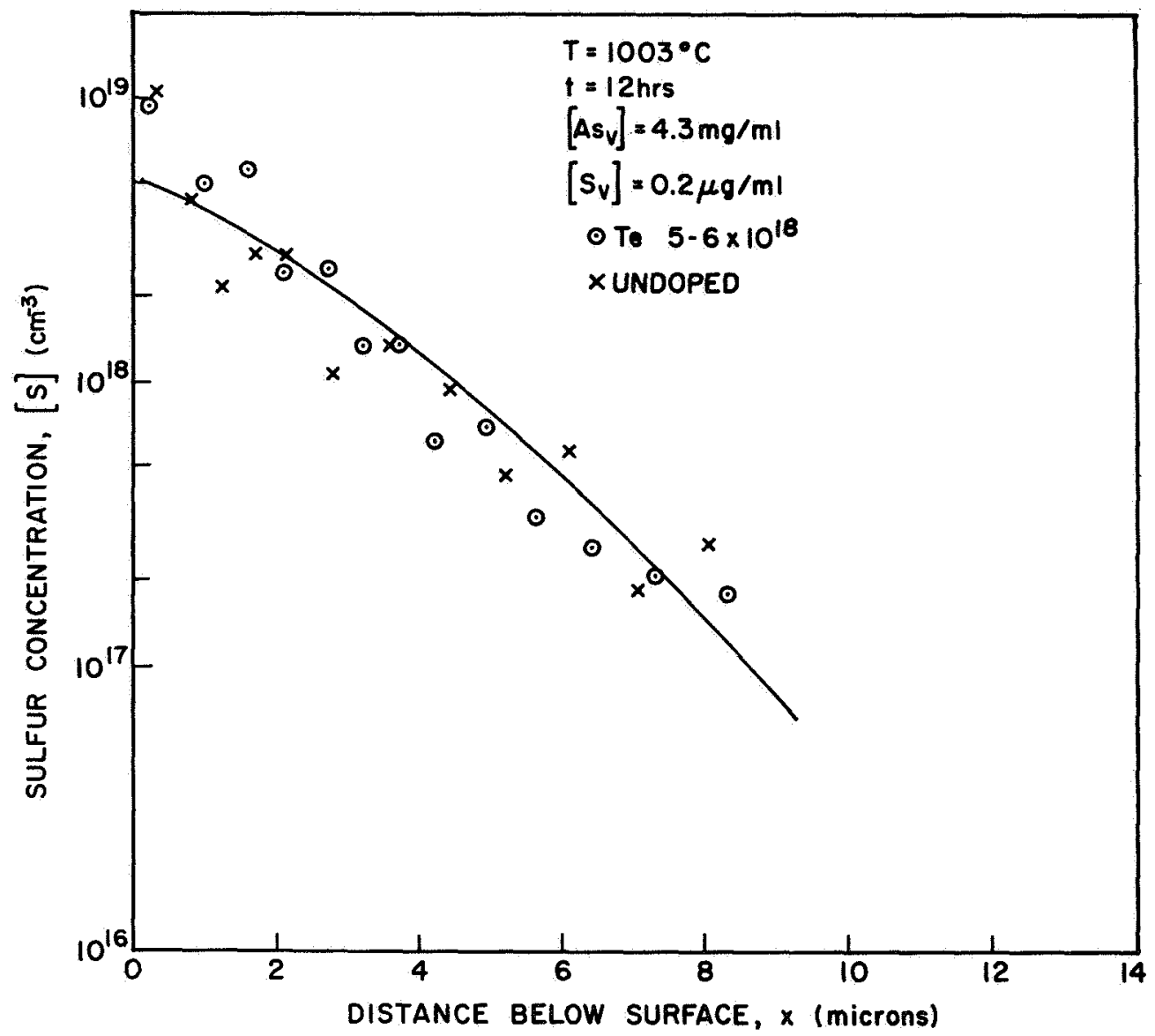

Fig. 24. DIFFUSION PROFILES OF SULFUR IN UNDOPED AND HEAVILY-DOPED n-TYPE GaAs.

would be expected in analogy with our results of sulfur diffusion in GaAs reported previously. However, there has been no report in the literature concerning the variation of Te diffusion in GaAs with arsenic pressure.

The significance of these results is discussed in Chapter V. 


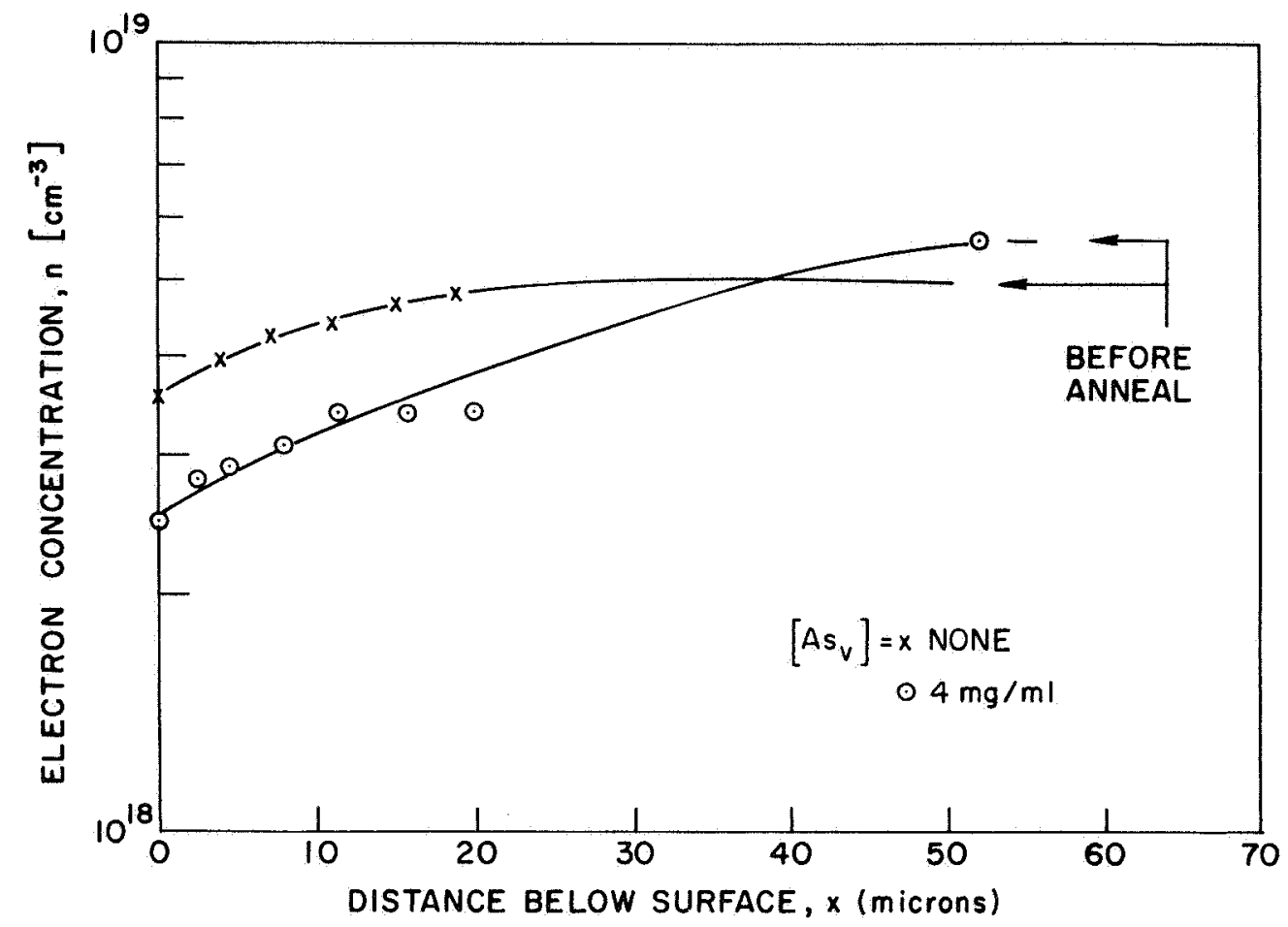

Fig. 25. OUTDIFHUSION PROFILES OF TELLURIUM FROM HEAVILY-DOPED GaAs UNDER HIGH AND LOW ARSENIC PRESSURES. The electron concentrations were determined by the plasma reflection technique described in Chapter IV. $T=1000^{\circ} \mathrm{C} ; t=11.25$ hours. 



\title{
PRECEDING PAGE BLANK NOT FILMED.
}

\author{
Chapter IV \\ ELECTRICAL PROPERTIES OF SULFUR IN GaP AND GaAS
}

The radiotracer technique discussed in the previous chapter is useful in diffusion and solubility studies because information about the total impurity content is obtained. However in the fabrication of devices, it is frequently more important to have information about the electrically active part of the total impurity concentration. This is particularly true when a one-to-one correspondence between donor impurity and electron concentrations does not exist.

The total impurity and electron profiles in sulfur-diffused layers in GaP and GaAs were determined in this study by the use of incremental radiotracer and Hall or plasma reflection techniques. In this chapter, the experimental techniques are described and the experimental results are presented. All measurements of electron concentration were made at room temperature. A large discrepancy was found between the total sulfur concentration and the electron concentration in the diffused layers. The existence of electrically inactive impurities in homogeneous GaP and GaAs crystals heavily doped with the group VI donors have been previously reported in the literature [22, 39-45]. However, there appears to have been little consideration of such effects in diffused layers in these materials.

A comparison between the doping behavior of sulfur in diffused layers and in homogeneous melt-grown GaAs crystals is presented. The results obtained in this study show that the room temperature electron concentration in a melt-grown crystal doped with sulfur can be reversibly controlled by suitable annealing at elevated temperatures. For a given annealing temperature, the maximum electron concentration in a melt-grown crystal is greater than in GaAs doped by diffusion at the same temperature. However, the electron concentration is independent of arsenic pressure in both cases. It is suggested that precipitation caused by the diffusion process may be responsible for the difference between the crystals doped by the two methods. 
Finally, a comparison of the diffusion results of sulfur in GaAs obtained from this study and from other reports in the literature is presented. It is suggested that the discrepancy among different experimenters may be due in part to the presence of electrically inactive sulfur in the diffused layers.

\section{A. Sulfur Diffused Layers in GaP}

1. Incremental Hall Measurements

Undoped GaP samples were prepared for diffusion as described in the previous chapter. An additional step was added, however, in an attempt to reduce any contamination due to copper adsorbed on the sample surface. The samples, as well as the quartz plates, were soaked in a warm aqueous solution of $\mathrm{KCN}$ ( 5 percent) for 10 minutes [46], rinsed in deionized water, and dried on a piece of filter paper. They were then loaded into the quartz ampoules with appropriate amounts of phosphorus and non-radioactive sulfur ${ }^{*}$, and diffused under the appropriate conditions. After the ampoules were quenched in water, the samples were removed. A wire saw was used to eliminate any edge diffusion. Rectangular samples approximately $1 / 8 \times 1 / 4$ in. were cut with the wire saw. The samples were etched (see Chapter III) to remove about 0.5 micron and then dipped in HF for 15 seconds.

Ohmic contacts were alloyed on a graphite strip heater in a forming gas atmosphere to form Van der Pauw samples [47]. The ohmic contacts were formed from a 1 mil thick foil of Au-Ge. ${ }^{\dagger}$ Incremental Hall measurements were then performed. After each measurement, the contacts were masked with Apiezon $W$ wax, and the samples were etched to remove approximately 1 micron. Although the diffused layers were thin, the measurement sensitivity was high. Apparently the bulk of the GaP samples became insulating during the heat treatment in spite of the KCN rinse.

Although in principle the mobility, resistivity, and carrier concentration can be obtained at each point in the diffused layer from

*6 9's purity, Electronic Space Products, Inc., Los Angeles, California. $\dagger$ I2 percent Ge, Western Gold and Platinum, Belmont, California. 
incremental Hall measurements [48], the calculation involves derivatives and squares of derivatives of experimentally measured quantities. Any small errors are magnified by the calculation. In the work reported here, an average mobility, $\bar{\mu}_{n}$, of $50 \mathrm{~cm}^{2} / \mathrm{v}-\mathrm{sec}$ (estimated from the incremental measurements) was assumed. The technique thus was essentially an incremental sheet resistivity measurement. The conductivity, $\sigma$, at each point in the diffused layer was obtained from the measured sheet conductivity, $\sigma_{\mathrm{s}}$, through the relation

$$
\sigma(x)=\frac{d}{d x} \sigma_{s},
$$

and the electron concentration at each point in the diffused layer was obtained from the conductivity by

$$
\sigma(x)=q \bar{\mu}_{n} n(x)
$$

The electron concentration profiles were obtained from Eqs. (4.1) and $(4.2)$.

\section{Experimental Results}

Diffusions were performed at $1217^{\circ} \mathrm{C}$ for 3 hours to determine the effect of phosphorus pressure on the electron concentration profiles in GaP. In one case, no excess phosphorus was added, and in the other, $2.0 \mathrm{mg} / \mathrm{ml}$ was added. The results are illustrated in Fig. 26. The total sulfur concentration was determined by the radiotracer technique on $a$ separate sample diffused under identical conditions. Although it would have been desirable to perform the electrical and radiotracer measurements simultaneously on the same sample, the masking step to protect the ohmic contacts during etching would have introduced large errors in the tracer measurement.

It is seen that at high sulfur concentrations, there is a large discrepancy between the total sulfur and the electron concentrations. In addition, the phosphorus pressure appears to have little or no effect on the electron concentration. 


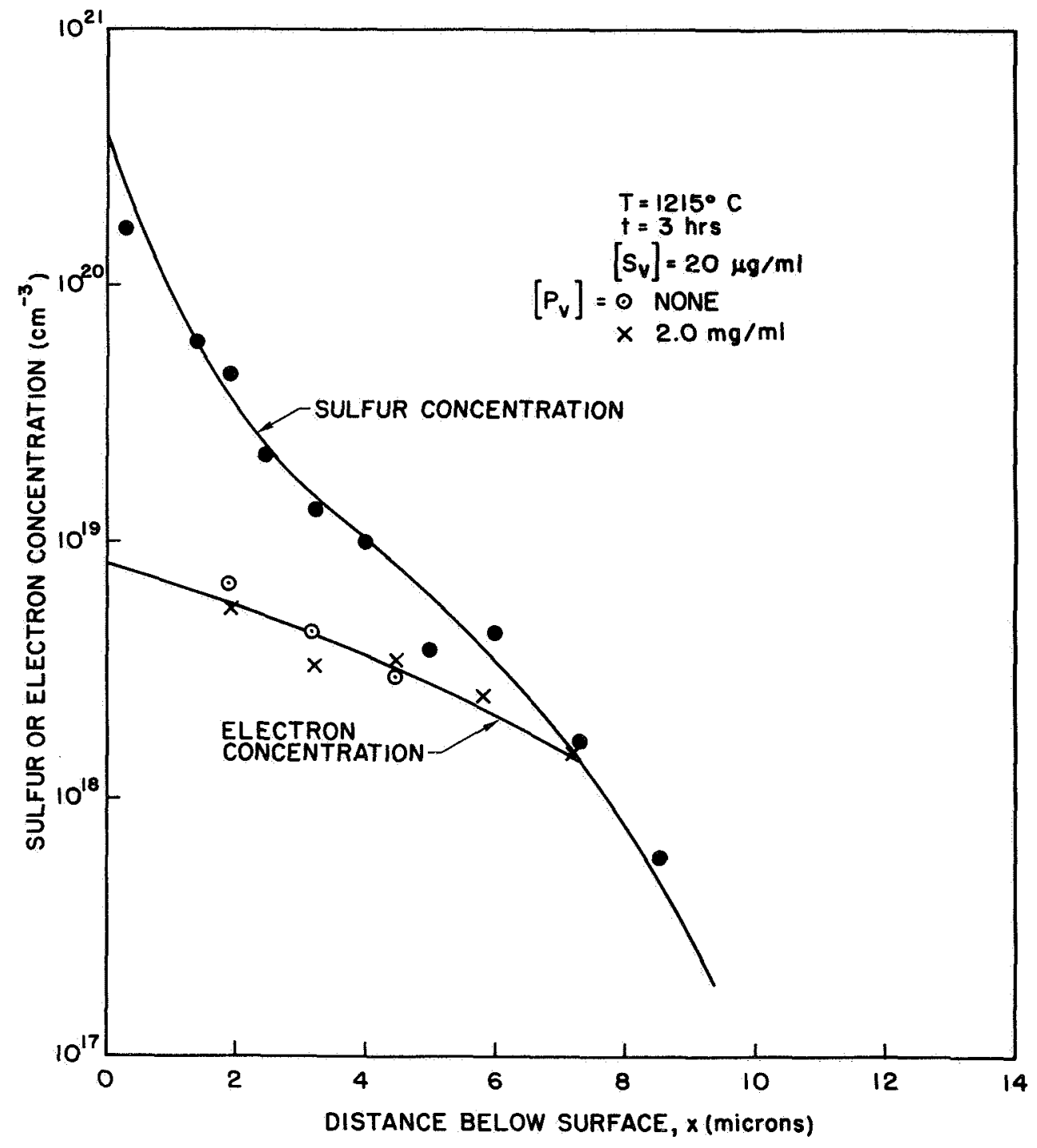

Fig. 26. COMPARISON OF THE ELECTRON (DETERMINED BY INCREMENTAL HALI MEASUREMMENTS) AND TOTAI SULFUR CONCENTRATION (DETERMTIVED BY RADIOTRACER TECHIIQUES) PROFILES IN DIFFUSED LAYERS IN GaP AT HIGH AND LOW PHOSPHORUS PRESSURES. Only one total suifur profile is given since sulfur diffusion in GaP was found to be independent of phosphorus pressure.

B. Sulfur Diffused Layers in GaAs

1. Plasma Reflection Measurements

Undoped GaAs samples were prepared for diffusion as described in the previous section on the GaP Hall measurements. They were then loaded with appropriate amounts of arsenic and radioactive sulfur into quartz ampoules. After the diffusion anneal, the ampoules were quenched. 
The samples were removed and $0.150 \mathrm{in}$. circular discs were cut out with an ultrasonic cutting tool. A determination of the electron and total sulfur concentration profiles was made simultaneously on a single sample. Because of its simplicity and sensitivity, a plasma reflection technique was used to determine the electron concentration profiles [49,50]. In this technique, the infrared reflection spectrum of a heavily doped sample has a distinct minimum whose position depends on the electron concentration. Since the reflection is essentially a surface phenomenon, involving a distance on the order of a fractional part of the wavelength of the light in the crystal, the electron concentration at the surface is measured directly. By etching away thin layers of GaAs and determining the position of the plasma reflection minimum as a function of depth, the electron distribution profile was obtained. The relation between the position of the minimum in the reflection spectrum and the electron concentration was taken from the literature [50]. A Perkin-Elmer 621 Grating Spectrophotometer was used in these measurements.

It would have been desirable to use the plasma reflection technique to measure the electron profiles in GaP because of the greater sensitivity of this technique. However there are several difficulties in applying this technique to GaP. First, there has been no experimental determination of the relationship between electron concentration and plasma minimum for this material. Second, it is known that low mobility semiconductors, such as p-type GaAs, yield minima that are not well defined, and whose position as a function of carrier concentration is in disagreement with the simple model that applies to high mobility semiconductors [51]. In the work described here, reproducible reflection spectra could not be obtained on low mobility sulfur-diffused layers in GaP.

\section{Experimental Results}

A typical result for a sulfur diffused layer in GaAs is shown in Fig. 27. This data was obtained from a $900^{\circ} \mathrm{C}$ diffusion. The electron concentration is constant over a large part of the profile, while at lower concentrations, the electron and total sulfur profiles appear to merge. One or two points near the surface indicate a somewhat lower 


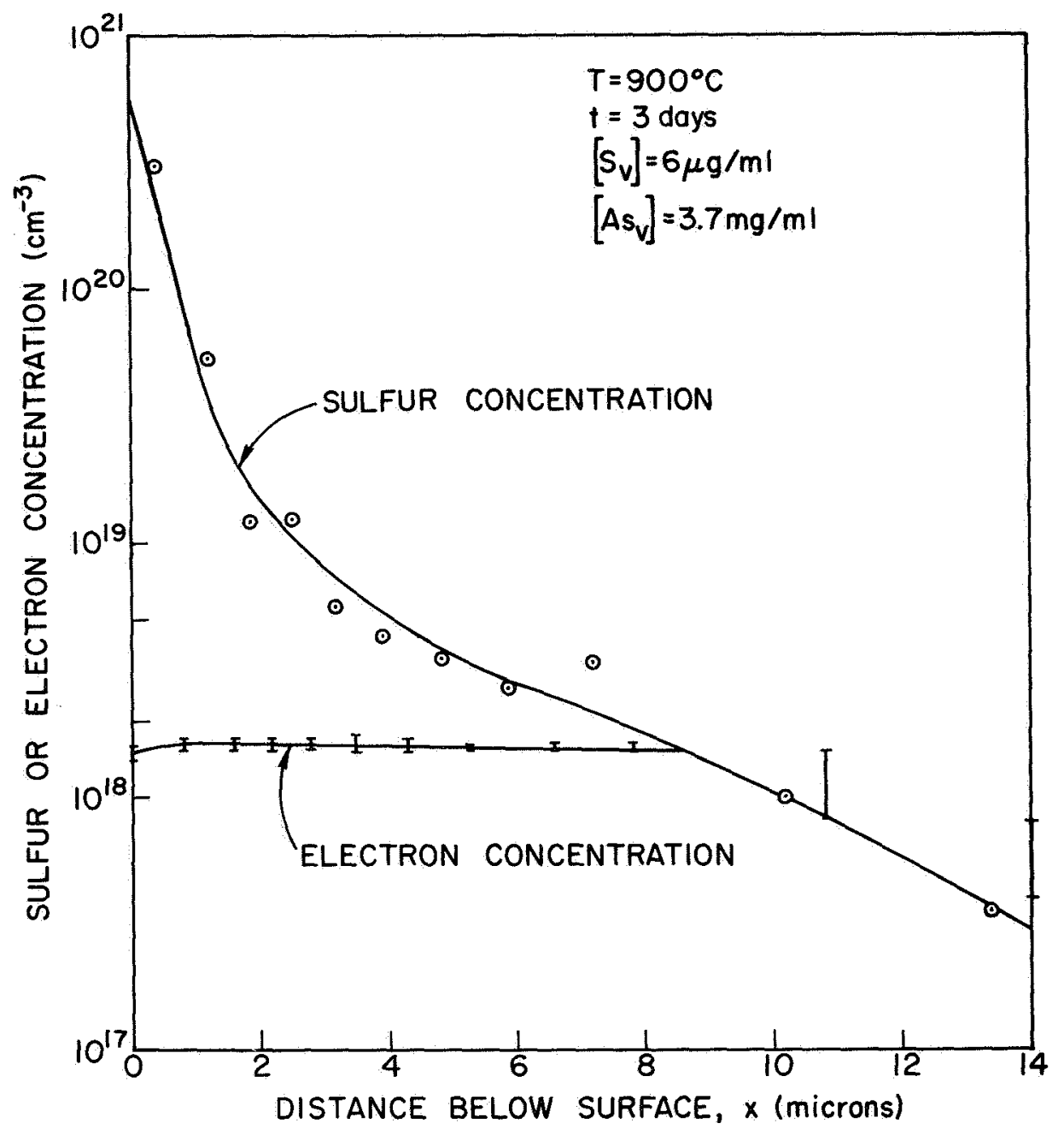

Fig. 27. COMPARISON OF THE ELECTRON (DETERMTNED BY PLASMA REFLECTION TECHNIQUES) AND TOTAL SULFUR CONCENTRATION (DETERMINED BY RADIOTRACER TIECENIQUES) PROFILES IN A DIFFUSED LAYER IN GaAS.

electron concentration than in the bulk. However this is believed to be a surface effect and not one due to the high sulfur concentration for the following reason. Experiments at $1130^{\circ} \mathrm{C}$ in which the surface concentration was lowered from $2 \times 10^{20}$ to $2 \times 10^{19} \mathrm{~cm}^{-3}$ indicated that, although the electron concentration in the bulk remained unchanged, the surface point again was low. The exact nature of this surface effect is not known, but it is interesting to note that similar effects have been observed in tin-diffused layers in GaAs [23]. In any case, a comparison 
of the two profiles in Fig. 21 indicates that a large concentration of the sulfur in the diffused layer is inactive electrically.

The results discussed above can be replotted to show the electron concentration, $n$, as a function of the total sulfur concentration, [S]. This is shown in Fig. 28 for a number of temperatures ranging from 900 to $1200^{\circ} \mathrm{C}$. At lower concentrations, there appears to be a linear dependence of $n$ on [S], while at high sulfur concentrations, the electron concentration appears to saturate. The dropoff at the highest concentrations is due to the surface effect mentioned in the previous paragraph. It can be seen that as the temperature increases, the maximum electron concentration increases from $1.6 \times 10^{18} \mathrm{~cm}^{-3}$ at $900^{\circ} \mathrm{C}$ to $5 \times 10^{18} \mathrm{~cm}^{-3}$ at $1130^{\circ} \mathrm{C}$. The point at $900^{\circ} \mathrm{C}$ agrees well with the data of KendaII [2].

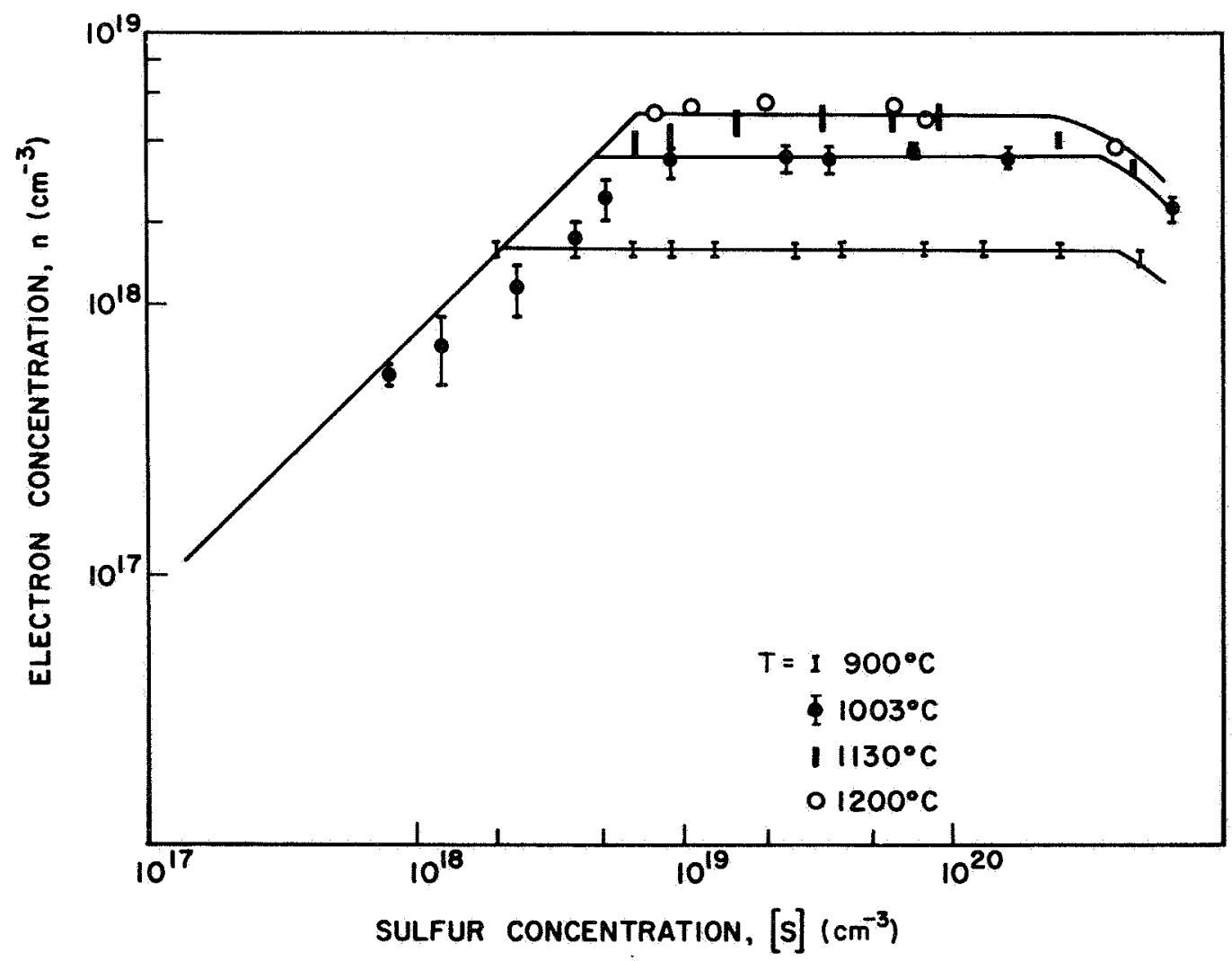

Fig. 28. DEPEINDENCE OF THE ELECTRON CONCENTRATION ON THE TOTAL SULFUR CONCENTRATION IN DIFFUSED LAYERS IN GaAS AT VARIOUS TEMMPERATURES. $\left[\mathrm{As}_{\mathrm{V}}\right]=3-5 \mathrm{mg} / \mathrm{ml},\left[\mathrm{S}_{\mathrm{V}}\right]=6 \mu \mathrm{g} / \mathrm{ml}$. 
Although these diffusion were done with an arsenic pressure of I-2 atmospheres, experiments at $1130^{\circ} \mathrm{C}$ indicate that the maximum electron concentration was unchanged when no excess arsenic was added. This result is in agreement with the GaP results.

\section{Homogeneous Sulfur-Doped GaP and GaAs Crystals}

In order to understand the large discrepancy between the electron and sulfur concentration profiles in the diffused layers, it is necessary to determine whether this property is intrinsic to a given semiconductorimpurity system, or whether it depends on the method by which this impurity is introduced into the crystal. It is known that in solutiongrown crystals of GaP [39,53] and melt-grown crystals of GaAs [40-45] heavily doped with the group VI impurities $\mathrm{S}$, Se, and $\mathrm{Te}$, a large concentration of these donor impurities is electrically inactive. It is also known that it is possible to reversibly control the electron concentration in melt-grown GaAs heavily-doped with se and Te by suitable annealing at elevated temperatures [42]. In order to determine if sulfur behaved in the same manner, experiments similar to that of Fuller and. Wolfstirn [42] were performed on a Czochralski pulled GaAs crystal. This crystal was heavily-doped with sulfur* with a nominal (as received) electron concentration of $3 \times 10^{18} \mathrm{~cm}^{-3}$, mobility of $1000 \mathrm{~cm}^{2} / \mathrm{v}-\mathrm{sec}$, and dislocation density of $10^{5} \mathrm{~cm}^{-2}$. The orientation was $\langle 111\rangle$.

The samples were prepared as described in Chapter III, and then soaked in a warm KCN solution for 10 minutes to reduce copper contamination. They were then sealed in quartz ampoules (generally with no excess arsenic) with volumes of about $0.5 \mathrm{~cm}^{3}$, heated to $1100^{\circ} \mathrm{C}$ for 10 minutes, and quenched. They were then annealed at various temperatures between $600^{\circ} \mathrm{C}$ and $1200^{\circ} \mathrm{C}$ for times long enough to attain an equilibrium electron concentration. The electron concentration was determined using the plasma reflection technique described previously. After each anneal, the crystal was mechanically polished to eliminate surface effects and those due to outdiffusion of sulfur before the plasma reflection measurement was made. Typically, removal of $1-2 \mathrm{mils}$ was sufficient for this purpose. Van der * Monsanto Company, St. Louis, Missouri. 
Pauw measurements [47] on several samples indicated that the annealing phenomenon was a bulk effect. Experiments on several samples indicated that the equilibrium electron concentration was a function of temperature alone, and appeared to be independent of the history of the sample.

The time to attain equilibrium at each temperature was approximately the same as reported by Fuller and Wolfstirn for Se and Te, ranging from less than 1 hour at $1200^{\circ} \mathrm{C}$ to 6 weeks at $600^{\circ} \mathrm{C}$. These times did not appear to be markedly affected by the arsenic pressure during the anneal. The equilibrium electron concentrations at each annealing temperature for the sulfur-doped crystal used are shown in Fig. 29, along with some additional data for a Te-doped GaAs crystal (the properties of the Te-doped crystal were given in Chapter II). The data of Fuller and Wolfstirn is also shown in Fig. 29. Although there is a slight difference between our data and that of Fuller and Wolfstirn, the behavior of melt-grown crystals doped with $\mathrm{S}$, Se, and Te appears to be similar.

Several experiments in which excess arsenic pressures of 1-2 atmospheres were used indicated that the equilibrium electron concentration was not affected by the arsenic pressure. This result is consistent with the behavior of the sulfur-diffused layers in GaP and GaAs discussed previously. The electron concentration that is "frozen" into the asreceived melt-grown crystals appears, from Fig. 29, to be characteristic of temperatures between 800 and $900^{\circ} \mathrm{C}$. This is in good agreement with Schottky's estimate [40] for Se-doped GaAs crystals.

The maximum electron concentration in GaAs crystals doped with sulfur by diffusion is also shown in Fig. 29. It is seen that for a given diffusion temperature, the maximum electron concentration in the diffused layer is significantly less than in GaAs doped from the melt and annealed at the same temperature. Although copper contamination effects cannot be ruled out completely (Spectrosil quartz was not used [54]), the effect of copper at a given temperature should be about the same for both diffused and melt-grown samples, since the same grade of quartz was used in both experiments. Thus at a given temperature, there appears to be a real difference between the electron concentration in crystals grown from the melt and crystals doped by diffusion. 


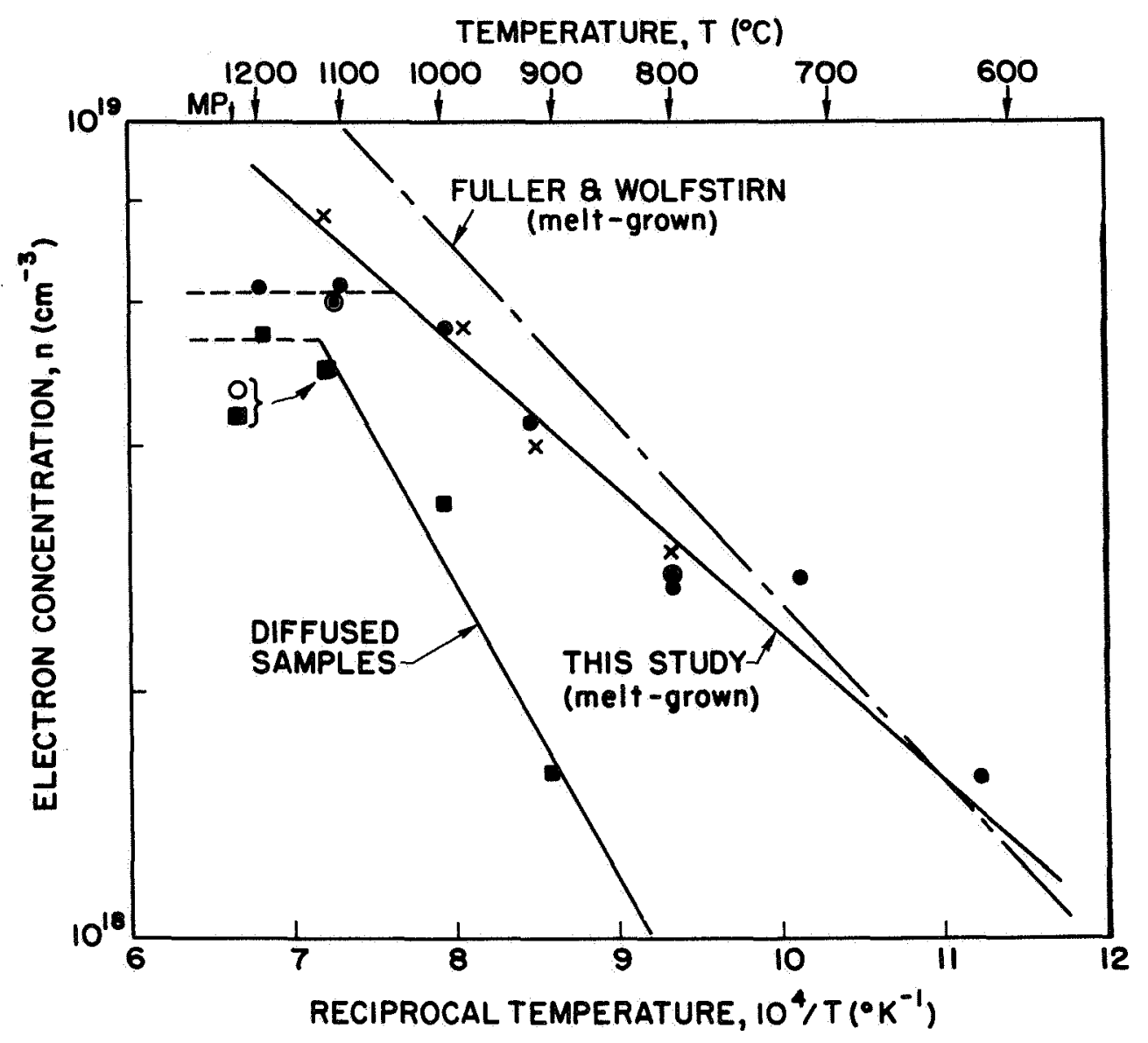

Fig. 29. MAXIMUM ELECTRON CONCENTRATION VERSUS RECIPROCAL TEMPERATURE FOR GaAs DOPED WITH SULFUR FROM THE MELT AND BY DIFFUSION.

Fuller and Wolfstirn:melt-grown, doped with Se and

Te (arsenic pressure not specified).

This study: melt-grown, doped with $\mathrm{S}$ and $\mathrm{Te}$

$$
\begin{aligned}
& \text { - } S \text { NO ARSENIC } \\
& \text { - } S P_{\mathrm{As}_{4}}=1-2 \text { otm } \\
& \times \text { Te NO ARSENIC }
\end{aligned}
$$

This study: diffused samples, doped with $\mathrm{S}$

$$
\text { - S } P_{A_{4}}=1-2 \mathrm{~atm}
$$

OS NO ARSENIC 


\section{Discussion}

1. Homogeneous Crystals of GaAs and GaP

The presence of electrically inactive impurities in heavilydoped semiconductors is not unusual since such effects have been observed previously in Ge and Si crystals [55]. Extensive work on this problem has been done on GaAs heavily-doped with se and Te [40-45]. Although there has been little reported on the electrical properties of sulfurdoped GaAs, the annealing results reported in the previous section indicate that the electrical behavior of all group VI donors ( $\mathrm{S}$, Se, and $\mathrm{Te}$ ) in GaAs is probably due to a common phenomenon. It is likely that the doping behavior of these donors in GaP is also due to a similar cause [39]. The behavior of melt-grown GaAs crystals heavily doped with sulfur will be discussed in this section. First, an equilibrium model will be presented to explain the existence of a large concentration of electrically inactive impurities. Then the reversible changes in the electron concentration during annealing will be discussed.

Compensation is not believed to be a major reason for the discrepancy between the impurity and free electron concentrations for several reasons. For a given electron concentration, the mobilities in GaAs crystals heavily-doped with se were reported to be higher than in silicondoped (self-compensated) crystals [14]. Furthermore, the spectral shape of recombination radiation from Te-doped GaAs excited by an electron beam was not characteristic of a compensated sample [56]. By analogy with these examples, compensation is not expected to be an important factor in explaining the electrical properties of sulfur-doped GaAs.

The usual model that is invoked to explain the large concentrations of electrically inactive impurities in melt-grown GaAs heavilydoped with Se and Te $[40,41]$ will be used here to explain the behavior of sulfur-doped GaAs. The compound $\mathrm{Ga}_{2} \mathrm{~S}_{3}$ is known to be quite soluble in GaAs (up to 8 equimol percent) and GaP (up to 70 equimol percent) [57]. $\mathrm{Ga}_{2} \mathrm{~S}_{3}$ is a diamond-like defect semiconductor, having a zincblende lattice structure with one-third of the gallium sites vacant. Isolated sulfur atoms on the anion site are assumed to be normal donors. At high sulfur 
concentrations, however, the neutral complex $\mathrm{V}_{\mathrm{Ga}} \mathrm{S}_{3}$ may be formed. This is, of course, simply the solid solution of $\mathrm{Ga}_{2} \mathrm{~S}_{3}$ in GaAs or GaP.

The formation reaction in GaAs may be written as

$$
3 \mathrm{~S}_{\mathrm{As}}^{+}+3 \mathrm{e}^{-}+\mathrm{V}_{\mathrm{Ga}} \rightleftarrows \mathrm{V}_{\mathrm{Ga}} \mathrm{S}_{3}
$$

where $\mathrm{S}_{\mathrm{As}}^{+}$is the usual sulfur donor on the arsenic site, and $\mathrm{V}_{\mathrm{Ga}}$ is a gallium vacancy. Because of the merging of the impurity band with the conduction band, there probably are no neutral donors at room temperature. (This may not be true for GaP for which the ionization energy for sulfur is much larger than for GaAs $[40,58,59]$.) The mass action equation for $\mathrm{Eq}$. (4.3) is

$$
\left[\mathrm{V}_{\mathrm{Ga}} \mathrm{S}_{3}\right]=\mathrm{K}_{1}\left[\mathrm{~S}_{\mathrm{As}}^{+}\right]^{3} \mathrm{n}^{3}\left[\mathrm{~V}_{\mathrm{Ga}}\right]
$$

where $K_{1}$ is an equilibrium constant that depends only on temperature. At high sulfur concentrations when the GaAs is extrinsic and sulfur can be assumed to be predominately in the form of the complex,

$$
3\left[\mathrm{~V}_{\mathrm{Ga}} \mathrm{S}_{3}\right] \approx\left[\mathrm{C}_{\text {Total }}\right]
$$

Equations (4.4) and (4.5) may be solved for the electron concentration, yielding

$$
\mathrm{n}=\mathrm{K}_{2}\left[\mathrm{C}_{\text {Total }}\right]^{+1 / 6}\left[\mathrm{P}_{\mathrm{As}_{4}}\right]^{-1 / 24}
$$

Equation (4.6) indicates that, at high sulfur concentrations, the electron concentration should depend only weakly on the total sulfur concentration (this implies a large concentration of electrically inactive impurities) and on the arsenic vapor pressure. These results are in qualitative agreement with the results reported in the previous sections. The exact 
dependence of the electron concentration on the total impurity concentration at a given annealing temperature was not determined for homogeneous sulfur-doped GaAs crystals in this study. Powers ranging from $+1 / 6-1 / 3$ have been reported for melt-grown GaAs doped with se [22,40-41]. These results, however, were obtained from measurements on as-grown crystals subjected to unspecified annealing treatments during the cooling cycle, and do not necessarily represent equilibrium results $[40,44]$. The equidata of Fuller and Wolfstirn [42] indicate that for a given annealing temperature, the electron concentration appears to be relatively independent of the total impurity concentration. Unfortunately, their data are limited, and the total impurity concentrations in their crystals are not specified. More work is needed to determine the exact dependence of electron concentration on the total impurity concentration.

There is some evidence that neutral complexes, such as $\mathrm{V}_{\mathrm{Ga}} \mathrm{S}_{3}$, cannot account fully for the electrically inactive form of the impurity. Small precipitates of $\mathrm{Ga}_{2} \mathrm{Se}_{3}$ and $\mathrm{Ga}_{2} \mathrm{Te}_{3}$ have been detected in heavilydoped GaAs grown from the melt, and by liquid and vapor phase epitaxy using electron microscopy techniques $[60,61]$. A similar observation was made for Te-doped GaP [53]. These precipitates may be regarded as microscopic clusterings of the complexes invoked in the equilibrium model. It has been suggested that isolated complexes, $\mathrm{V}_{\mathrm{Ga}} \mathrm{Te}_{3}$, are present at medium tellurium concentrations, but that the precipitates form when the solid solubility limit of $\mathrm{Ga}_{2} \mathrm{Te}_{3}$ in GaAs is exceeded [60]. However, it is difficult to account for the $\mathrm{Ga}_{2} \mathrm{Se}_{3}$ precipitates in GaAs using this argument since $\mathrm{Ga}_{2} \mathrm{Se}_{3}$ and GaAs are soluble over the whole range of compositions [57]. It appears that non-equilibrium arguments must be invoked in this case.

In view of the difficulties discussed above relating to the unknown variation of electron concentration with total impurity concentration, and possible non-equilibrium effects during crystal growth, a quantitative application of the simple equilibrium model discussed previously seems unwise. However, the large concentrations of electrically inactive sulfur atoms observed in homogeneous GaAs crystals appears to be adequately explained, at least qualitatively, by the formation of neutral complexes, and possibly precipitates. Data on annealed meltgrown GaAs [43,56] and solution-grown GaP [39] indicates that the 
discrepancy between total impurity and electron concentrations decreases in the series : $S$, Se, Te. Whether this is a fundamental difference or an effect due to different rates of precipitation could only be determined by additional studies.

The reversible changes in electron concentration observed in GaAs heavily-doped with Se and Te have been attributed to the formation and dissolution of molecular-sized aggregates of donor atoms, possibly the $\mathrm{V}_{\mathrm{Ga}} \mathrm{Se}_{3}$ complexes discussed previously [42]. In view of the results for sulfur-doped GaAs presented in the previous section, it seems likely the same phenomenon is responsible for the annealing behavior of GaAs doped with all group VI donor impurities.

\section{Sulfur Diffused Layers in GaP and GaAs}

The results of the first two sections of this chapter indicate that a large concentration of the sulfur in the diffused layers in GaP and GaAs is electrically inactive. Similar results have also been observed in phosphorus-diffused layers in silicon $[62,63]$. In the previous section, it was shown that homogeneoús GaAs crystals doped with sulfur aiso exhibit this discrepancy between electron and total impurity concentration; in homogeneous crystals this result was attributed to the formation of neutral complexes and possibly precipitation of a second phase. The behavior of the layers doped by diffusion is certainly related to that of the homogeneous crystals. However it was shown previously for GaAs at a given temperature that the maximum electron concentration in the diffused layer was significantly less than in the homogeneous crystal.

A possible reason for this difference is the formation of diffusion-induced dislocations and precipitation due to stresses caused by the incorporation of high concentrations of sulfur in the GaAs lattice. This possibility has been suggested in the literature for highconcentration Te and Se diffusions in GaAs [44], and there is experimental evidence for such precipitation when $\mathrm{Zn}$ is diffused into GaAs [64,65] and GaP [18]. Although no evidence for such precipitates was found in this study using etch techniques and optical microscopy, a more careful study using electron microscopy would be useful. 
Due to the lack of homogeneous GaP crystals heavily-doped with sulfur, annealing experiments similar to those done with GaAs were not performed. Because of this, it is difficult to make any comment about the possibility of sulfur precipitation in the GaP diffused layers. However, it is noted that the mismatch between the tetrahedral covalent radii of $P(1.10 \mathrm{~A})$ and $\mathrm{S}(1.04 \mathrm{~A})$ is significantly less than between that of As (1.18 A) and S [105]; so that less precipitation might be expected in sulfur-diffused layers in GaP.

E. Some Consequences of the High Concentration Electrical Behavior of Group VI Donors in GaP and GaAs

GaAs which is heavily-doped with se and Te exhibits, in addition to the usual shallow donor level, a deep donor level near the valence band [41,60]. This level is usually attributed to the neutral complexes discussed previously. Kressel has shown that the photoluminesence efficiency of solution-grown GaAs and GaP decreases sharply at high donor concentrations, and has attributed this to the formation of complexes and precipitates which introduce non-radiative recombination centers $[53,60]$. This result obviously has important device implications.

The presence of electrically inactive sulfur in diffused layers is also of interest because it might explain some of the discrepancies among reported values of the diffusion coefficient of sulfur in GaAs. Figure 30 summarizes the results of different experimenters [2], as well as those of this study. Some possible reasons for the differences between different observers have already been discussed in the literature $[2,66]$. In the following discussion, two additional reasons are proposed to explain these differences. These are the effect of arsenic pressure and the presence of electrically inactive sulfur in the diffused layers.

It is believed that the anomalously low values obtained by Goldstein are due to vapor etching of the samples during the diffusion [2,21]. From the data in the previous chapter, it is clear that the diffusion coefficient of sulfur in GrAs depends strongly on the arsenic pressure. This might explain the slight difference between the results of Kendall [2] and Vieland [4]. 


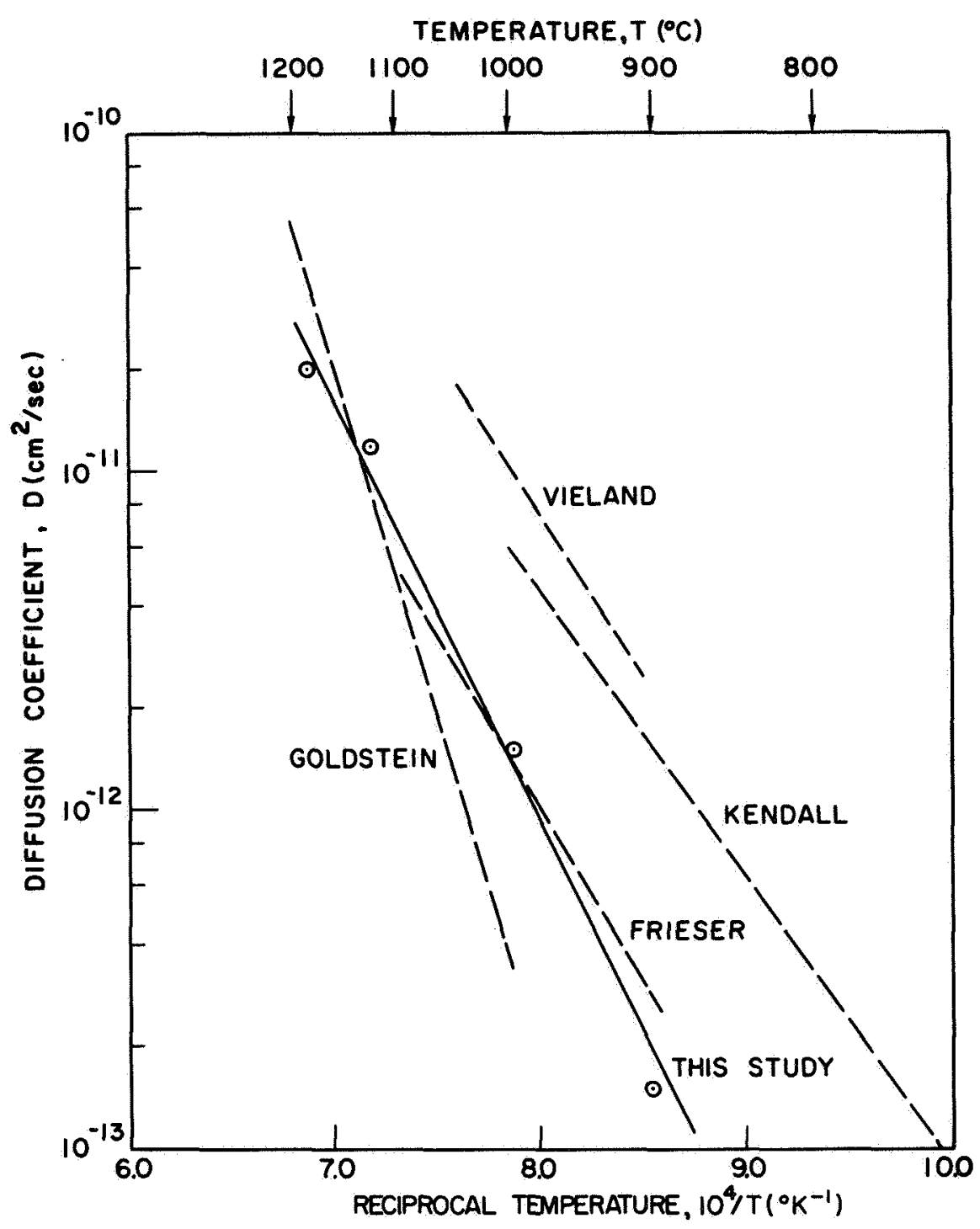

Fig. 30. COMPARISON OF THE TEMPERATURE DEPENDENCE OF THE DIFFUSION COEFFICIENT OF SULFUR IN GaAS AS REPORTED BY DIFFEREINT WORKERS.

There remains, however, a rather large discrepancy between the values of Kendall and Vieland, on the one hand, and that of Frieser [3] and this study, on the other. An important difference is that, in this study, the radiotracer technique was used in conjunction with Hall and plasma reflection methods to study the diffusion and doping process, while $p-n$ junction or sheet resistivity techniques were used in the other studies. An implicit assumption in the latter methods is that all 
impurities are ionized at the measurement temperature. The results discussed previously in this chapter show clearly that this assumption is not valid at high impurity concentrations. It can be seen from Figs. 26 and 27 that experiments that measure only the electrically active part of the impurity distribution in the diffused layers can easily result in apparent diffusion coefficients that are too high. Unfortunately, a general criticism of most of the work previously reported in the literature is that insufficient details are given as to the degree to which the results are affected by vapor etching phenomena, arsenic pressure variations, or the presence of electrically inactive impurities. 



\author{
Chapter V \\ DIFFUSION MODELS FOR SULFUR IN GaP AND GaAs
}

Impurity and self diffusion in III-V compounds have been reviewed by a number of authors [2,66-69]. A model of vacancy diffusion within a single sublattice has been proposed to explain the observed behavior of both host and impurity atoms in these materials [66-69]. However, this model was based solely on measurements of diffusion coefficient as a function of temperature. In this chapter, the applicability of this model to sulfur diffusion in GaP and GaAs is examined. Particular emphasis is placed on the dependence of diffusion coefficient on component pressure. It is concluded that the sublattice model is not in agreement with the experimental results. The interstitial-substitutional model, also suggested to explain sulfur diffusion in GaAs [70], is examined and similar conclusions are reached.

Models that explain the observed diffusion behavior of sulfur in GaP and GaAs are proposed. In addition, the anomalous variation of surface concentration with sulfur pressure is pointed out, and possible reasons for this behavior are discussed.

\title{
A. Sublattice Model of Diffusion
}

The sublattice model was proposed as a possible mechanism of self diffusion in an ordered binary system such as a III-V compound semiconductor [71]. This model is essentially that of substitutional diffusion by means of vacancies. However the basic jump process is not to a nearest-neighbor vacancy, as in the case of $\mathrm{Ge}$ and $\mathrm{Si}$, but to a vacancy located at the second-nearest-neighbor position on the same sublattice [68]. This model was motivated by the zincblende structure of the III-V compounds which can be regarded as two interpenetrating f.c.c. lattices. Since little experimental evidence of anti-structure defects, i.e., of either atomic species on the wrong sublattice, had been presented, the model appeared to be a reasonable one.

Experimental evidence in support of the sublattice model was given by Eisen and Birchenall from self diffusion experiments in GaSb and InSb 
[72], and by Goldstein for similar work in GaAs and InP [1]. In all these cases, self diffusion measurements as a function of temperature showed that the group $V$ element diffused slower, and with a larger activation energy, than the group III element, regardless of the size of the atoms. The covalent bonds around each atom in the crystal contain eight electrons. If diffusion is by means of neutral atoms, the formation of a group $V$ vacancy would require the removal of five electrons from the bonds, while the formation of a group III vacancy would require the removal of only three. Presumably, then, more energy would be required to move the group $V$ element into the vacancy in its own sublattice. This reasoning was used to explain the observed difference in diffusion rates between the two groups of host atoms.

The sublattice model was also used to explain the diffusion behavior of substitutional impurities in InAs [73] and GaAs [6]. It was observed that the impurities believed to be substitutional on the group III sublattice had approximately the same activation energy regardless of whether they were donors (group IV) or acceptors (group II). The same was true for impurities on the group $V$ sublattice, but the activation energy was larger than for impurities on the group III sublattice. This result was consistent with the self diffusion measurements. Thus for GaAs, the activation energies of impurities on the gallium sublattice were found to be: $2.49 \mathrm{eV}(\mathrm{Zn}), 2.43 \mathrm{eV}(\mathrm{Cd}), 2.5 \mathrm{eV}(\mathrm{Sn})$, and $2.75 \mathrm{eV}$ (Mn); for impurities on the arsenic sublattice, the corresponding values were: $4.0 \mathrm{eV}(\mathrm{S})$, and $4.2 \mathrm{eV}$ (Se) [66].

It should be pointed out that the experimental results presented as evidence for the sublattice model could also be interpreted simply by having a common mode of diffusion for atoms on the group III sublattice, and another mode for atoms on the group $V$ sublattice. There was, however, no strong evidence to indicate that the basic jump process was to a second-nearest-neighbor vacancy on the same sublattice.

Slifkin and Tomizuka had suggested that a vacancy diffusion mechanism in a zincblende lattice by means of jumps to nearest neighbors, that is, a movement not confined to a single sublattice, would result in equal diffusion coefficients for both types of host atoms [71]. Thus the 
experimental observation that the self diffusion coefficients were different in a number of III- $V$ compounds led to the exclusion of diffusion by means of nearest-neighbor-vacancies as a possible model [1,72].

Lidiard, however, pointed out that the simple geometrical argument used by Slifkin and Tomizuka was valid only in an alloy with no longrange order. By imposing a thermodynamic restriction relating to establishment of an equilibrium degree of order in the lattice, Lidiard concluded that a diffusion mechanism by jumps to nearest-neighbor sites could still lead to different diffusion coefficients for the two components of a compound semiconductor [75].

In addition to the arguments presented above that indicate that the sublattice model of diffusion need not be invoked to explain the experimental results of self and impurity diffusion in a number of III-V compounds, there appears to be some doubt about the validity of the experimental evidence itself. An extensive review of self diffusion in III-V compounds has been published by Kendall [2] who points out the large variation among the results of different experimenters. As an example, the activation energies of In and $\mathrm{Sb}$ and $\mathrm{InSb}$ have been reported by Boltaks as 0.28 and $0.75 \mathrm{eV}$, respectively [76], by Eisen and Birchenall at 1.82 and $1.94 \mathrm{eV}$ [72], and by Kendall as 4.3 and $4.3 \mathrm{eV}$ [2]. As a further example, Goldstein has reported the activation energies of self diffusion of $\mathrm{Ga}$ and $\mathrm{As}$ in GaAs as $5.6 \mathrm{eV}$ and $10.2 \mathrm{eV}$, respectively [1]. However, Kendall reported several measurements indicating an activation energy of $3.2 \mathrm{eV}$ for As self diffusion [2] in GaAs.

Data on impurity diffusion in GaAs also demonstrates such discrepancies. For example, Goldstein has reported an activation energy of $4.04 \mathrm{eV}$ for sulfur diffusion in GaAs, which was in good agreement with his value of $4.16 \mathrm{eV}$ for Se [1]. However, other experimenters have since reported values for sulfur ranging from 1.6 to $2.6 \mathrm{eV}[2$, this work]. In view of these large differences, the evidence claimed in support of the sublattice model of diffusion should be questioned.

In order to formulate a meaningful model of diffusion processes in compound semiconductors, the variation of diffusion coefficient with 
component pressure, impurity concentration, and background doping of the crystal must be examined.

Consider the dependence of the diffusion coefficient of sulfur in GaAs on the arsenic pressure. The sublattice model implies that the diffusion rate of impurities on the arsenic sublattice should be proportional to the concentration of arsenic vacancies [4]. Thus,

$$
\mathrm{D}=\mathrm{K}_{3}\left[\mathrm{~V}_{\mathrm{As}}\right],
$$

where $D$ is the diffusion coefficient, $\left[\mathrm{V}_{\mathrm{As}}\right]$, the arsenic vacancy concentration, and $\mathrm{K}_{3}$, an equilibrium constant. From simple mass action arguments, the relation between the arsenic vacancy concentration and the external arsenic pressure is

$$
\left[\mathrm{V}_{\mathrm{As}}\right]=\mathrm{K}_{4}\left(\mathrm{P}_{\mathrm{As}_{4}}\right)^{-1 / 4}
$$

Combining these two equations, it is found that

$$
\mathrm{D}=\mathrm{K}_{5}\left(\mathrm{P}_{\mathrm{As}}\right)^{-1 / 4}
$$

As the arsenic pressure increases, the diffusion coefficient should decrease if the sublattice model is valid. The experimental results for sulfur diffusion in GaAs, however, are not even in qualitative agreement with this prediction. As shown in Chapter III, the diffusion coefficient varies as $\left(\mathrm{P}_{\mathrm{As}_{4}}\right)^{+1 / 2}$ at low pressures, and is independent of arsenic pressure above 0.5-1 atmospheres. A similar conclusion can be made about the applicability of the sublattice model to sulfur diffusion in GaP since the diffusion coefficient of sulfur in this material was found to be independent of phosphorus pressure.

It is of some interest to review the literature to determine the quantitative effect of component pressure on diffusion in other III-V systems. Such studies have been neglected except for self diffusion in 
Insb [77], $\mathrm{Zn}$ in GaAs [78], $\mathrm{Zn}$ in GaP [18], Se in GaAs [22], and Mn in GaAs [34]. At the present time, it appears that the variation of diffusion coefficient with component pressure predicted by the sublattice model has not been observed for any III-V compound system. The qualitative behavior of $\mathrm{Sn}$ [22] and Si [36] in GaAs appears to be an exception. However, the amphoteric nature of these impurities complicates an interpretation of the experimental results.

At low zinc concentrations, the diffusion coefficient of zinc in GaAs was found to be enhanced when the arsenic pressure was increased [79]. This observation suggests sublattice diffusion. However, a more accurate quantitative determination of this relationship at low zinc concentrations would be extremely valuable in confirming this conclusion.

For a jump to a second-nearest-neighbor vacancy to occur, an atom must squeeze between three atoms on the opposite sublattice [72]. Longini has suggested that sublattice diffusion in the zincblende structure must be difficult, and proposed as alternatives, the divacancy and interstitial-substitutional modes of diffusion [80]. These models and their application to sulfur diffusion in GaP and GaAs are discussed in the following sections.

\section{B. Interstitial-Substitutional Model}

Kendall has commented that the diffusion of sulfur in GaAs is quite rapid when compared to the rates of such impurities as $\mathrm{Sn}, \mathrm{Mg}, \mathrm{Cd}, \mathrm{Zn}$, Se and Te at their low concentration limit, and has suggested that an interstitial-substitutional mode of diffusion could account for this observation [70]. The interstitial-substitutional model has been used quite successfully in explaining the dependence of the diffusion coefficient of zinc in GaAs on temperature [65], arsenic pressure [78], and zinc concentration [31].

The diffusion profiles obtained in this study for sulfur in GaAs at high sulfur concentrations are characterized by a surface region of rapidly decreasing concentration (see Chapter III). Similar profiles were observed for $\mathrm{Zn}$ diffusion in InP and attributed to an interstitial- 
substitutional mode of diffusion [81]. The activation energies for both sulfur in GaAs and Zn in InP appear to be similar (about $2 \mathrm{eV}$ ).

However, there are several important differences in the diffusion behavior that indicate that the diffusion mechanism may not be the same for the two cases. The profiles for $\mathrm{Zn}$ in $\mathrm{InP}$ have a steep front at concentrations below $10^{19} \mathrm{~cm}^{-3}$. The profiles for $S$ in GaAs do not exhibit such behavior. The diffusion coefficient of $S$ in GaAs also appears to be 3-4 orders of magnitude less than that of $\mathrm{Zn}$ in InP at equivalent temperatures (which account for the difference in melting points of the two compounds).

It is of some interest to compare the experimental results for sulfur in GaAs with the predictions of the interstitial-substitutional model. Particular emphasis is placed on the dependence of the diffusion coefficient on sulfur concentration, arsenic pressure, and Fermi level. The equilibrium between interstitial and substj.tutional sulfur is given by

$$
\mathrm{S}_{i}^{0}+\mathrm{V}_{\mathrm{As}} \rightleftarrows \mathrm{S}_{\mathrm{As}}^{+}+\mathrm{e}^{-},
$$

where $S_{i}^{0}$ is the sulfur interstitial (assumed for the moment to be neutral), and $\mathrm{S}_{\mathrm{As}}^{+}$is the substitutional sulfur (assumed to be the usual donor on an arsenic site). The mass action equation for $\mathrm{Eq} \cdot(5.4)$ is

$$
\frac{\left[\mathrm{S}_{i}^{\circ}\right]}{\left[\mathrm{S}_{\mathrm{As}}^{+}\right]}=\mathrm{K}_{6}\left[\mathrm{~V}_{\mathrm{As}}\right]^{-1} \mathrm{n}=\mathrm{K}_{7}\left(\mathrm{P}_{\mathrm{As}_{4}}\right)^{+1 / 4} \mathrm{n}
$$

where $K_{6}$ and $K_{7}$ are equilibrium constants. If it is assumed, in analogy with Zn diffusion in GaAs, that

1. sulfur is present in the crystal either as a neutral interstitial or as an ionized substitutional donor,

2. most of the sulfur is substitutional (this is a reasonable assumption at low sulfur concentrations), and 
3. the diffusion is dominated by the interstitial species, then from Eq. (5.5) and [31],

$$
\bar{D}=D_{i} \frac{\left[S_{i}^{o}\right]}{\left[S_{A s}^{+}\right]}=D_{i} K_{1}\left(P_{A s_{4}}\right)^{+1 / 4} \mathrm{n},
$$

where $\bar{D}$ is the effective diffusion coefficient, and $D_{i}$ is the interstitial diffusion coefficient. In initially undoped material, $\mathrm{n}=\left[\mathrm{S}_{\mathrm{As}}^{+}\right] \approx\left[\mathrm{C}_{\text {Total }}\right]$, so that

$$
\overline{\mathrm{D}}=\mathrm{D}_{\mathrm{i}} \mathrm{K}_{7}\left(\mathrm{P}_{\mathrm{As}_{4}}\right)^{+1 / 4}\left[\mathrm{C}_{\text {Total }}\right],
$$

where $\left[\mathrm{C}_{\text {Total }}\right]$ is the total sulfur concentration. In material with a large background concentration of donors $\left[\mathrm{N}_{\mathrm{D}}^{+}\right], \mathrm{n}=\left[\mathrm{N}_{\mathrm{D}}^{+}\right]$, and

$$
\bar{D}=D_{i} K_{7}\left(P_{A s_{4}}\right)^{+1 / 4}\left[N_{D}^{+}\right]
$$

The model thus predicts that the diffusion coefficient should vary as the 0.25 power of the arsenic pressure. The experimental results presented in Chapter III for sulfur in GaAs are not in quantitative agreement with this model.

The interstitial-substitutional model also predicts that the diffusion coefficient in initially undoped material should be dependent on the first power of the sulfur concentration, thus leading to diffusion profiles with steep fronts. The model also predicts that diffusion in GaAs heavily-doped with donor impurities should be greatly enhanced. These predictions are not in agreement with the experimental results presented in Chapter III.

However, several points must be kept in mind when interpreting the experimental results. First, the interstitial sulfur has been assumed 
to be a neutral species [70]. This assumption is consistent with the experimental results of chalcogen diffusion in II-VI compounds [74,82]. Because of its electronegativity, however, sulfur might be expected to be an interstitial acceptor. However, several factors make this unlikely. The large size of the ionized acceptor species would greatly inhibit its incorporation into interstitial sites [83]. In addition, the dependence of diffusion coefficient on concentration and Fermi level would be even stronger than calculated previously for the neutral interstitial. Postulation of an ionized interstitial donor would lead to a diffusion coefficient that was independent of concentration and Fermi level. Although this assignment seems unlikely in view of the large electronegativity of sulfur, it should not be ruled out completely.

Second, even assuming a neutral interstitial, the prediction of a steep-fronted diffusion profile depends on having the sulfur concentration much greater than the intrinsic carrier concentration over a major portion of the profile (it is noted that the diffusion coefficient should be independent of concentration in intrinsic material). The diffusion should be considerably enhanced in n-type material provided that the $n-$ type doping is much larger than the intrinsic carrier concentration, and the sulfur concentration is less than the intrinsic carrier concentration.

The intrinsic carrier concentration in GaAs may be calculated using the values of energy gap $E_{g}$, intervalley gap between the $(000)$ and (100) conduction band minima $\Delta$, and the density-of-states effective mass for electrons and holes given in the literature. These are

$$
\begin{aligned}
\mathrm{E}_{\mathrm{g}} & =1.522-5.8 \times 10^{-4} \mathrm{~T}^{2}(\mathrm{~T}+300)^{-1} \mathrm{eV},[84] . \\
\Delta & =0.36 \mathrm{eV}, \quad[85]
\end{aligned}
$$

and

$$
\begin{aligned}
\left(\mathrm{m}_{100}^{*} / \mathrm{m}_{0}\right) & =1.2 \\
\left(\mathrm{~m}_{000}^{*} / \mathrm{m}_{\mathrm{o}}\right)_{r} & =0.068 \\
\left(\mathrm{~m}_{\mathrm{h}}^{*} / \mathrm{m}_{\mathrm{o}}\right) & =0.5
\end{aligned}
$$


Using these parameters, $n_{i}\left(900^{\circ} \mathrm{C}\right)$ is calculated to be $2.2 \times 10^{17} \mathrm{~cm}^{-3}$, while $\mathrm{n}_{i}\left(1000^{\circ} \mathrm{C}\right)$ is $5 \times 10^{17} \mathrm{~cm}^{-3}$. Results of solubility and diffusion experiments, however, suggest that $n_{i}$ may be considerably larger [87-89].

From the experimental profiles in Chapter III and the preceding calculations, it is clear that the necessary conditions for detecting diffusion coefficients that are dependent on concentration and Fermi level have only been partially met. Diffusions with lower surface concentrations would have been a more sensitive test. However, the specific activity of the radioisotope used was too low to permit measurements under these conditions.

In summary, the experimental results of sulfur diffusion in GaAs are not completely compatible with the predictions of the interstitial-substitutional model. The dependence of the diffusion coefficient on arsenic pressure is not in quantitative agreement with the model. In view of the non-ideal experimental conditions and the large uncertainty in $n_{i}$, no meaningful conclusion can be made about the dependence of diffusion on the Fermi level.

The results of Chapter IV suggest that Kendall's values for the diffusion coefficient of sulfur in GaAs may be too high because the presence of electrically inactive impurities in the diffused layer was not considered. Thus, although the interstitial-substitutional model cannot be completely dismissed, the rather low values of diffusion coefficient near the melting temperature would suggest that a substitutional- mechanism of diffusion is more likely.

\section{Proposed Models of Diffusion}

From the previous sections in this chapter, it is clear that neither the sublattice model nor the interstitial-substitutional model can satisfactorily explain the diffusion behavior of sulfur in GaP and GaAs. In this section, alternative models are proposed. These models can explain the observed dependence of diffusion coefficient on component pressure and impurity concentration for the systems of interest. 


\section{Sulfur in GaP}

In Chapter III, the diffusion of sulfur in GaP was shown to be independent of component pressure over several orders of magnitude in phosphorus pressure. This dependence cannot be explained by either the sublattice or the interstitial-substitutional models discussed previously.

Because self diffusion of phosphorus in $\mathrm{GaP}$ is expected to be quite slow, it might be thought that sulfur diffusion in GaP could be independent of phosphorus pressure simply because the vacancy concentration would not have time to equilibrate with the external vapor. However, experiments indicate that the diffusion rate of zinc in GaP can be changed. significantly by varying the phosphorus pressure [18]. This result implies that the rate of equilibration of vacancies with the external vapor is at least comparable to the diffusion rate of zinc. Since zinc diffusion at high concentrations is much faster than sulfur diffusion, it appears unlikely that the non-equilibrium effect proposed is responsible for the lack of pressure dependence.

A simple model that can explain the lack of dependence of diffusion on phosphorus pressure is that of diffusion by means of divacancies. From simple mass action equations, it can be shown that the concentration of divacancies, $\left[\mathrm{V}_{\mathrm{Ga}}-\mathrm{V}_{\mathrm{P}}\right]$, is a function only of temperature and is independent of phosphorus pressure [2]. This relation is valid if both vacancies are neutral, or if they are oppositely charged. In the basic jump process, sulfur on a phosphorus site presumably jumps to the phosphorus vacancy end of the divacancy. Although the basic jump to a phosphorus vacancy is exactly the same as in the sublattice model, the presence of the gallium vacancy makes it unnecessary for the diffusing atom to squeeze through the space between the three gallium atoms as is necessary in the sublattice model. [72]. Since less distortion of the lattice is involved, diffusion by means of divacancies might be expected to be more rapid than the process involving isolated phosphorus vacancies. The divacancy model has previously been used in the literature to explain self diffusion in InSb [77] and $\mathrm{PbS}$ [82]. Divacancies have also been shown to be important defects in silicon [90]. 
There are other models that can explain the lack of pressure dependence of the diffusion coefficient of sulfur in GaP. For example, if the diffusion was by jumps into charged phosphorus vacancies, $\mathrm{V}_{\mathrm{P}}^{+}$, the charge neutrality equation might be

$$
\left[\mathrm{V}_{\mathrm{P}}^{+}\right]=\left[\mathrm{N}_{\mathrm{A}}^{-}\right]
$$

where $\mathrm{N}_{\mathrm{A}}^{-}$is either an acceptor impurity, or a native acceptor defect such as a phosphorus interstitial or a gallium vacancy. The concentration of charged phosphorus vacancies could then be independent of pressure over some pressure range. This possibility has been used to explain the lack of pressure dependence of self diffusion of $\mathrm{Zn}$ in $\mathrm{ZnTe}$ [91] and. that of $\mathrm{Cd}$ in CaTe [92]. If this model were used to explain the lack of pressure dependence for sulfur diffusion in GaP, the concentrations of these acceptor defects, in order to dominate the charge neutrality equation, would have to be much larger than the sulfur concentrations used in the experiments described in Chapter III. This implies impurities or native defects with concentrations greater than $10^{19} \mathrm{~cm}^{-3}$. The presence of a large number of acceptor impurities appears to be ruled out by Hall measurements performed on the GaP crystals after epitaxial growth (admittedly at temperatures much lower than the diffusion anneal). Although the presence of a large number of charged native defects at high temperatures cannot be ruled out completely, there is little evidence to support this possibility in GaP.

Although the lack of pressure dependence of sulfur diffusion in GaP can be explained satisfactorily by the divacancy model discussed previously, the nature of the profiles at high sulfur concentrations must also be explained. As seen in Chapter III, profiles with surface concentrations above $10^{20} \mathrm{~cm}^{-3}$ are characterized by an initial surface layer of rapidly decreasing sulfur concentration, followed by a deeper region that is more well-behaved. Similar profiles were reported when phosphorus was diffused into GaAs [93].

Since the profiles at high sulfur concentrations are not simple complementary error functions, they cannot be characterized by a single diffusion coefficient. HalI's modification [30] of the Boltzmann-Matano 
technique was used to evaluate the concentration dependence of the diffusion coefficient of sulfur in GaP. Figure 31 a shows that the profiles scale as the square root of time, indicating that the diffusion coefficient is dependent only on concentration, but not on time, and that it is valid to use the Matano analysis [94].

The dependence of the diffusion coefficient on sulfur concentration obtained from the profiles in Fig. 3la is shown in Fig. 3lb. Only the qualitative aspects of this relationship are stressed here. It is clear from Fig. 3lb that, at high sulfur concentrations, the diffusion coefficient decreases with increasing concentration. This is in contrast to the diffusion behavior of $\mathrm{Zn}$ in GaAs and $\mathrm{P}$ in $\mathrm{Si}$ at high impurity concentrations [31,62]. In the latter two systems, the diffusion coefficient increases with increasing concentration.

In Chapter IV, it was shown that at high sulfur concentrations, a large concentration of the sulfur atoms in GaP is not electrically active at room temperature. The neutral complex $\mathrm{V}_{\mathrm{Ga}} \mathrm{S}_{3}$ was proposed to explain this observation. The diffusion behavior at high concentrations can also be qualitatively understood in terms of the same complex. The following assumptions are made:

(I) At high concentrations under diffusion conditions, most of the sulfur is in the form of complexes, $\mathrm{V}_{\mathrm{Ga}} \mathrm{S}_{3}$.

(2) Sulfur atoms in the complex are relatively immobile [40].

(3) Isolated substitutional sulfur donors $S_{p}^{+}$are relatively mobile, and diffuse by means of divacancies $\mathrm{V}_{\mathrm{Ga}}-\mathrm{V}_{\mathrm{P}}$ with a diffusion coefficient $\mathrm{D}_{\mathrm{vv}}$.

In analogy with other two-stream diffusion processes such as interstitial-substitutional diffusion, the effective diffusion coefficient [3I] is:

$$
\overline{\mathrm{D}}=\mathrm{D}_{\mathrm{vv}} \frac{\partial\left[\mathrm{s}_{\mathrm{P}}^{+}\right]}{\partial\left[\mathrm{C}_{\text {Total }}\right]} \approx \frac{\mathrm{D}_{\mathrm{vv}}}{3} \frac{\partial\left[\mathrm{S}_{\mathrm{P}}^{+}\right]}{\partial\left[\mathrm{V}_{\mathrm{Ga}} \mathrm{S}_{3}\right]}
$$




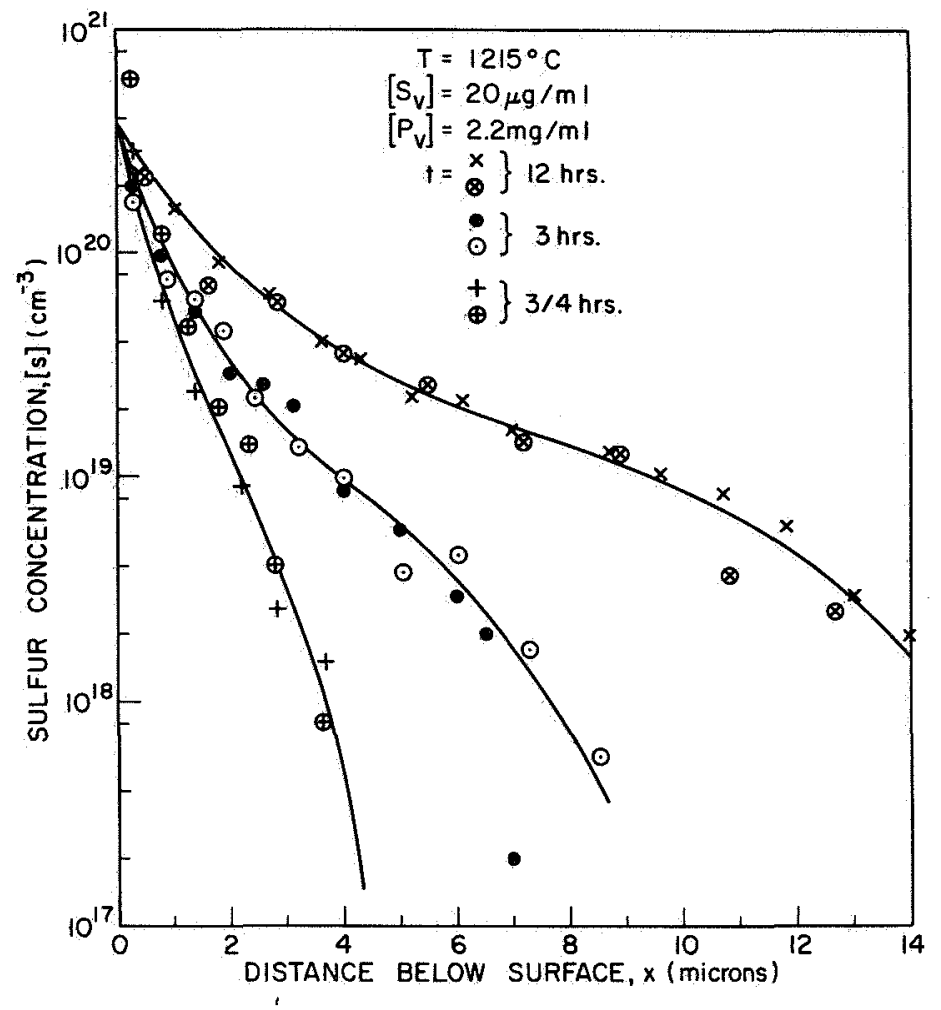

a. Diffusion profiles for various times

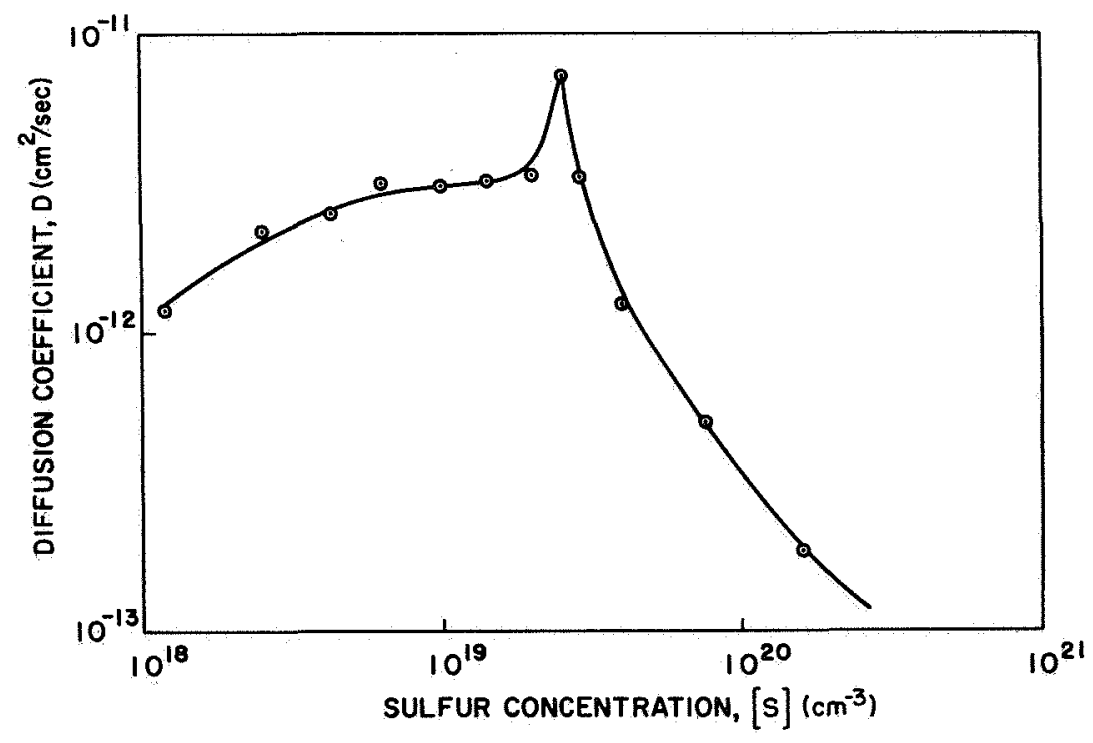

b. Dependence of the diffusion coefficient on sulfur concentration

Fig. 31. CONCEINTRATION DEPENDENCE OF THE DIFFUSION COEFFICIENT OF SULFUR IN GaP AT $1215^{\circ} \mathrm{C}$ AS DETERMTNED FROM A BOLTZMANN-MATANO ANALYSIS. 
The equilibrium between the mobile and immobile forms of sulfur is

$$
3 \mathrm{~S}_{\mathrm{P}}^{+}+3 \mathrm{e}^{-}+\mathrm{V}_{\mathrm{Ga}} \rightleftarrows \mathrm{V}_{\mathrm{Ga}} \mathrm{S}_{3}
$$

The corresponding mass action equation is

$$
\left[\mathrm{V}_{\mathrm{Ca}} \mathrm{S}_{3}\right]=\mathrm{K}_{8}\left[\mathrm{~S}_{\mathrm{P}}^{+}\right]^{3} \mathrm{n}^{3}\left[\mathrm{~V}_{\mathrm{Ga}}\right]
$$

In the extrinsic region, Eq. (5.13) becomes

$$
\left[\mathrm{V}_{\mathrm{Ga}} \mathrm{S}_{3}\right]=\mathrm{K}_{8}\left[\mathrm{~S}_{\mathrm{P}}^{+}\right]^{6}\left[\mathrm{~V}_{\mathrm{Ga}}\right]
$$

From Eqs. (5.11) and (5.14), it can be shown that

$$
\overline{\mathrm{D}} \propto\left[\mathrm{C}_{\text {Total }}\right]^{-5 / 6}
$$

Equation (5.15) implies that the diffusion coefficient should decrease at high sulfur concentrations, because a smaller fraction of the total sulfur is free to move. Although the immobile species has been taken in this discussion to be the complex $\mathrm{V}_{\mathrm{Ga}} \mathrm{S}_{3}$, the same qualitative result would have been obtained for any model which invoked an immobile molecular majority species at high sulfur concentrations. A second phase of $\mathrm{Ga}_{2} \mathrm{~S}_{3}$ (which can be thought of as a macroscopic clustering of isolated complexes) might be responsible for the shape of the diffusion profiles at high sulfur concentrations [1,93]. It is noted, however, that the diffusion temperature at which the profiles in Fig. 3la were obtained $\left(1215^{\circ} \mathrm{C}\right)$ is considerably higher than the melting temperature of $\mathrm{Ga} \mathrm{S}_{2}$ $\left(1090^{\circ} \mathrm{C}\right)$. Under equilibrium conditions at the diffusion temperature, $\mathrm{Ga}_{2} \mathrm{~S}_{3}$ should not exist as a stable solid phase. It would be interesting to do isoconcentration diffusions at high sulfur concentrations to see if complementary error function profiles were obtained, and to determine quantitatively the dependence of diffusion coefficient on sulfur concentration. 


\section{Sulfur in GaAs}

In Chapter III, the diffusion coefficient of sulfur in GaAs for sulfur concentrations less than $10^{19} \mathrm{~cm}^{-3}$ was shown to be independent of arsenic pressure above $0.5-1$ atmospheres, and varied as $\left(\mathrm{P}_{\mathrm{As}_{4}}\right)^{1 / 2}$ at lower pressures. This variation cannot be explained by either the sublattice or the interstitial-substitutional models. Possible explanations for the knee in the $D$ versus $P_{A s}$ curve were proposed in Chapter III and their limitations were pointed out.

In this section, a model is proposed to explain both the $\left(\mathrm{P}_{\mathrm{As}_{4}}\right)^{1 / 2}$ dependence at Iow pressures and the appearance of the knee at higher pressures. This model again invokes the double-stream process of diffusion. At relatively low concentrations, sulfur is assumed to be present in two forms, one mobile, the other immobile. The immobile species, $\mathrm{C}_{2}$, can interact with a gallium divacancy, $\mathrm{V}_{\mathrm{Ga}}-\mathrm{V}_{\mathrm{Ga}}$, to form the mobile species, $C_{1}$, The latter species, $C_{1}$, moves with a diffusion coefficient of $D_{1}$. An arsenic divacancy has been proposed in the literature to explain Mn diffusion in GaAs [34]. The electrical and solubility behavior of $\mathrm{Cu}$ in GaAs has been explained by impurity interaction with a divacancy on the opposite sublattice [15,45].

In the model proposed here to explain sulfur diffusion in GaAs, the equilibrium between the mobile and immobile species is given

$$
\mathrm{C}_{2}+\mathrm{V}_{\mathrm{Ga}}-\mathrm{V}_{\mathrm{Ga}} \rightleftarrows \mathrm{C}_{1}
$$

and the corresponding mass action equation is

$$
\left[\mathrm{C}_{2}\right]\left[\mathrm{V}_{\mathrm{Ga}}-\mathrm{V}_{\mathrm{Ga}}\right]=\mathrm{K}_{9}\left[\mathrm{C}_{1}\right]
$$

The concentration of gallium divacancies is

$$
\left[\mathrm{V}_{\mathrm{Ga}}-\mathrm{V}_{\mathrm{Ga}}\right]=\mathrm{K}_{10}\left(\mathrm{P}_{\mathrm{As}_{4}}\right)^{1 / 2},
$$


and the "conservation-of-sulfur" equation is

$$
\left[\mathrm{C}_{1}\right]+\left[\mathrm{C}_{2}\right]=\left[\mathrm{C}_{\text {Total }}\right]
$$

Solving Eqs. (5.17), (5.18), and (5.19), it is found that

$$
\left[\mathrm{C}_{1}\right]=\left[\frac{\mathrm{K}_{11}\left(\mathrm{P}_{\mathrm{As}_{4}}\right)^{1 / 2}}{1+\mathrm{K}_{11}\left(\mathrm{P}_{\mathrm{As}_{4}}\right)^{1 / 2}}\right]\left[\mathrm{C}_{\text {Total }}\right],
$$

and

$$
\left[\mathrm{C}_{2}\right]=\left[\frac{1}{1+\mathrm{K}_{1 I}\left(\mathrm{P}_{\mathrm{As}_{4}}\right)^{1 / 2}}\right]\left[\mathrm{C}_{\text {TotaI }}\right] .
$$

The K's in the above equations are equilibrium constants. In analogy with the interstitial-substitutional model [3]], the effective diffusion coefficient is given by

$$
\bar{D}=D_{1} \frac{\partial\left[\mathrm{C}_{1}\right]}{\partial\left[\mathrm{C}_{\text {Total }]}\right]}=D_{1}\left[\frac{\mathrm{K}_{11}\left(\mathrm{P}_{\mathrm{As}_{4}}\right)^{1 / 2}}{1+\mathrm{K}_{11}\left(\mathrm{P}_{\mathrm{As}_{4}}\right)^{1 / 2}}\right] \text {. }
$$

The variation of diffusion coefficient with arsenic pressure predicted by the model agrees with the experimental results. At low arsenic pressures, the concentration of gallium vacancies, and also gallium divacancies by Eq. (5.18) is low. Thus the concentration of the mobile species, $\mathrm{C}_{1}$, given by Eq. (5.20) is small, and the effective diffusion coefficient is low. As the arsenic pressure increases, however, the number of gallium divacancies increases, as does the concentration of $C_{1}$. There is a corresponding increase in the effective diffusion coefficient. Finally at some high arsenic pressure, essentially all of the sulfur is in the mobile form, and the effective diffusion coefficient saturates at 
the value of $D_{1}$, which is simply the diffusion coefficient of the complex $\mathrm{C}_{1}$.

Thus far the exact nature of the species $C_{1}$ and $C_{2}$ has not been discussed. A reasonable assignment for $C_{2}$ would be $s_{A s}^{+}$, that is, the usual substitutional donor on an arsenic site. $C_{1}$ would then be the complex $\mathrm{V}_{\mathrm{Ga}}-\mathrm{S}_{\mathrm{As}}^{+}-\mathrm{V}_{\mathrm{Ga}}$, a substitutional sulfur atom in a complex with a gallium divacancy. The gallium vacancies have been assumed neutral in this model, and $C_{1}$ and $C_{2}$ have the same charge state, so the diffusion rate would not be affected by a change in the Fermi level. This is in agreement with the experimental results described in Chapter III.

If the gallium vacancy were assumed to be an acceptor, this would imply that $C_{1}$ was also negatively charged (to preserve charge neutrality in Eq. (5.16)). The equilibrium between the donor and acceptor states of sulfur would now be changed by variations in the arsenic pressure. However, as discussed in Chapter IV, the experimental results indicate that the electron concentration in sulfur-doped GaAs appears to be independent of the arsenic pressure. In addition, the saturation behavior of the diffusion coefficient cannot be explained if the gallium vacancy were assumed to be an acceptor. Thus, if the gallium divacancy model proposed here is valid, the gallium vacancy must be assumed to be neutral.

Although the mass action equations indicate that diffusion by means of gallium divacancies is a possible mechanism for sulfur diffusion in GaAs, the detailed atomic jump process is not known. It is reasonable, however, to assume that a direct exchange between sulfur on an arsenic site, and an arsenic atom (not an arsenic vacancy as in the sublattice model) at the second-nearest-neighbor position can be considerably enhanced in the presence of a gallium divacancy. If at any given time only a small fraction of the sulfur or arsenic atoms were on the gallium site during the interchange process, it would be difficult to detect the presence of these antistructure defects.

Another assignment that gives the same pressure dependence that was measured experimentally is letting $C_{1}$ be a mobile interstitial sulfur donor, $S_{i}^{+}$, which can react with an arsenic divacancy 
$V_{A s}-V_{A s}$ to form the immobile complex $S_{A s^{-}}^{+}-V_{A s}$. This is essentially a modified version of the interstitial-substitutional model, and is more in agreement with the defect structure of GaAs at high temperatures in undoped material. Potts and Pearson reported that the principal vacancy occurred on the arsenic, not the gallium, sublattice with a vacancy concentration at $1100^{\circ} \mathrm{C}$ of $1.8 \times 10^{19} \mathrm{~cm}^{-3}$ [95]. If this assignment of $C_{1}$ and $C_{2}$ were assumed, then in the saturation region at high arsenic pressures, most of the sulfur would be in the interstitial position. Under our experimental conditions, interstitial concentrations of nearly $10^{19} \mathrm{~cm}^{-3}$ are implied. This seems rather high, in comparison with interstitial solubilities in Ge and $\mathrm{Si}$.

In principle it is possible to calculate the solubility of interstitial sulfur in GaAs using a theory developed by Weiser for Ge and $\mathrm{Si}$ [96]. However in practice, too many parameters are unknown, and the result would seem to be removed from firm experimental data by too many steps of approximation. The only other related result concerns sulfur diffusion in silicon [97]. In silicon, sulfur appears to be a double donor as would be expected if it were a substitutional impurity. However, the diffusion coefficient is quite large $\left(D=6 \times 10^{-8} \mathrm{~cm}^{2} / \mathrm{sec}\right.$ at $1200^{\circ} \mathrm{C}$ ) and seems to be interstitially controlled. A comparison with the much smaller diffusion rates obtained in this study would suggest that sulfur diffusion in GaAs is not controlled by an interstitial species.

Up to this point, the discussion has been concerned with models to explain the variation of diffusion with arsenic pressure for sulfur concentrations less than $10^{19} \mathrm{~cm}^{-3}$ (the experimental data reported in Chapter III were taken under these conditions). At these concentrations, most of the sulfur could be assumed to be electrically active at the diffusion temperature. At higher concentrations, the profiles exhibit the same behavior discussed previously for GaP. It is likely that the same mechanism is responsible for the high concentration behavior of sulfur in both GaP and GaAs.

The effect of arsenic pressure has also been studied for diffusions when the surface concentration was $3-5 \times 10^{20} \mathrm{~cm}^{-3}$. The results SEL-69-017 
are shown in Fig. 32. The diffusion increases as the arsenic pressure increases, but at a slower rate than was observed at lower sulfur concentrations. This behavior is not understood at the present time, but it does illustrate the necessity of specifying precisely the conditions under which experiments are done.

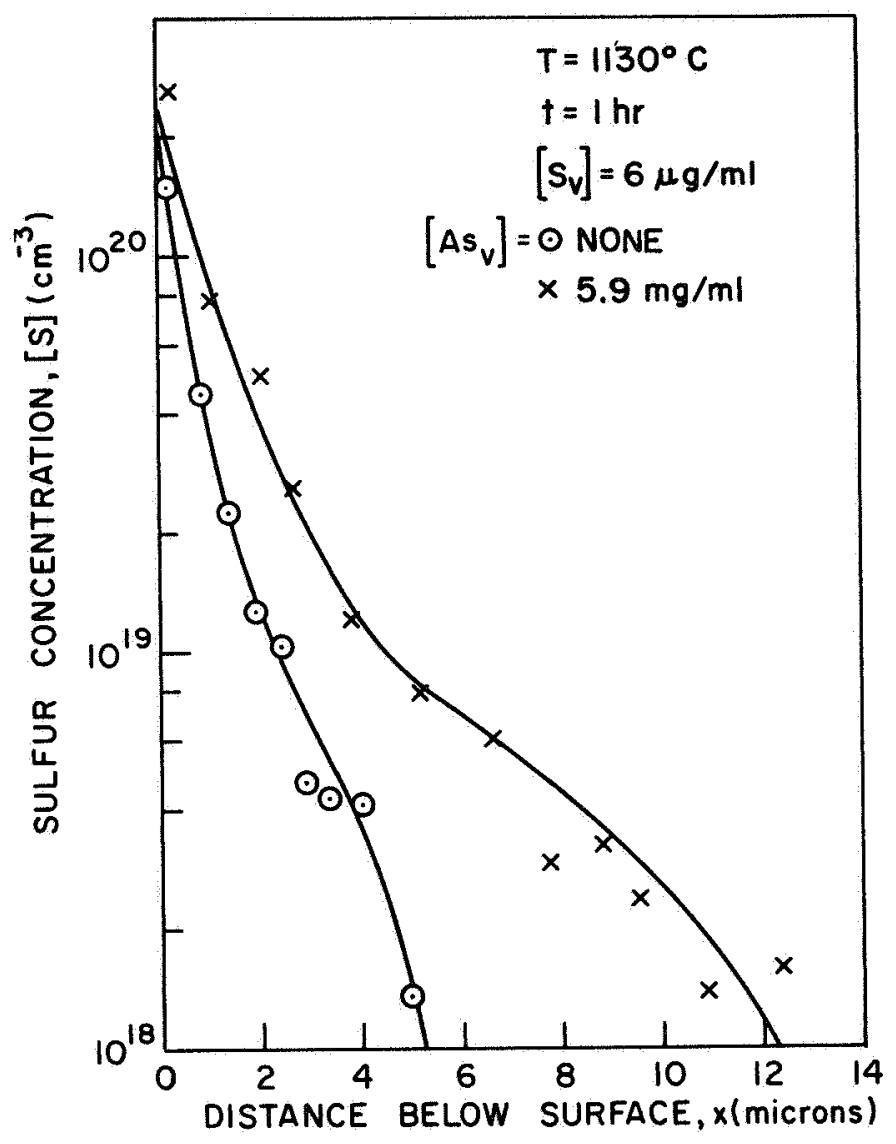

Fig. 32. DIFFUSION PROFILES OF SULFUR IN GaAs AT VARIOUS ARSENIC PRESSURES. The apparent dependence of the diffusion coefficient on the arsenic pressure is weaker at these high sulfur concentrations (compare with Fig. 20).

The experimental results discussed in the previous section indicated that the diffusion of sulfur in GaP appeared to be independent of pressure. However, the surface concentration in this experiment was $10^{20} \mathrm{~cm}^{-3}$. In view of the results for sulfur diffusion in GaAs at high sulfur concentrations, it seems desirable to repeat the GaP experiment at low sulfur concentrations. 
D. Solid Solubility Versus Vapor Pressure of Gaseous Impurities

Diffusion experiments give information about the movement of impurities in crystals. In previous sections of this chapter, models that explain the dependence of the diffusion coefficient on component pressure and impurity concentration for sulfur in GaP and GaAs have been discussed.

Diffusion experiments can also give information about the dependence of solubility on impurity and component pressure. If an infinite source is provided and no surface rate limitation is present, the surface concentration of the diffusion profile should represent the solubility under diffusion conditions. The usual model for incorporating sulfur donors from the vapor phase into phosphorus sites in a GaP crystal can be described by the reaction

$$
\frac{1}{2} S_{2} \text { (vapor) }+V_{P} \rightleftarrows S_{P}^{+}+e^{-}
$$

The corresponding mass action equation is

$$
\left[\mathrm{S}_{\mathrm{P}}^{+}\right] \mathrm{n}=\mathrm{K}_{12}\left(\mathrm{P}_{\mathrm{S}_{2}}\right)^{1 / 2}\left[\mathrm{~V}_{\mathrm{P}}\right]
$$

In extrinsic material, the results may be rewritten

$$
\left[\mathrm{S}_{\mathrm{P}}^{+}\right]=\left(\mathrm{K}_{12}\right)^{1 / 2}\left(\mathrm{P}_{\mathrm{S}_{2}}\right)^{1 / 4}\left(\mathrm{P}_{\mathrm{P}_{2}}\right)^{-1 / 4}
$$

Thus the simple model predicts that the solubility should increase as the 0.25 power of the sulfur pressure $\mathrm{P}_{\mathrm{S}_{2}}$.

The experimental results in Chapter III indicate clearly that this dependence is not observed. The dependence of the surface concentration on the sulfur pressure for both GaP and GaAs was found to be considerably stronger, as given by the relation

$$
\text { surface concentration } \propto\left[\mathrm{S}_{\mathrm{V}}\right]^{\mathrm{W}},
$$


where $\left[\mathrm{S}_{\mathrm{V}}\right]$ is the sulfur vapor density, and $\mathrm{y}$ is 1.3 for GaP at $1215^{\circ} \mathrm{C}$ and 1.0 for GaAs at $1130^{\circ} \mathrm{C}$. Figure 11 indicates that the sulfur vapor should be predominantly in the form of diatomic molecules for the diffusion conditions in this study. Thus Eq. (5.26) can be rewritten as

$$
\text { surface concentration } \propto\left(\mathrm{P}_{\mathrm{S}_{2}}\right)^{\mathrm{W}}
$$

A limited number of experiments indicated that the profiles scaled as the square root of time and that the surface concentration was relatively independent of time. Thus, the assumption of an infinite source seems to be valid.

If, as suggested by the nature of the profiles and the electrical activity of the sulfur at high concentrations, the sulfur is predominantly in the form of the complexes $\mathrm{V}_{\mathrm{Ca}} \mathrm{S}_{3}$, the solubility should vary as the $3 / 2$ power of the sulfur pressure. The reaction for formation of these complexes can be written as

$$
\mathrm{V}_{\mathrm{Ga}}+(3 / 2) \mathrm{S}_{2} \text { (vapor) }+3 \mathrm{~V}_{\mathrm{P}} \rightleftarrows \mathrm{V}_{\mathrm{Ga}} \mathrm{S}_{3}
$$

The corresponding mass action equation is

$$
\left[\mathrm{V}_{\mathrm{Ga}} \mathrm{S}_{3}\right]=\mathrm{K}_{14}\left(\mathrm{P}_{\mathrm{S}_{2}}\right)^{3 / 2}\left[\mathrm{~V}_{\mathrm{Ga}}\right]\left[\mathrm{V}_{\mathrm{P}}\right]^{3}
$$

which can be rewritten as

$$
\left[\mathrm{V}_{\mathrm{Ga}} \mathrm{S}_{3}\right]=\mathrm{K}_{15}\left(\mathrm{P}_{\mathrm{S}_{2}}\right)^{3 / 2}\left(\mathrm{P}_{\mathrm{P}_{2}}\right)^{-1}
$$

Thus there should be a strong dependence of solubility on phosphorus pressure if the sulfur is predominantly in complex form. Figure 14 shows that this was not observed. 
It should be noted that the results reported here from diffusion studies are in disagreement with the results of Trumbore et al [39] which were obtained from crystal growth experiments at a somewhat lower temperature. They found that the incorporation of sulfur from a gallium-rich solution into the GaP crystal obeyed Eq. (5.25) for sulfur concentrations in the crystal between $2 \times 10^{19}$ and $5 \times 10^{19} \mathrm{~cm}^{-3}$. At lower concentrations, incorporation of sulfur in the solid was less than expected. This behavior was later attributed [98] to a non-equilibrium process involving a facet effect [99].

A possible reason for the anomalous behavior of surface concentration with sulfur vapor pressure reported in Chapter III is a non-equilibrium steady-state phenomenon at the surface of the crystal, perhaps caused by the necessity to dissociate the diatomic sulfur vapor into the atomic species. This model has been proposed to explain anomalous effects when $\mathrm{Sb}$ is diffused into $\mathrm{Ge}$ [32]. Experiments in which sulfur is diffused into GaP of various orientations would be helpful in evaluating this model since orientation effects have been observed in GaAs and GaP crystals grown by vapor phase epitaxy [100-102].

Another possibility that should be considered is a modified gas phase. In discussing the variation of surface concentration with sulfur pressure, it has been assumed that the sulfur is predominantly in the form of diatomic molecules. Calculations based on high temperature equilibrium constants (Fig. 11) indicate that this should be true providing there is no interaction between the sulfur and other gaseous species. J. Arthur of Bell Laboratories has found that $\mathrm{Ga} 2^{\mathrm{Te}}$ is an important species in the vapor phase in the GaAs-Te system [103]. If the analogous species, Ga $2^{\mathrm{S}}$, were predominant under our diffusion conditions, the predicted results, at least at lower sulfur concentrations, would be more in agreement with the observed experimental results for the following reason. If most of the sulfur were present in the vapor phase as $\mathrm{Ga}_{2} \mathrm{~S}$ then

$$
\left[\mathrm{Ga}_{2} \mathrm{~S}\right] \approx\left[\mathrm{S}_{\mathrm{V}}\right]
$$


A possible reaction for incorporation of sulfur into the solid is

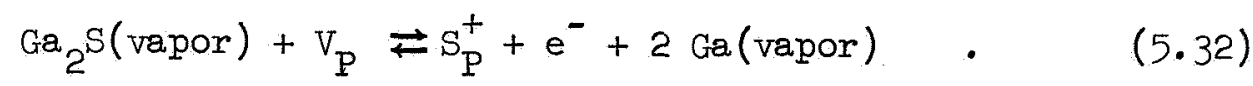

In extrinsic GaP the mass action equation after some manipulations becomes

$$
\left[\mathrm{S}_{\mathrm{P}}^{+}\right]=\mathrm{K}_{16}\left(\mathrm{P}_{\mathrm{Ga}_{2} \mathrm{~S}}\right)^{1 / 2}\left(\mathrm{P}_{\mathrm{P}_{2}}\right)^{1 / 4}
$$

The use of the perfect gas law together with Eqs. (5.31) and (5.33) yields

$$
\left[\mathrm{S}_{\mathrm{P}}^{+}\right]=\mathrm{K}_{17}\left[\mathrm{~S}_{\mathrm{V}}\right]^{1 / 2}\left(\mathrm{P}_{\mathrm{P}_{2}}\right)^{1 / 4}
$$

Equation (5.34) indicates that the solubility should depend only weakly on the phosphorus pressure, but should vary as the 0.50 power of the sulfur vapor density. Although it does not account for the observed variation with $\left[\mathrm{S}_{\mathrm{v}}\right]$, it does indicate a step in the right direction. Anomalous effects have been reported in the literature for arsenic diffusion in $\mathrm{Ge}$, and attributed to a modified gas phase [104].

A third possibility to account for the anomalous results of surface concentration reported here is the formation of a second phase, such as the compound $\mathrm{Ga}_{2} \mathrm{~S}_{3}$, at the surface [1]. However, as noted in section C.I of this chapter, the diffusion in $\mathrm{GaP}$ at $1215^{\circ} \mathrm{C}$ takes place above the melting point of all Ga-S compounds, and still exhibits the anomalous behavior. Experiments at lower temperatures would be helpful in evaluating this possibility.

At this time, it is not possible to propose a definite model to explain the anomalous dependence of the surface concentration on the sulfur vapor density during diffusion. 



\section{PRECEDING PAGE BLANK NOT FILMED.}

Chapter VI

CONCLUSION

The purpose of the research reported here was to investigate the diffusion of sulfur in GaP and GaAs to determine the relevant diffusion mechanisms. The importance of uniquely defining the experimental conditions has been stressed, and the necessity of determining the quantitative dependence of the diffusion coefficient on component pressure has been emphasized in view of the inadequacies of previous investigations.

In the work reported here, a critical analysis of previous studies of sulfur diffusion in GaAs has been presented. Previous investigations have been shown to be inadequate for elucidating the relevant diffusion mechanisms for several reasons. First, no quantitative measurement of the dependence of the diffusion coefficient of sulfur in GaAs on arsenic pressure has been reported. In fact, the arsenic pressure was often neither specified nor controlled in previous investigations. Second, $p-n$ junction techniques have frequently been used to determine diffusion coefficients. However, the possibility of the presence of electrically inactive impurities in the diffused layers has not been considered. Finally, the only experimental evidence to support the model of vacancy diffusion within the arsenic sublattice that was proposed for sulfur diffusion in GaAs has been the activation energy of the diffusion coefficient determined by Goldstein. However, these results appear to be unreliable due to vapor etching of the samples and possibly neglect of the significance of the arsenic pressure. The validity of the previously mentioned sublattice model is subject to question because of these uncertainties.

A summary of the experimental results of this study and some suggestions for future research are presented in the following sections.

A. Summary of Experimental Results

1. The quantitative dependence of the diffusion coefficient of sulfur in GaP and GaAs on component pressure has been measured. Sulfur diffusion in GaP was found to be independent 
of phosphorus pressure, while the diffusion coefficient of sulfur in GaAs varied as $\left(\mathrm{P}_{\mathrm{As}_{4}}\right)^{1 / 2}$ at low arsenic pressures, and saturated at pressures greater than 0.5-1 atmosphere. Both of these observations are in conflict with the predictions of the sublattice model of vacancy diffusion within the anion sublattice that has been proposed in the literature to explain the diffusion of substitutional impurities in III-V compounds. The diffusion of sulfur in GaP is consistent with a model of diffusion via the divacancy $\mathrm{V}_{\mathrm{Ge}}-\mathrm{V}_{P}$, while sulfur diffusion in GaAs can be explained by movement via the gallium divacancy $\mathrm{V}_{\mathrm{Ga}}-\mathrm{V}_{\mathrm{Ga}}$. Although the experimental results obtained in this study pertain to two specific systems, a review of the literature indicates that the failure of the previously mentioned sublattice model to explain the dependence of impurity and self diffusion on component pressure may be a general phenomenon in III-V compounds.

2. Sulfur diffusion in GaP and GaAs has been studied as a function of the sulfur vapor density. At low concentrations, the diffusion profiles were found to be well-behaved and fit complementary error function solutions of the diffusion equation reasonably well. However, for surface concentrations greater than $10^{20} \mathrm{~cm}^{-3}$, the profiles were not well-behaved, and could not be characterized by a concentration-independent diffusion coefficient. The dependence of the surface concentration on the sulfur vapor density was found to be in disagreement with the usual model of incorporation of sulfur atoms on isolated anion sites.

3. The doping efficiency of sulfur in GaAs has been studied, both in diffused layers, and in a homogeneous melt-grown crystal. At high concentrations, a large concentration of the sulfur was found to be electrically inactive. This observation is of practical importance since previous reports in the Iiterature concerning sulfur diffusion in GaAs have often assumed complete ionization of the impurities in the diffused 
layer. Diffusion coefficients calculated using this assumption may be in error. In the work reported here, it was shown that the room temperature electron concentration in the sulfurdoped melt-grown GaAs crystal could be reversibly controlled by suitable annealing, and that this concentration was independent of the arsenic pressure during the anneal. For a given annealing temperature, the electron concentration in the melt-grown crystal was significantly higher than the maximum electron concentration in GaAs doped by diffusion at the same temperature. Thus the doping efficiency of sulfur in GaAs appears to depend not only on thermodynamic variables, such as sulfur concentration, arsenic pressure, and temperature, but on the method of doping as well. It is suggested that the difference may be due, in part, to precipitation due to stresses induced in the crystal during the diffusion process.

\section{B. Suggestions for Future Research}

A number of experiments would be helpful in bringing into perspective the results of this study. There is a need for more quantitative data relating to the dependence of the diffusion coefficient on component pressure for both self and impurity diffusion in III-V compound semiconductors. In particular, studies of diffusion in GaAs as a function of arsenic pressure would be useful to determine if the apparent saturation behavior of the diffusion coefficient of sulfur at high arsenic pressures is unique to the GaAs-S system or if this behavior is related to a more fundamental property of the defect structure of GaAs.

Isoconcentration diffusions in both GaP and GaAs would be helpful in evaluating the true concentration dependence of the diffusion coefficient of sulfur in high concentrations. Electron diffraction studies should be made to determine if compound formation is a major influence on the diffusion behavior at high sulfur concentrations.

More detailed information about the gas phase equilibria in the ternary system under diffusion conditions would be helpful in explaining the anomalous dependence of the surface concentration on the sulfur vapor density. 



\title{
PRECEDING PAGE BLANK NOT FILMED.
}

\author{
RE FERENCES
}

1. B. Goldstein, Phys. Rev. 121, 1305 (1961).

2. D. L. Kendall in Semiconductors and Semimetals Vol. 4, ed. R. K. Willardson and A. C. Beer, (Academic Press, New York, 1968), p. 198.

3. R. G. Frieser, J. Electrochem. Soc. 112, 697 (1965).

4. L. J. Vieland, J. Phys. Chem. Solids 21, 318 (1961); L. J. Vieland, unpublished data quoted in Ref. 66.

5. T. H. Yeh, J. Electrochem. Soc. 111, 253 (1964).

6. B. Goldstein in Compound Semiconductors Vol. 1, ed. R. K. Willardson and H. L. Goering, (Rheinhold, New York, 1962), p. 345.

7. M. B. Panish, J. Electrochem. Soc. 114, 91 (1967).

8. M. B. Panish, J. Electrochem. Soc. 114, 1161 (1967).

9. J. W. Allen and G. L. Pearson, "Ternary Phase Diagrams For the Ga-P-Zn and Ga-As-Zn Systems With Applications to Diffusion Problems," Rept. No. SU-SEL-65-053, Stanford Electronics Laboratories, Stanford, California (1965).

10. C. D. Thurmond, J. Phys. Chem. Solids 26,785 (1965).

11. R. M. A. Lieth, H. J. M. Heijligers, and C. W. M. v.d. Heijden, J. Electrochem. Soc. 113,789 (1966).

12. Handbook of Chemistry and Physics, (Chemical Rubber Publishing Co., Cleveland, 1960).

13. L. S. Darken and R. W. Gurry, Physical Chemistry of Metals (McGraw Hil1, New York, 1953), p. 249.

14. JANAF Thermochemical Tables (Thermal Laboratories, Dow. Chemical Co.) 1961 .

15. Y. Furukawa and C. D. Thurmond, J. Phys. Chem. Solids 26,1535 (1965).

16. Ref. 13, p. 287 .

17. D. H. Loescher, "A Crystal Field Analysis of Cobalt Impurities in GaP," Report No. SU-SEL-66-087, Stanford Electronics Laboratories, Stanford, California (1966).

18. S. F. Nygren, "Preparation and Properties of $p-n$ Junctions in Gallium Phosphide, "Report No. SU-SEL-68-080, Stanford Electronics Laboratories, Stanford, California (1968). 
19. E. G. Dierschke, "Properties of GaP Green Electroluminescent Diodes," Ph. D. Thesis, Stanford University, to be published.

20. M. I. Valkovskaya and Y. S. Boyarskaya, Sov. Phys,-Solid State $\underline{8}$, 1976 (1967).

21. B. Goldstein, RCA Scientific Report No. 7, Contract AF19(604)6152 , October 31,1961, p. 33.

22. R. W. Fane and A. J. Goss, Solid State Electronics $\underline{6}, 383$ (1963).

23. W. Von Münch, IBM Journal 10, 438 (1966).

24. B. Goldstein, Phys. Rev. 118, 1024 (1960).

25. M. V. Sullivan and L. A. Pompliano, J. Electrochem. Soc. 108, Enlarged Abstracts No. 47, (1961).

26. B. I. Boltaks, Diffusion in Semiconductors (Academic Press, New York, 1963), p. 131 .

27. W. J. Price, Nuclear Radiation Detection (McGraw-Hill, New York, 1958), p. 19,128 .

28. D. R. Stull and G. C. Sinke, Thermodynamic Properties of the Elements (American Chemical Society, Washington, D. C., 1956).

29. P. G. Shewmon, Diffusion in Solids (McGraw-Hill, New York, 1963), p. 158 .

30. L. D. Hall, J. Chem. Phys. 21, 87 (1953).

31. L. L. Chang and G. L. Pearson, J. Appl. Phys. 35, 1960 (1964).

32. J. E. McNamara, J. Electrochem. Soc. 108, 199 (1961).

33. J. R. Arthur, J. Phys. Chem. Solids 28, 2257 (1967).

34. M. Seltzer, J. Phys. Chem. Solids 26, 243 (1965).

35. H. H. Woodbury, Phys. Rev. 134, A 492 (1964).

36. G. R. Antell, Solid State Electronics $\underline{8}, 943$ (1965).

37. M. W. Valenta and C. Ramasastry, Phys. Rev. 106, 73 (1957).

38. M. F. Millea, J. Phys, Chem. Solids 27, 315 (1966).

39. F. A. Trumbore, H. G. White, M. Kowalchik, R. A. Logan, and C. L. Luke, J. Electrochem. Soc. 112, 782 (1965).

40. G. Schottky, J. Phys. Chem. Solids 27, 1724 (1966). 
41. L. J. Vieland and I. Kudman, J. Phys. Chem. Solids 24, 437 (1963).

42. C. S. Fuller and K. B. Wolfstirn, J. Appl. Phys. 34, 2287 (1963)

43. M. G. Mil'vidskii, Sov. Phys.-Semiconductors 1 , 813 (1968).

44. J. Black and P. Lublin, J. Appl. Phys. 35, 2462 (1964).

45. C. S. Fuller, K. B. Wolfstirn, and H. W. Allison, J. Appl. Phys. $\underline{38}, 4339(1967)$.

46. R. N. Hall and J. H. Racette, J. Appl. Phys. 35, 379 (1964).

47. L. J. Van der Pauw, Phillips Res. Repts. 13, 1 (1958).

48. M. G. Buehler, "A Point-Contact Method for Determining the Charge Carrier Density and Mobility in Thin Semiconducting Layers," Rept. No. SU-SEL-66-064, Stanford Electronics Laboratories, Stanford, California (1966).

49. T. S. Moss, T. D. F. Hawkings, and G. J. Burrell, J. Phys. C (Proc. Phys. Soc.) 1,1435 (1968).

50. P. A. Schumann and R. P. Phillips, Solid State Electronics 10, 943 (1967).

51. L. A. Murray, J. J. Rivera, and P. A. Hoss, J. Appl. Phys 37, 4743 (1966).

52. C. E. Jones and A. R. Hilton, J. Electrochem. Soc. 112, 908 (1965).

53. H. Kressel and I. Ladany. Solid State Electronics 11, 647 (1968).

54. J. T. Edmond, J. Appl. Phys. 31, 1428 (1960).

55. M. G. Mil'vidskii, Sov. Phys.-Solid State $\underline{6}, 2198$ (1965).

56. H. C. Casey, J. Electrochem. Soc. 114, 153 (1967).

57. N. A. Goryunova and S. I. Radautsan, Soviet Research in New Semiconducting Materials, ed. D. N. Nasledov and N. A. Goryunova, 1 (1965).

58. H. C. Montgomery and W. L. Feldmann, J. Appl. Phys. 36, 3228 (1965).

59. O. V. Emel'yanenko, T. S. Lagunova, and D. N. Nasledov, Sov. Phys.Solid state 2,176 (1960).

60. H. Kressel, F. Z. Hawrylo, M. S. Abrahams, and C. J. Buiocchi, J. Appl. Phys. 39, 5139 (1968).

61. M. S. Abrahams, C. J. Buiocchi, and J. J. Tietgen, J. Appl. Phys. 38, 760 (1967). 
62. E. Tannebaum, Solid State Electronics $\underline{2}, 123$ (1961).

63. M. L. Joshi and S. Dash, IBM Journal 10, 446 (1966).

64. J. Black and E. D. Jungbluth, J. Electrochem. Soc. 114, 181 (1967).

65. C. H. Ting, "Interstitial-Substitutional Diffusion in III-V Compound Semiconductors: Zn in GaAs," Rept. No. SU-SEL-68-069, Stanford Electronics Laboratories, Stanford, California (1968).

66. L. R. Weisberg, Trans. AIME 230, 291 (1964).

67. C. Hilsum and A. C. Rose-Innes, Semiconducting III-V Compounds (Pergamon Press, New York, 1961) p. 81.

68. O. Madelung, Physics of III-V Compounds (John Wiley and Sons, Inc., New York, 1964), p. 240.

69. B. Goldstein and H. Keller, J. Appl. Phys. 32, 1180 (1961).

70. Ref. 2, p. 258 .

71. L. Slifkin and C. T. Tomizuka, Phys. Rev. 97, 836 (1955).

72. F. H. Eisen and C. E. Birchenal1, Acta, Met. 5, 265 (1957).

73. E. Schillmann in Compound Semiconductors, ed. R. K. Willardson and H. L. Goering (Rheinhold, New York, 1962), p. 358.

74. H. H. Woodbury and R. B. Hall, Phys. Rev. 157, 641 (1967).

75. A. B. Lidiard, Phys. Rev. 106, 823 (1957).

76. B. I. Boltaks and G. S. Kulikov, Sov. Phys.-Tech. Phys. 2,67 (1957).

77. D. L. Kendall, "Diffusion in III-V Compounds With Particular Reference to Self-Diffusion in Indium Antimonide," Rept. No. SU-DMS65-29, Dept. of Materials Science, Stanford University, Stanford, California (1965).

78. K. K. Shih, J. W. Allen, and G. L. Pearson, J. Phys. Chem Solids 29, 379 (1968).

79. H. Rupprecht and C. Z. LeMay, J. Appl. Phys. 35, 1970 (1964).

80. R. L. Longini, Solid State Electronics 5 , 127 (1962).

81. L. L. Chang and H. C. Casey, Solid State Electronics 7,481 (1964),

82. M. S. Seltzer and J. B. Wagner, J. Phys. Chem. Solids 26, 233 (1965).

83. F. A. Kroger, The Chemistry of Imperfect Crystals (J. Wiley and Sons, Inc., New York, 1964), p. 811. 
84. M. B. Panish and H. C. Casey, J. Appl. Phys. 40, 163 (1969).

85. H. Ehrenreich, Phys. Rev. 120, 1951 (1960).

86. C. Hilsum in Semiconductors and Semimetals, Vol. 1, ed. R. K. Willardson and A. C. Beer (Academic Press, New York, 1966), p. 3.

87. L. L. Chang and G. L. Pearson, J. Phys. Chem. Solids 25, 23 (1964).

88. H. C. Casey and G. L. Pearson, J. Appl. Phys. 35, 3401 (1964).

89. J. O. McCaldin, J. Appl. Phys. 34, 1748 (1963).

90. G. D. Watkins and J. W. Corbett, Disc. Far. Soc 31, 86 (1961).

91. R. A. Reynolds, "The Self-Diffusion of Zinc and Tellurium in Zinc Telluride," Rept. No. SU-DMS-65-32, Department of Materials Science, Stanford University, Stanford, California (1965).

92. P. M. Borsenberger, "Self Diffusion in Cadmium Selenide and Cadmium Telluride," Rept. No. SU-DMS-67-20, Department of Materials Science, Stanford University, Stanford, California (1967).

93. B. Goldstein, Solid State Electronics 5, 411 (1962).

94. J. Crank, Mathematics of Diffusion (Oxford University Press, London, $1956)$, p. 148 .

95. H. R. Potts and G. L. Pearson, J. Appl. Phys. 37, 2098 (1966).

96. K. Weiser, J. Phys. Chem. Solids 17, 149 (1960).

97. R. O. Carlson, R. N. Hall, and E. M. Pell, J. Phys. Chem. Solids 8, 81 (1959).

98. F. A. Trumbore, private communication.

99. M. D. Banus and H. C. Gatos, J. Electrochem. Soc. 109, 829 (1962).

100. F. V. Williams, J. Electrochem. Soc. 111, 886 (1964).

101. R. C. Taylor, J. F. Woods, and M. R. Lorenz, J. Appl. Phys. 39, 5404 (1968).

102. L. C. Luther and D. D. Roccasecca, J. Electrochem. Soc. 115, 850 (1968).

103. J. Arthur in private communication from M. B. Panish.

104. W. Albers, Solid State Electronics $\underline{2}, 85$ (1961).

105. L. Pauling, Nature of the Chemical Bond (Cornell University Press, Ithaca, 1944$),$ p. 179 . 
Mrs. Margie M. Watts

2759 Xavier Street

East Palo Alto, California 94303

325-5375 


\section{STANFORD ELECTRONICS LABORATORIES}

15 May 1969

Mr.John R. Craig, III

Chief, Research Branch

Office OR Space Science and Applications

NASA

Washington, D.C. 20546

Dear Mr. Craig:

I am sending you under separate cover ten copies of technical report No. 50116-1 entitled "Diffusion of Sulfur in Gallium Phosphide and Gallium Arsenide" by Alvin Bau Yuen Young. This completes the work on this project and Dr. Young has accepted a position with Fairchild Semic onductor.

This work was supported by NASA Research Grant NGR-05-020-043.

$\mathrm{GLP} / \mathrm{mcb}$

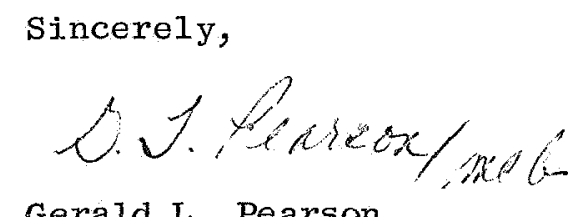

Gerald L. Pearson

Professor 